\title{
Maatlatten voor doorstroommoerassen en moerasbeken
}

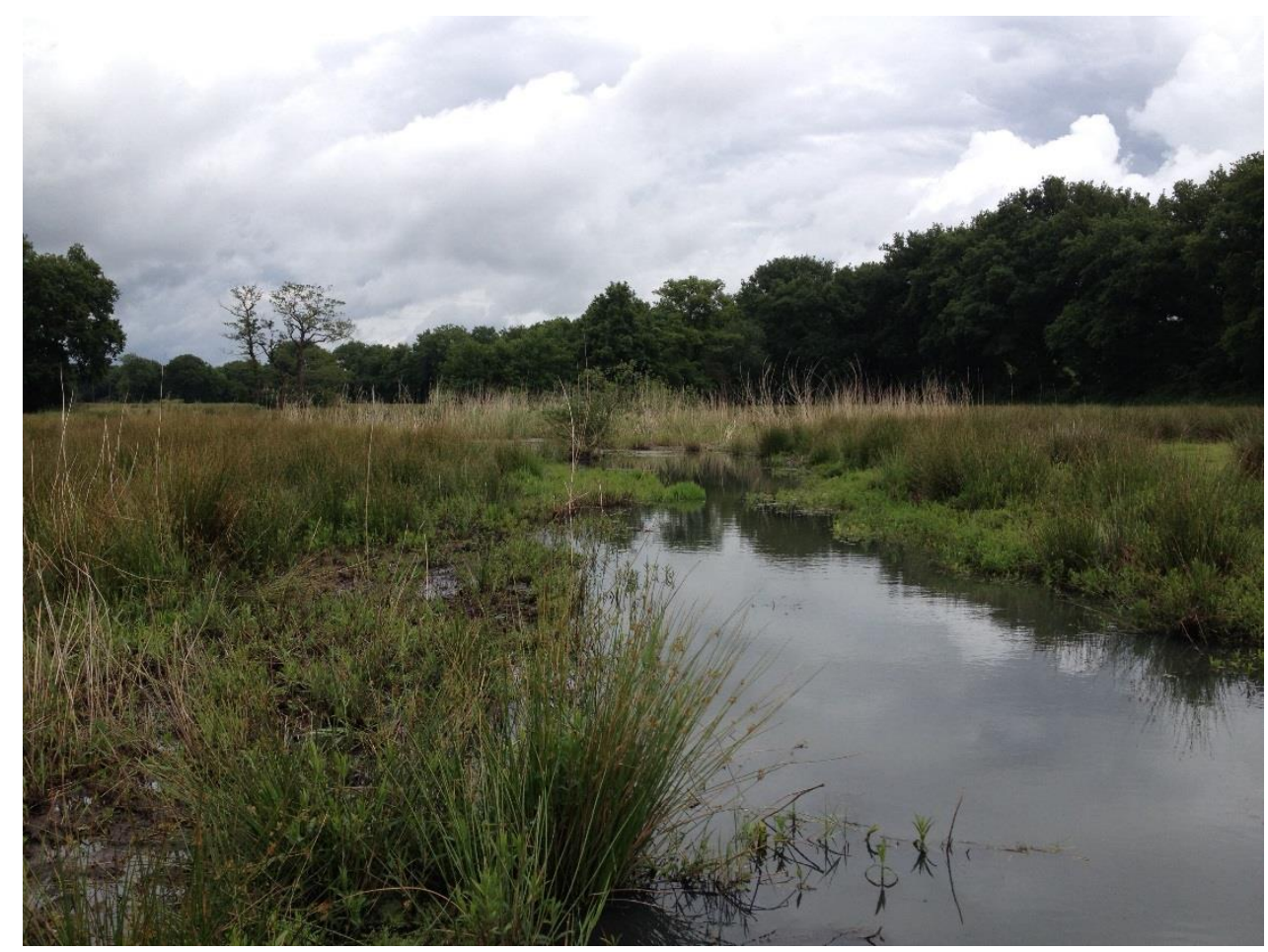

Ralf Verdonschot \& Piet Verdonschot

Notitie Zoetwatersystemen, Wageningen Environmental Research

Oktober 2018 


\author{
Auteurs \\ Ralf Verdonschot, Piet Verdonschot
}

\title{
Opdrachtgever
}

Provincie Noord Brabant, programmabureau KRW/DHZ Maasregio; contactpersoon Noud Kuijpers

\section{Projectgroep}

Marco Beers (Waterschap Brabantse Delta); Rob Fraaije (Waterschap Aa en Maas); Ron Schippers \& Mark Scheepens (Waterschap de Dommel); Barend van Maanen (Waterschap Limburg); Petra Schep (Waterschap Drents Overijsselse Delta), Bert Klutman \& Bastiaan van Zuidam (Waterschap Rijn en IJssel), Gertie Schmidt (Waterschap Vechtstromen), Harry Boonstra (Wetterskip Fryslân) m.m.v. Jeroen van Mil \& Monique Korsten (Waterschap Limburg), Brechje Rijkens (Waterschap Drents Overijsselse Delta), Pieter Bieren (AQUON), Hans Hop (Aqualysis waterlaboratorium), Roelf Pot (Roelf Pot onderzoek en adviesbureau), Frank van Herpen (Royal Haskoning DHV).

\section{Referaat}

Verdonschot, R.C.M., Verdonschot P.F.M. (2018) Maatlatten voor doorstroommoerasssen en moerasbeken. Notitie Zoetwatersystemen, Wageningen Environmental Research, Wageningen UR, Wageningen.

\section{Trefwoorden}

indicatoren, KRW, beoordeling, ecologische kwaliteit, typologie, moerassen

\section{Beeldmateriaal \\ Ralf Verdonschot}

ISBN 978-94-6343-343-3

DOI https://doi.org/10.18174/458510

(C) 2018 Wageningen Environmental Research, Wageningen UR

- Overname, verveelvoudiging of openbaarmaking van deze uitgave is toegestaan mits met duidelijke bronvermelding.

- Overname, verveelvoudiging of openbaarmaking is niet toegestaan voor commerciële doeleinden en/of geldelijk gewin.

- Overname, verveelvoudiging of openbaarmaking is niet toegestaan voor die gedeelten van deze uitgave waarvan duidelijk is dat de auteursrechten liggen bij derden en/of zijn voorbehouden. 


\section{Inhoud}

1. Aanleiding en doel 1

2. Systeembeschrijving van doorstroommoerassen en moerasbeken 2

2.1 Het doorstroommoeras 2

2.2 De moerasbeek 4

2.3 Systeembenadering $\quad 7$

$\begin{array}{lll}2.4 & \text { De vegetatie als structuurvormend element } & 7\end{array}$

2.5 Herstel van doorstroommoerassen en moerasbeken 10

3. Aanpassingen macrofaunamaatlat 12

3.1 Aanpak 12

3.1.1 Aanpassingen indicatortaxalijst 12

3.1.2 Vaststellen belang beekloop en moeraszone t.b.v. beoordeling en aanpassingen bemonstering 14

3.1.3 Vaststellen grenswaarden aangepaste maatlat 14

$\begin{array}{llr}3.2 & \text { Resultaten } & 14\end{array}$

3.2.1 Aanpassingen indicatortaxalijst 14

3.2.2 Vaststellen belang beekloop en moeraszone t.b.v. beoordeling en aanpassingen bemonstering 15

$\begin{array}{ll}\text { 3.2.3 Vaststellen grenswaarden maatlatten } & 16\end{array}$

$\begin{array}{ll}\text { 3.2.4 Maatlat } & 20\end{array}$

3.3 Discussie en aanbevelingen 21

4. Macrofyten 22

4.1 Aanpak 22

4.1.1 Deelmaatlat soortensamenstelling $\quad 22$

4.1.2 Deelmaatlat abundatie $\quad 22$

4.2 Resultaten 23

4.2.1 Deelmaatlat soortensamenstelling 23

4.2.2 Deelmaatlat abundantie, toepassing op vegetatieopnamen 24

$\begin{array}{ll}4.2 .3 \text { Eindoordeel macrofyten } & 26\end{array}$

$\begin{array}{lll}4.3 & \text { Discussie en aanbevelingen } & 28\end{array}$

$\begin{array}{ll}\text { 5. Vissen } & 29\end{array}$

6. Tekstherzieningen maatlatdocument 32

$\begin{array}{ll}\text { 7. Literatuur } & 47\end{array}$

$\begin{array}{ll}\text { Bijlage 1: Indicatorlijst macrofauna } & 49\end{array}$

$\begin{array}{ll}\text { Bijlage 2: Indicatorlijst macrofyten } & 72\end{array}$ 


\section{Aanleiding en doel}

In 2016 heeft Wageningen Environmental Research (WEnR; destijds Alterra geheten) het rapport 'Doorstroommoerassen en moerasbeken; typebeschrijvingen en ontwikkeling maatlatten voor de biologische kwaliteitselementen' opgesteld (Verdonschot et al. 2016). Dit rapport bevat een beschrijving van de nieuwe watertypen 'Doorstroommoeras' en 'Moerasbeek' en de bijbehorende maatlatten. Echter, doordat er tijdens het project bleek dat er onvoldoende gegevens van deze nieuwe watertypen beschikbaar waren (van het beekmoeras waren amper monitoringsdata voorhanden omdat hier simpelweg niet bemonsterd werd), was het niet mogelijk om klassengrenzen op te stellen. Dit betekende dat de nieuwe watertypen wel getoetst kunnen worden, maar nog niet beoordeeld. De waterschappen zijn vervolgens aan de slag gegaan met de implementatie van het rapport en hebben daarnaast in beken met kenmerken van doorstroommoerassen en moerasbeken gegevens verzameld, die gebruikt kunnen worden om de klassengrenzen voor de nieuwe typen te bepalen.

Daarnaast is geconstateerd dat de huidige R4-macrofaunamaatlat niet goed passend is voor beken in gebieden met een relatief laag verhang (Verdonschot \& Verdonschot 2017). Een belangrijke bevinding in deze studie is de (on)geschiktheid van de macrofaunamaatlat voor KRW-type R4 om Noord-Brabantse bovenloopjes te beoordelen: de aanwezige levensgemeenschappen van macrofauna in de Noord-Brabantse R4 (langzaam stromend bovenloopje) en R5-beken (middenloop/benedenloop) komen zeer sterk overeen. Opvallend is daarom de veel lagere beoordeling van macrofauna voor R4-beken. Een reden daarvoor is de achteruitgang van R4-beken, maar er is ook een typologische oorzaak. De R4-maatlat is meer gebaseerd op het streefbeeld voor bovenlopen gevoed door bronnen in reliëfrijke gebieden (terrasranden, stuwwallen) dan op de oorspronkelijke situatie in Noord-Brabant, die uit doorstroommoerassen die ontsprongen in venen bestond: beken zonder duidelijke bron en een continue loop. In de studie concludeert WEnR dan ook dat de bruikbaarheid van de R4-maatlat voor tenminste een deel van de Brabantse beken twijfelachtig is. Dit probleem wordt door waterbeheerders ook herkend voor andere delen van Nederland. Deze conclusie heeft geleid tot het besluit de R4-maatlat landelijk aan te passen voor situaties met een relatief laag verval.

Omdat de huidige macrofaunamaatlat voor R4 ook gebruikt wordt om doorstroommoerassen te beoordelen, zit er een afhankelijkheid tussen beide problemen. Naar aanleiding hiervan hebben de waterbeheerders in Rijn-Oost en Maas aan WEnR gevraagd om 1.) het huidige rapport 'Doorstroommoerassen en moerasbeken' aan te vullen met klassengrenzen bij de maatlatten en de teksten te herzien naar aanleiding van opgedane ervaringen bij de waterschappen. 2.) de macrofaunamaatlat voor R4 te herzien. Deze herziening is opgenomen in een aparte notitie "Herziening macrofaunamaatlat R4" (Verdonschot \& Verdonschot 2018) en wordt verder niet in deze notitie besproken.

In deze notitie wordt eerst achtergrondinformatie over doorstroommoerassen en moerasbeken gegeven, afkomsting uit de notitie van Verdonschot et al. (2016). Vervolgens worden de aanpassingen aan de macrofaunamaatlatten behandeld, gevolgd door aanpassingen aan de macrofytenmaatlat. Deze aanpassingen volgen uit de ervaringen die zijn opgedaan tijdens de bemonsteringen van doorstroommoerassen en moerasbeken en uit de gegevens die deze monstercampagne heeft opgeleverd. In het daaropvolgende laatste hoofdstuk worden tekstsuggesties gegevens voor in het landelijke maatlatdocument (toevoeging typen doorstroommoeras R19 en moerasbeek R20 aan Van der Molen et al., 2016). 


\section{Systeembeschrijving van doorstroommoerassen en moerasbeken}

Deze systeembeschrijving is overgenomen uit Verdonschot et al. (2016) en vormen een inleiding om beter bekend te raken met beide watertypen. Doorstroommoerassen en moerasbeken waren tot voor kort uit Nederland verdwenen, maar zijn op een aantal plekken opnieuw ontstaan als gevolg van herstelmaatregelen.

\subsection{Het doorstroommoeras}

In beekdalen op de hogere zandgronden komt het in de hogere delen geïnfiltreerde regenwater uiteindelijk als opkwellend grondwater aan de oppervlakte, gestuurd door het reliëf (hellingshoek en daarmee het verval van het beekdal) en de opbouw van de bodem. De waterkwantiteit en het verval bepalen of dit water zich geconcentreerd vanuit een bron via een bovenloop of meer diffuus naar benedenstrooms verplaatst. Veel Nederlandse laaglandbeeksystemen hebben van nature te weinig verval en een te lage afvoer om in het bovenstroomse gedeelte van het beekdal een duidelijk herkenbare en continue loop te vormen. Het kleinschalige reliëf dat meestal in een beekdal aanwezig is, zorgt er echter voor dat er naar benedenstrooms telkens graduele overgangen zijn tussen relatief vlakke en steilere delen, waardoor er verschillen in stroomsnelheid optreden. In een natuurlijke situatie zullen de sneller stromende delen herkenbaar zijn als een 'echte' beekbovenloop in een relatief smal beekdal, terwijl de langzaamst stromende delen een doorstroommoeras vormen, het beekdal is hier breder en het water verplaatst zich diffuus over (hygropetrisch of in slenken) en door de bodem (Figuur 1; Foto 1, 2). Naast meer verval kunnen ook lokale onregelmatigheden in de bodem leiden tot loopvorming, bijvoorbeeld als gevolg van de aanwezigheid van ondoorlaatbare klei/leemlagen en ijzeroerbanken.

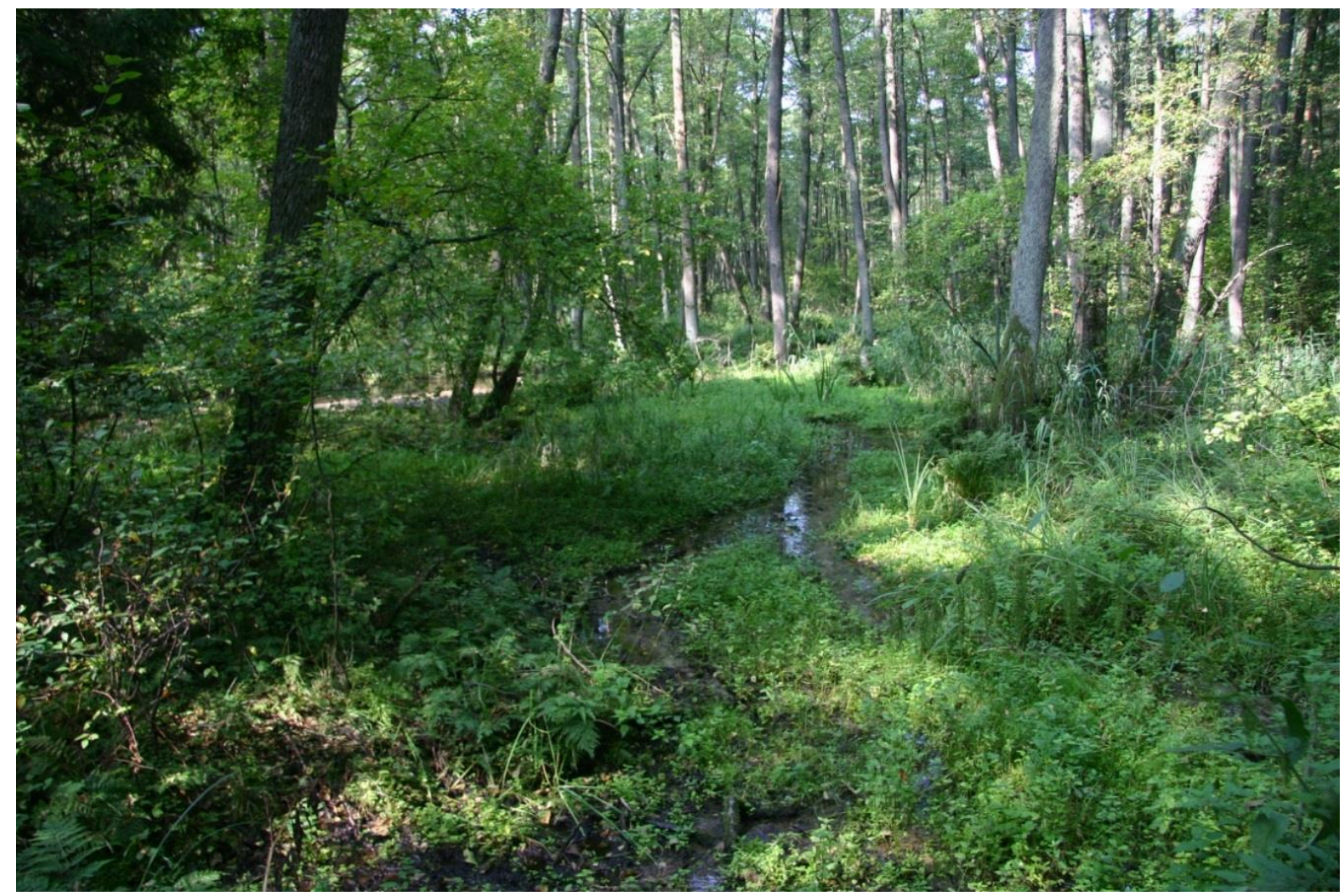

Foto 1: Doorstroommoeras in elzenbroekbos in Polen (stroomgebied van de Gac bij Lotz). Foto: Piet Verdonschot. 
In de vlakke delen van het dal zijn gewoonlijk alleen plaatselijk loopjes te onderscheiden; in stroomafwaartse richting is de beek dus onderbroken. De vegetatie heeft een belangrijke sturende rol voor het pad dat het water volgt in de laagtes. Omdat de vegetatie in structuur en samenstelling in de tijd verandert, al dan niet door de activiteit van grote zoogdieren (wildpaadjes, zoelplekken), kan ook verplaatsing van deze loopjes in de tijd optreden. Dit kan leiden tot het aanwezig zijn van meer lopen (diffuus vlechtend patroon) of van afgesloten delen van lopen waar nieuwe verlandingsprocessen optreden. Op de overgangen tussen de sneller stromende lopen en de vlakke delen kunnen diepere poelen voorkomen, omdat het toestromende water hier het op de minerale ondergrond opgehoopte organisch materiaal erodeert (Mactaggart et al. 2008). De afvoer in het doorstroommoeras is hoger in de winter en lager in de zomer, waardoor in de winter duidelijkere geulen/stroombanen in de vlakke delen te onderscheiden zijn. Dit is mede het gevolg van verschillen in de groei en ontwikkeling van de vegetatie in de verschillende seizoenen.

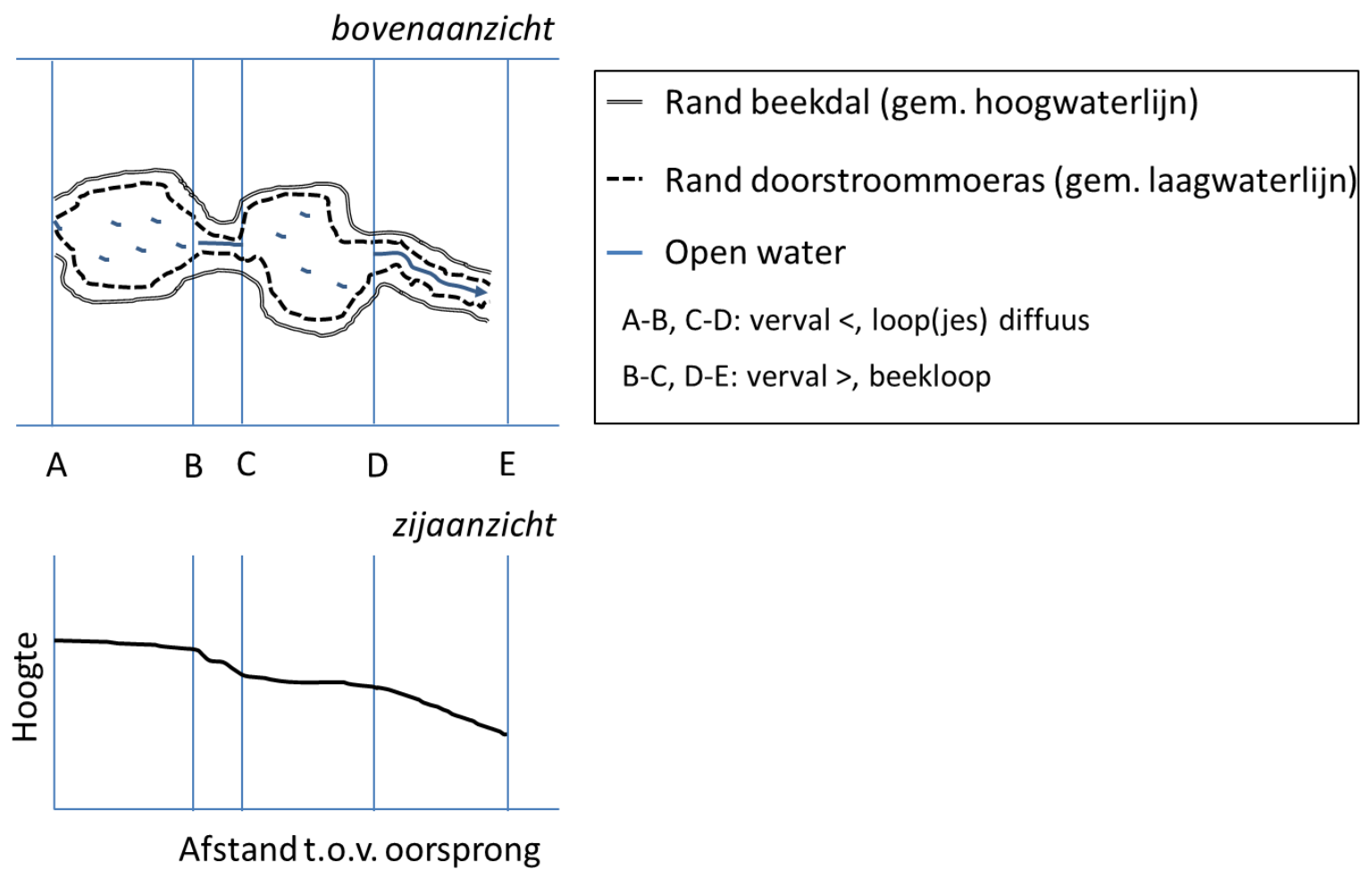

Figuur 1: Doorstroommoerassen ontstaan doordat er delen in het beekdal weinig verhang hebben, waardoor de beek als het ware uitwaaiert over het bredere dal (boven). Soms komen in het doorstroommoeras één of meerdere geultjes of geulen voor waar nog sprake is van afvoer. Dit kan het gevolg zijn van steilere delen in de vervallijn (onder), of door de aanwezigheid van onregelmatigheden in de ondergrond, zoals ondoorlatende lagen.

In de doorstroommoerassen treedt de zogenoemde 'sponswerking' op; het water wordt op deze plekken lang vastgehouden. Dit bergend vermogen in een stroomgebied zorgt er onder natuurlijke omstandigheden voor dat verder benedenstrooms niet vaak afvoerpieken optreden en dat de beek jaarrond watervoerend en traag stromend blijft (Blackwell \& Pilgrim 2011). Schommelingen in afvoer zijn dus relatief gering, omdat het water in het moeras een lange verblijftijd heeft. Het water stagneert echter niet; een continue, naar benedenstrooms gerichte waterstroming, vooral bestaand uit grondwater (Figuur 2), is een vereiste voor het ecologisch functioneren van deze systemen. Deze stroming is ook typologisch onderscheidend ten opzichte van de stagante moerastypen: moerassen in laagtes met een ondoorlatende bodem, rietlanden, laagveenmoerassen etc. De moerasplantenontwikkeling leidt tot een ophoping van afgestorven organisch materiaal in het doorstroommoeras. Onder mesotrofe omstandigheden zijn er mogelijkheden voor veenvorming, omdat het organische 
materiaal langzamer afbreekt ten opzichte van meer voedselrijke situaties.

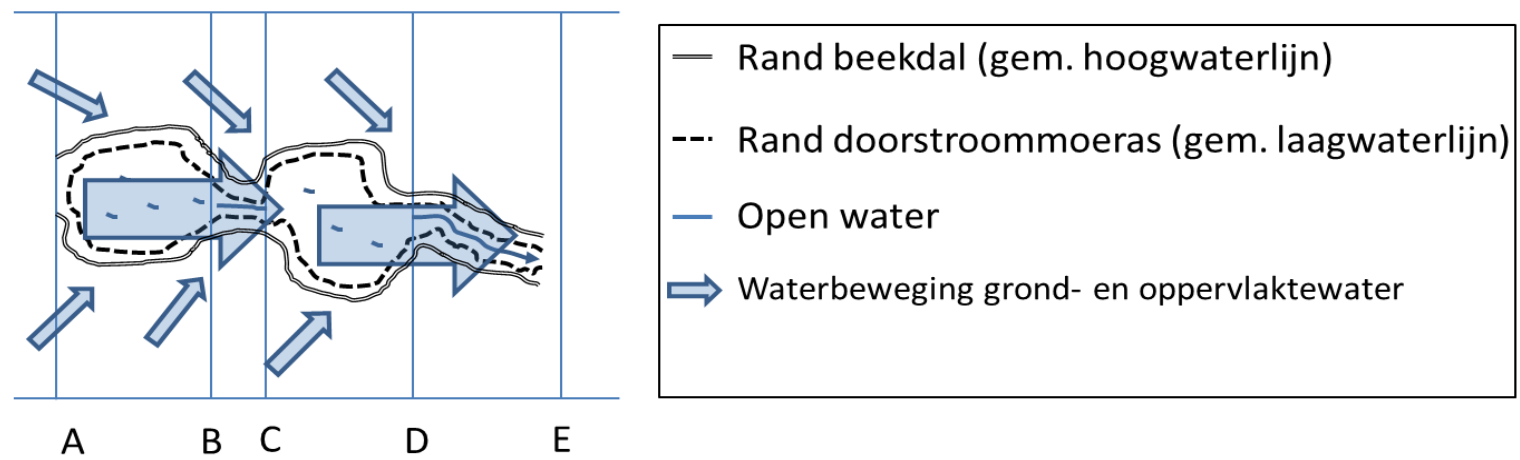

Figuur 2: In een doorstroommoeras is de waterstroming is naar benedenstrooms gericht en wordt gedomineerd door grondwater.

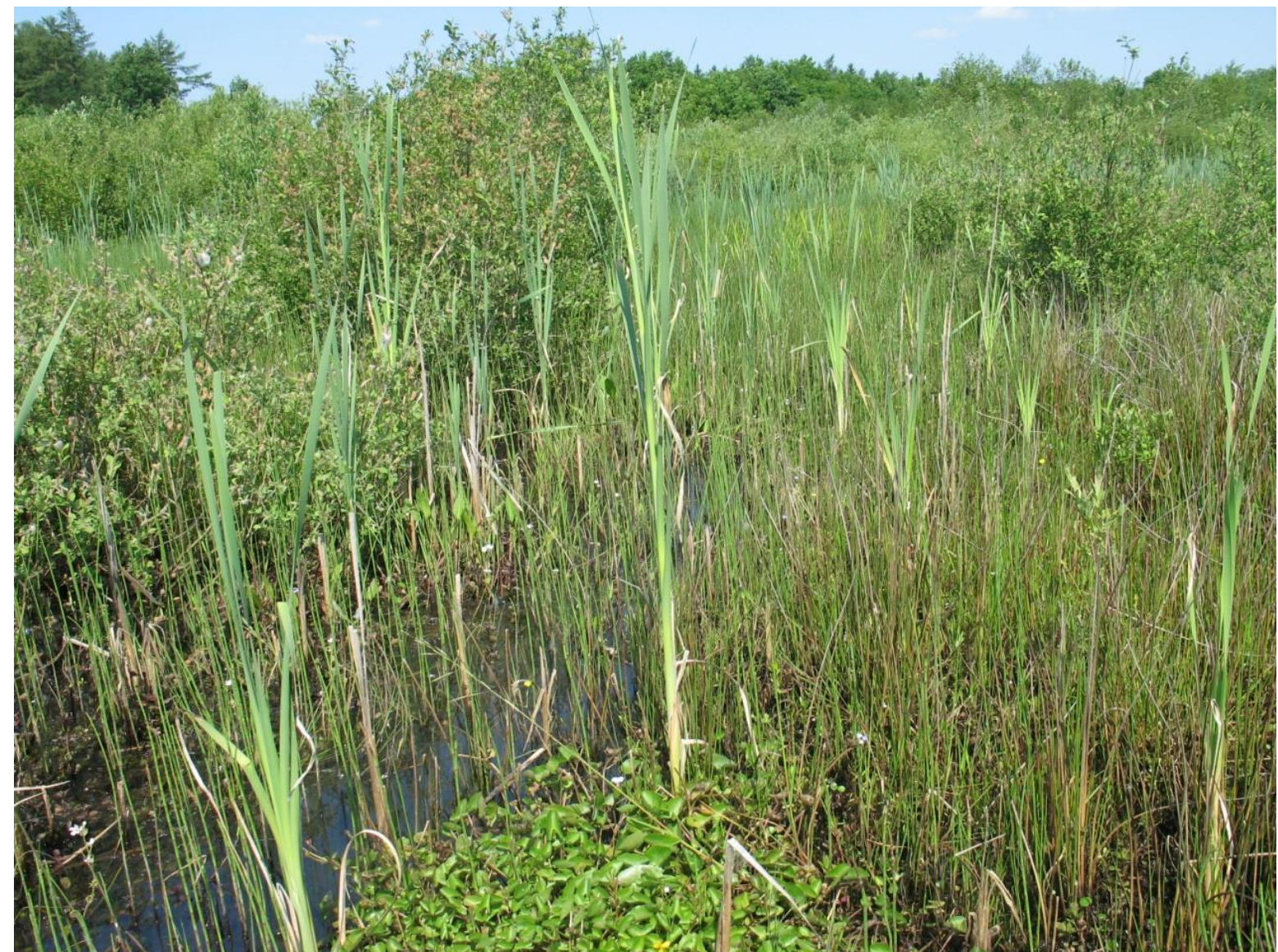

Foto 2: Hersteld doorstroommoeras in de Holmers, Drenthe. Foto: Ralf Verdonschot.

\subsection{De moerasbeek}

Verder benedenstrooms, ter hoogte van de midden- of benedenloop is de afvoer dusdanig ondanks het geringe verval en de daardoor lage stroomsnelheid - dat het water voldoende erosieve kracht heeft om een duidelijke loop te vormen in de moerassige laagte in het beekdal. Het gevolg is een situatie waarbij de loop, de moerasbeek, geflankeerd wordt door een beekmoeras, wat weer overgaat in een overstromingszone (Figuur 3; Foto 3, 4). In de dwarsrichting gaat de loop diffuus over in het beekmoeras. De overstromingszone valt in de zomer droog; hiermee onderscheidt deze zone (waar ook moerasplanten staan) zich van het beekmoeras, die permanent nat is. 


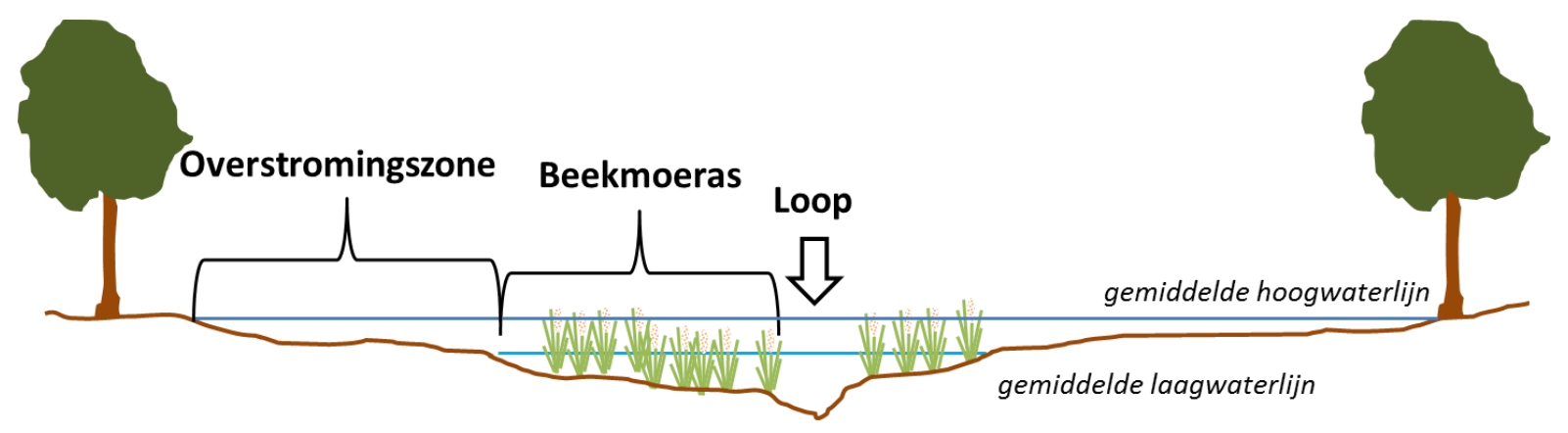

Figuur 3: Dwarsdoorsnede van een moerasbeek.

Dat er geen scherpe overgang is tussen moeras en beek is het gevolg van enerzijds de vegetatieontwikkeling (emergente moerasplanten die de loop in groeien) en anderzijds de langjarige patronen in de afvoer. In jaren met een relatief lage afvoer wordt de loop kleiner door de zich uitbreidende vegetatie vanuit het moerasdeel, in jaren met een hoge afvoer erodeert de beek een deel van deze vegetatie weer, waardoor de loop zich (plaatselijk) verbreedt. Wanneer in droge jaren een extreme ontwikkeling van vegetatie optreedt, kan de loop zich in de hierop volgende nattere periode verleggen als gevolg van de lokale weerstand van deze vegetatie. Anders dan bij het afsnijden van beekbochten ontstaan hierdoor afgesloten beeklopen of gaat de beek uit meer lopen bestaan. De maximale diepte van de met moerasplanten begroeide zones bedraagt enkele decimeters (maximale diepte waterlaag van circa $30 \mathrm{~cm}$; Mitsch \& Gosselink 2007).

In principe is de loop van een moerasbeek continu. Echter, na een periode van hoge afvoer kunnen stukken moerasvegetatie (drijftillen) losraken en een obstructie in de loop vormen. Deze onderbrekingen in de loop zijn altijd tijdelijk, dit in tegenstelling tot een doorstroommoeras waarin zones voorkomen waar het water zich diffuus door de bodem verplaatst en geen loop zichtbaar is, omdat het water ofwel een weg om de obstructie heen vindt of de obstructie na verloop van tijd erodeert.

In tegenstelling tot het doorstroommoeras bestaat het water in het beekmoeras van de moerasbeek meestal uit eutroof oppervlaktewater en is de invloed van grondwater geringer. Naast waterbeweging in benedenstroomse richting treedt er uitwisseling van oppervlaktewater tussen de beekloop, het beekmoeras en bij hoog water de overstromingszone op (Figuur 4). Deze laterale uitwisseling van water is onderscheidend ten opzichte van het doorstroommoeras, waarbij de waterbeweging overwegend in stroomafwaarste richting plaatsvindt.

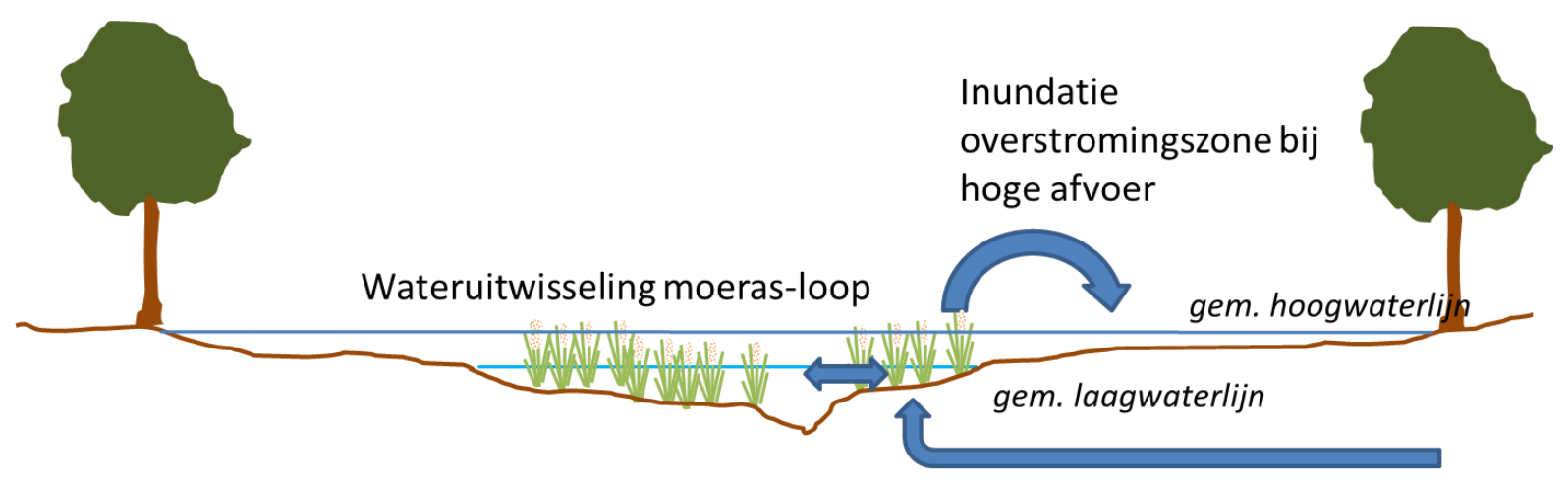

Grondwatervoeding moeras en loop

Figuur 4: Naast een naar benedenstrooms gerichte stroming is ook wateruitwisseling in de dwarsrichting tussen de beekloop, het beekmoeras en bij hoge waterstanden de overstromingszone kenmerkend voor de moerasbeek. 
Het opgehoopte organisch materiaal kan hierdoor veel sneller mineraliseren dan in het bovenstrooms gelegen doorstroommoeras en er treedt weinig tot geen veenvorming op (Mitsch \& Gosselink 2007).

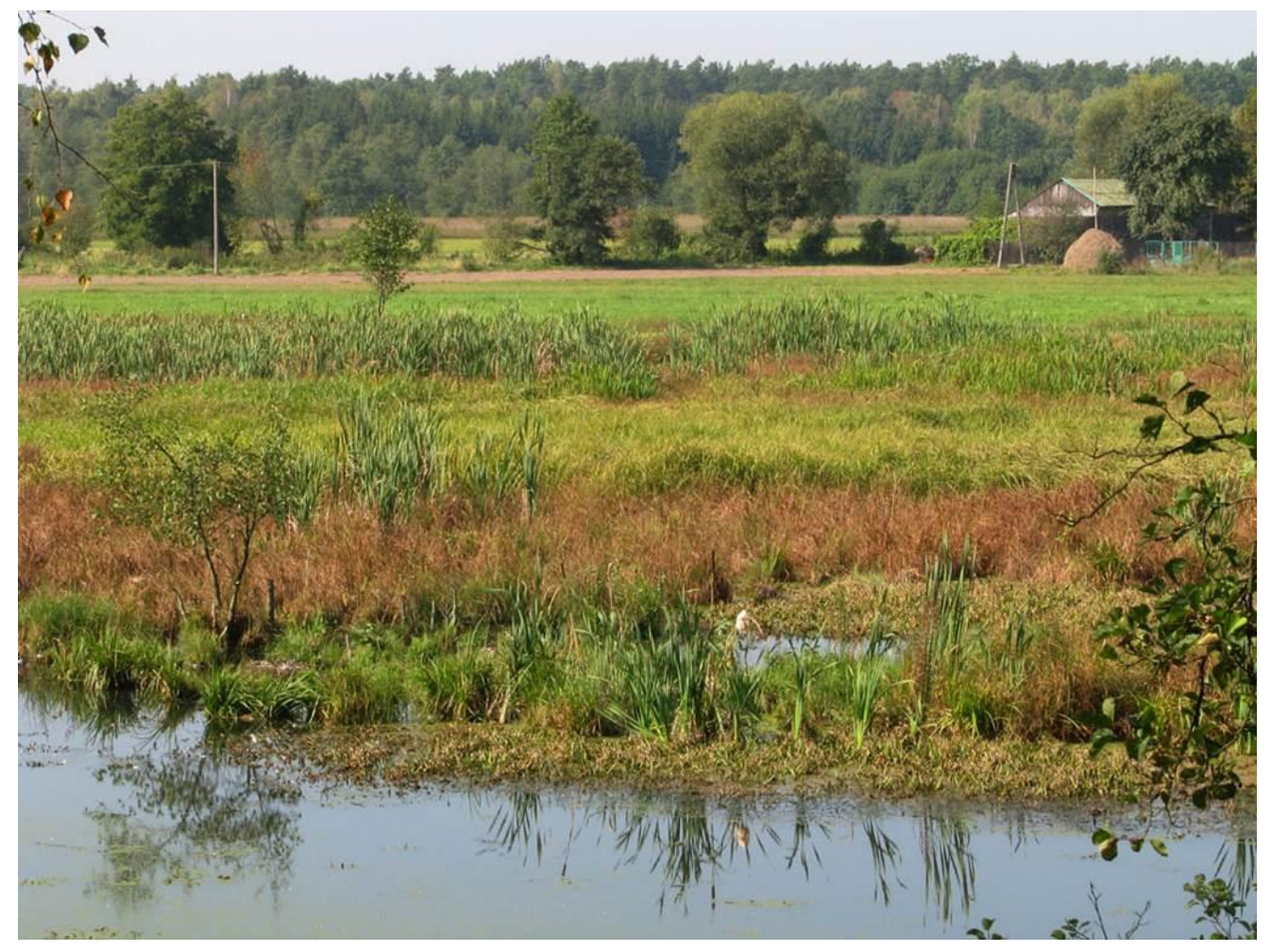

Foto 3: Moerasbeek in Polen. De stroomgeul gaat diffuus in de moeraszone over. Foto: Piet Verdonschot.

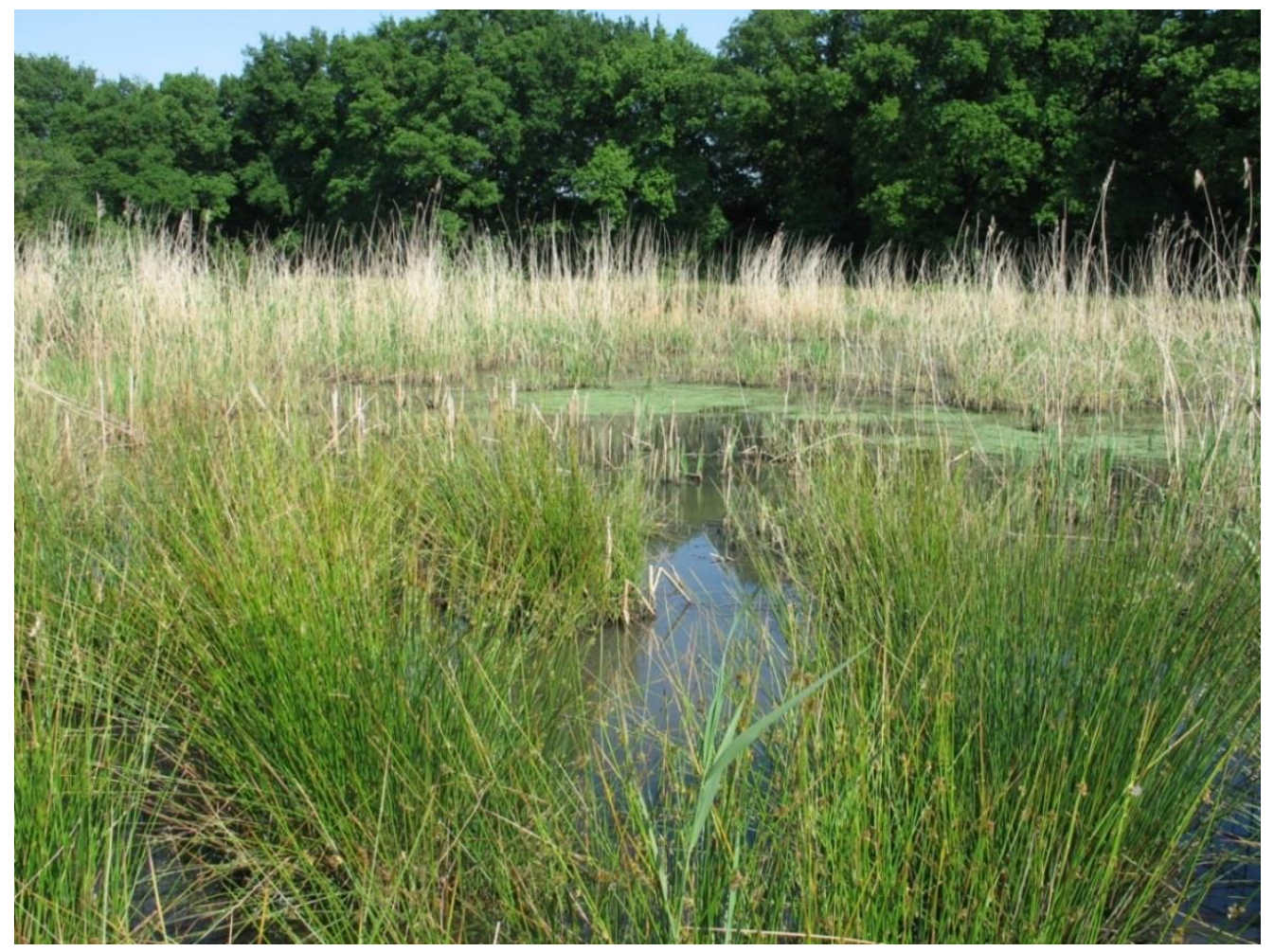

Foto 4: Herstelde moerasbeek in de Geeserstroom, Drenthe. Foto: Ralf Verdonschot. 


\subsection{Systeembenadering}

Het doorstroommoeras en de moerasbeek zijn als losse landschappelijke onderdelen te herkennen op beeksysteemschaal, maar hoeven niet lineair, wanneer een beek naar benedenstrooms gevolgd wordt, voor te komen. De strikte ordening in boven-, midden- en benedenloop gaat onder natuurlijke omstandigheden in laaglandbeken vaak niet op, omdat doorstroommoerassen niet alleen in de kop van het systeem voorkomen maar ook aan de flanken van het beekdal verder benedenstrooms (Figuur 5). Op plekken met veel kwel vanuit de randen van het beekdal in de moeraszone kunnen zich situaties ontwikkelen waarin zich op de flanken van het beekdal kwelgevoede loopjes vormen, analoog aan het meer bovenstrooms in het beekdal gelegen doorstroommoeras van waaruit de moerasbeek ontsprongen is. Water verplaatst zich in dat geval dus zowel vanuit de loop het moeras in en stroomt parallel aan de beekloop (oppervlaktewater) als dwars op de beek vanuit de flanken van het beekdal (kwel). Er is dus sprake van een landschappelijk mozaïek, wat bijvoorbeeld weer zijn weerslag heeft op het voorkomen van bijvoorbeeld de macrofauna, waarbij er overal in het stroomgebied een mengeling kan optreden van 'bovenloop-soorten' en 'benedenloop-soorten'.

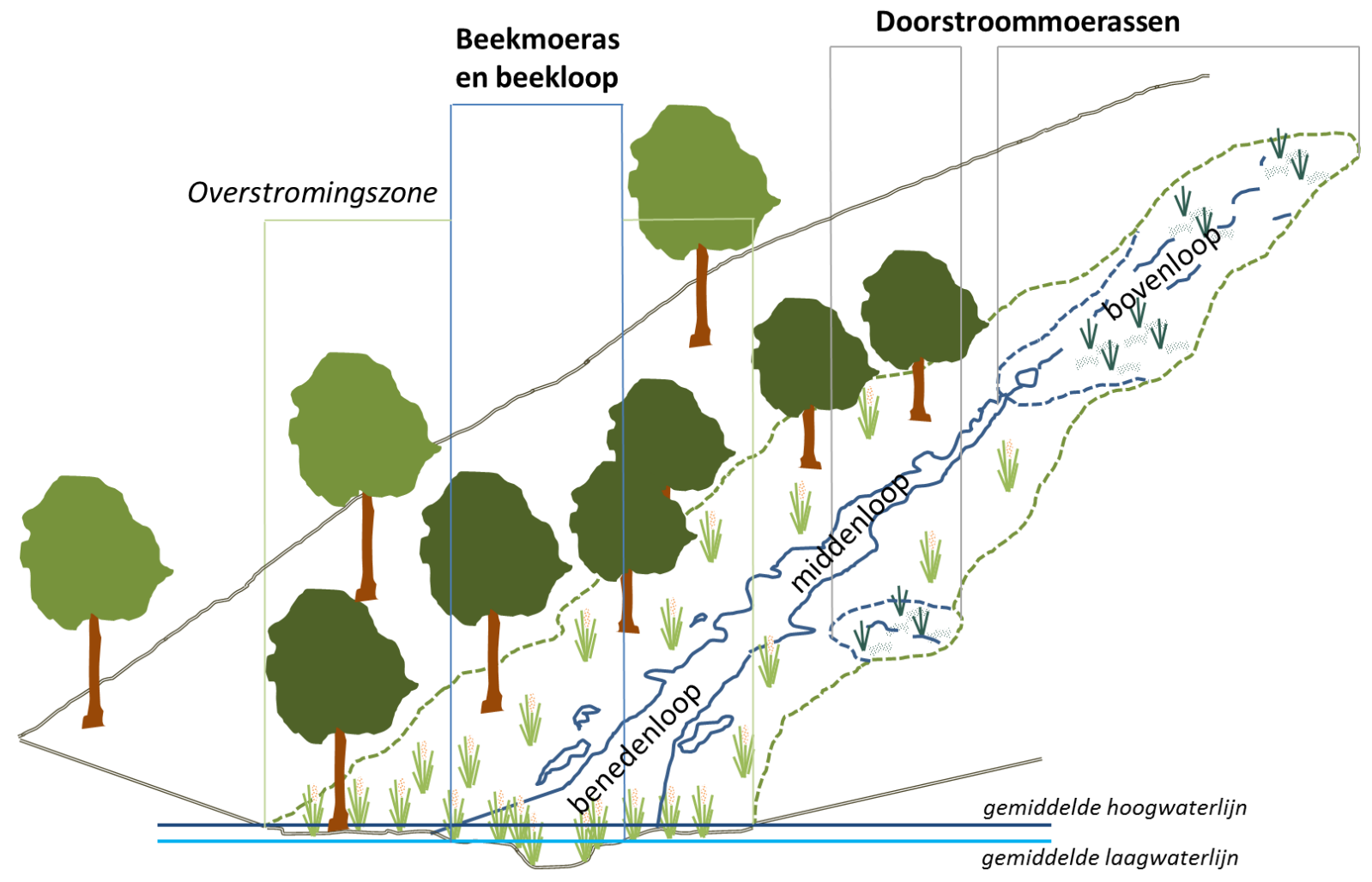

Figuur 5: Overzicht van een stroomgebied met hierin doorstroommoerassen en de moerasbeek (beekmoeras + beekloop + overstromingszone).

\subsection{De vegetatie als structuurvormend element}

In doorstroommoerassen en moerasbeken is de vegetatie het belangrijkste structuurvormende element. Verschillen in samenstelling en ontwikkeling van de vegetatie in het doorstroommoeras en het beekmoeras van de moerasbeek worden in de eerste plaats gestuurd door de herkomst van het water (grond- versus oppervlaktewatervoeding) en de 
stoffen (stikstof, fosfor, mineralen) die door het water aangevoerd worden. De hoge voedselrijkdom van de moerasbeek leidt gewoonlijk tot een hogere productiviteit van de vegetatie in vergelijking met de vooral grondwatergevoede doorstroommoerassen. In de tweede plaats is het hydrologische regime (waterpeil, timing van droogval/inundatie) in het moeras bepalend voor de vegetatieontwikkeling; vooral voor de kieming van zaden is het van belang of en wanneer delen van het beekdal droogvallen.

\section{De rol van verlanding}

Veel plantensoorten in moerassen zijn zogenoemde 'ecosysteem engineers', door aanpassingen/kenmerken zijn ze in staat hun omgeving naar hun hand te zetten. Zo is liesgras via zijn uitlopers in staat effectief slib in te vangen en zo de ideale groeiomstandigheden voor de plant te creëren, morfologisch gezien leidt dit tot aanslibbing en bankvorming in de beekloop (Gurnell 2014). Is de vegetatie eenmaal goed ontwikkeld, dan zorgen de wortelstelsels ervoor dat erosie van het opgehoopte materiaal (slib, afgestorven plantenresten, eventueel veen) bij hoge afvoeren geremd wordt en treedt er verlanding op (Figuur 6). Veel moerasplanten zijn in staat de bodem aan met zuurstof aan te rijken via hun wortelstelsel, waardoor er versnelde mineralisatie optreedt. Dit leidt weer tot het vrijkomen van extra voedingsstoffen, die de plant weer kan gebruiken voor groei en ontwikkeling.
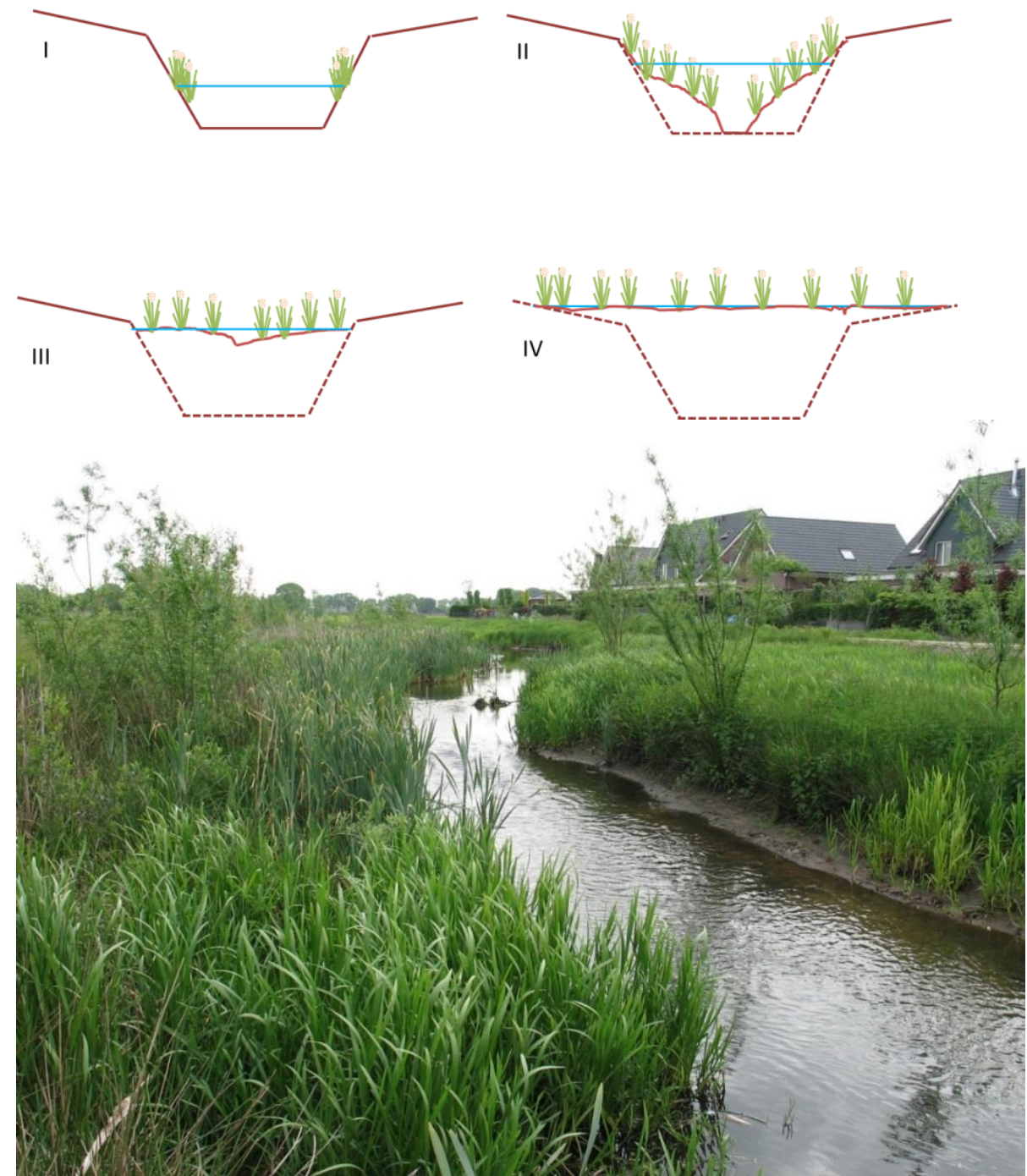

Figuur 6: Verlanding van een bovenloop met een normprofiel (I) tot een doorstroommoeras (IV) (boven). Liesgras zet het beekmilieu naar zijn hand door met zijn wortels slib in te vangen en zo banken te vormen (onder). Foto: Ralf Verdonschot. 


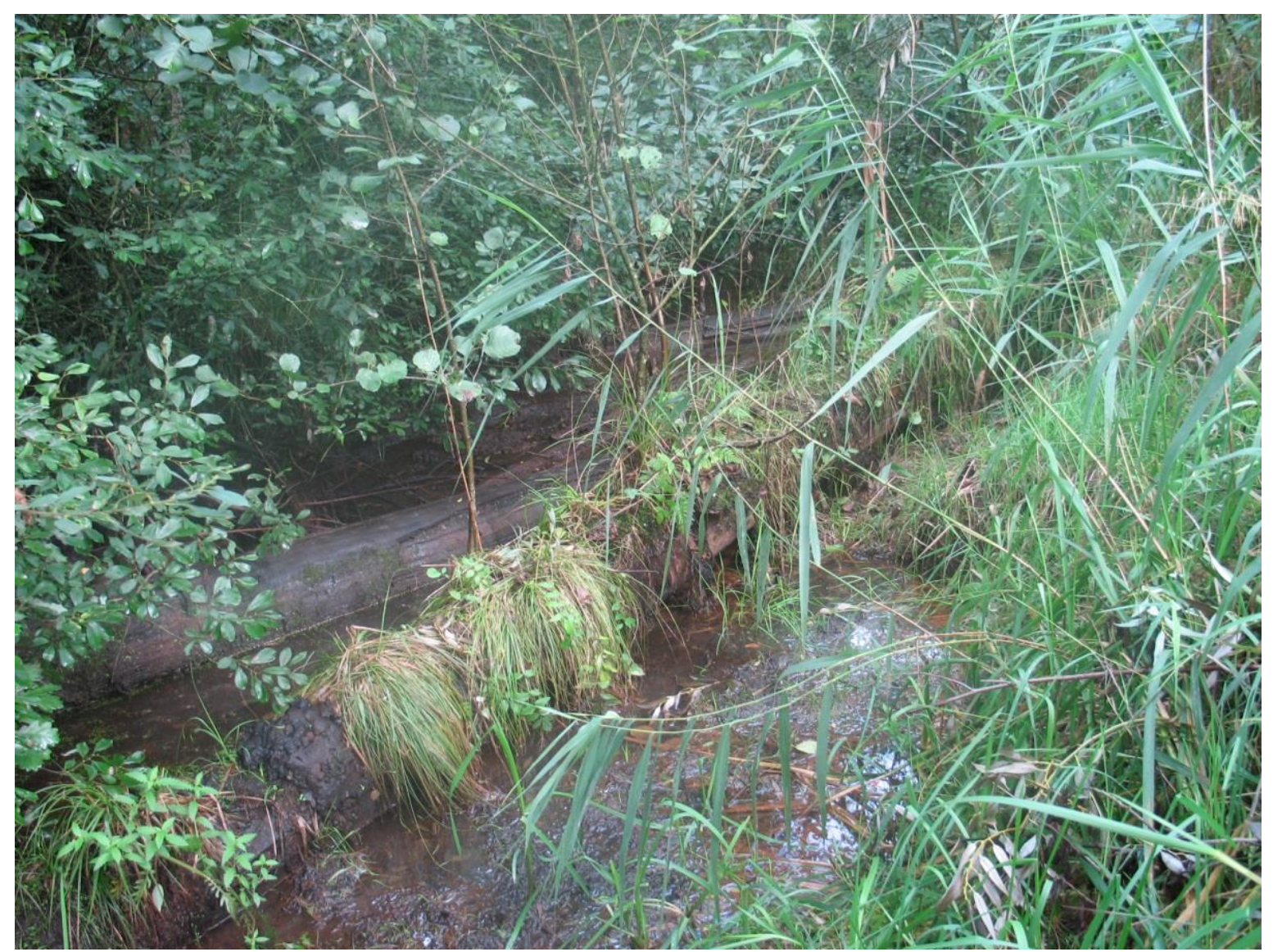

Foto 5: Op verterende boomstammen in de Oude Strijper Aa komt vegetatie tot ontwikkeling, waaronder enkele zaailingen van de els. Foto: Ralf Verdonschot.

\section{Bomen of geen bomen?}

Het gedeelte van de doorstroommoerassen en moerasbeken dat jaarrond nat is (beekmoeras), was waarschijnlijk in het verleden met verspreid staande bomen (els, wilg) begroeid, afgewisseld met open plekken (op de natste plekken) gedomineerd door moerasplanten, zoals zeggen (Aggenbach et al. 2014). Onder permanent geïnundeerde omstandigheden zijn zaden van bomen niet in staat te kiemen, waardoor verbossing geremd wordt. Voor hun ontwikkeling zijn bomen afhankelijk van ofwel extreme omstandigheden (langdurige droogte, waardoor plekken droogvallen die normaalgesproken nat zouden zijn) of de aanwezigheid van kleinschalig reliëf in het beekmoeras (oeverwalletjes, bankjes of bultjes). Een andere mogelijkheid zijn omgevallen bomen; wanneer een boom vanaf hoger gelegen delen in het beekdal in het moeras valt, vormt deze op de plek waar het hout neerkomt micro-reliëf. De stam van de boom fungeert als een verhoging/eiland en creëert drogere omstandigheden in de verder natte omgeving. Omdat de afbraak van boomstammen langzaam verloopt, vestigen zich allerlei planten en dieren op het verterende hout (Foto 5). Vaak krijgen deze bomen niet de kans zich tot hun volle omvang te ontwikkelen, omdat ze door de slappe bodem van het moeras vroegtijdig omvallen, bijvoorbeeld tijdens stormen (windworp). De overstromingszone was sterker bebost. Afhankelijk van de bodemsamenstelling en het hydrologisch regime ontwikkelt zich in de overstromingszone, waar bij lage afvoer geen water boven maaiveld staat, elzenbroekbos of alluviaal bos (Vochtige Elzen-Essenbossen). Dit bos kan weer invloed uitoefenen op het beekmoeras; in een smal beekdal kunnen breed uitwaaierende kronen van bomen in de overstromingszone of hogerop in het beekdal beschaduwing geven in het beekmoeras of de beekloop. Ten slotte kan monopolisatie van de beschikbare ruimte ook een rol in spelen bij het remmen van verbossing. Riet kan bijvoorbeeld na eenmaal tot ontwikkeling gekomen te zijn (kieming bij 
droogval in de zomer) het systeem lange tijd domineren, zelfs wanneer de omstandigheden na verloop van tijd minder gunstig voor deze planten zijn, bijvoorbeeld door verdroging.

\subsection{Herstel van doorstroommoerassen en moerasbeken}

Wanneer in beken niet de juiste randvoorwaarden aanwezig zijn voor het natuurlijk in stand houden van een (brede) loop, namelijk voldoende afvoer en stroming (verhang), stuurt het beheer en onderhoud de toestand waarin de beek zich bevindt. Feitelijk wordt de vegetatiesuccessie richting een moerassysteem door te maaien en eventueel te baggeren telkens teruggezet in een pionierstadium. De ontwikkeling van doorstroommoerassen en moerasbeken in een genormaliseerd en overgedimensioneerd profiel en een gekanaliseerde loop kan zowel passief als actief worden uitgevoerd.

Passieve ontwikkeling vindt plaats wanneer een beek extensiever of zelfs niet meer gemaaid wordt. Door vegetatieontwikkeling en de bijbehorende verlanding in een langzaam stromende bovenloop toe te laten (onderhoud staken) kan zich na verloop van tijd een doorstroommoeras ontwikkelen. In midden- en benedenlopen kan op dezelfde wijze een moerasbeek ontstaan, maar dit kan ook bereikt worden door in deze systemen extensiever te onderhouden (natuurvriendelijke oevers), bijvoorbeeld een vorm waarbij eenzijdig of alleen de stroombaan gemaaid wordt. Echter, onderhoud leidt in deze systemen wel tot aantasting van de gradiënt in vegetatiestructuur tussen open water en moerasvegetatie; deze wordt door het maaien scherper begrensd dan in een natuurlijke situatie het geval zou zijn. Ook het waterpeil in de moeraszone is belangrijk, op het moment dat de moeraszone bij lage waterstanden droogvalt, is er geen sprake meer van een beekmoeras (dat is immers altijd nat).

Een belangrijk aandachtpunt bij het passief omvormen van beken naar doorstroommoerassen en moerasbeken is de beschikbare ruimte/het landgebruik op de aanliggende percelen in het beekdal. Vernatting van de beekbegeleidende gronden is immers inherent aan het voorkomen van doorstroommoerassen en moerasbeken (Figuur 6). Ruimte in het beekdal voor het ontwikkelen van deze systemen is dan ook een belangrijke randvoorwaarde.

Wanneer er in een beekdal ruimte is voor beekdalbreed herstel kunnen doorstroommoerassen en moerasbeken actief ontwikkeld worden. Herprofilering, waarbij een natuurlijk profiel wordt gegraven (slenk, twee-fasen-profiel, zie Figuur 3, Foto 6) in combinatie met het dempen van drainerende watergangen (greppels, sloten) en het verwijderen van drainagebuizen kan de ontwikkeling van doorstroommoerassen en moerasbeken initiëren. Een andere vorm van beekherstel waarbij doorstroommoerassen of moerasbeken kunnen ontstaan is het opnieuw verbinden van een ingesneden beek met het beekdal door bodemophoging via hout/zand-inbreng (Foto 7).

Ten slotte moet er bij de ontwikkeling van doorstroommoerassen en moerasbeken rekening gehouden worden met de rol van eutroof en/of slibrijk beekwater op de ontwikkeling van deze systemen. Te hoge aanvoer van voedingsstoffen en afzetting van voedselrijk slib tijdens hoog water kan leiden tot het ontstaan van monoculturen van bijvoorbeeld liesgras. De ecologische consequenties van deze ontwikkeling op de langere termijn, zoals de vraag of andere plantensoorten na verloop van tijd kansen krijgen en de dominantie doorbroken wordt, zijn op dit moment nog niet duidelijk. 


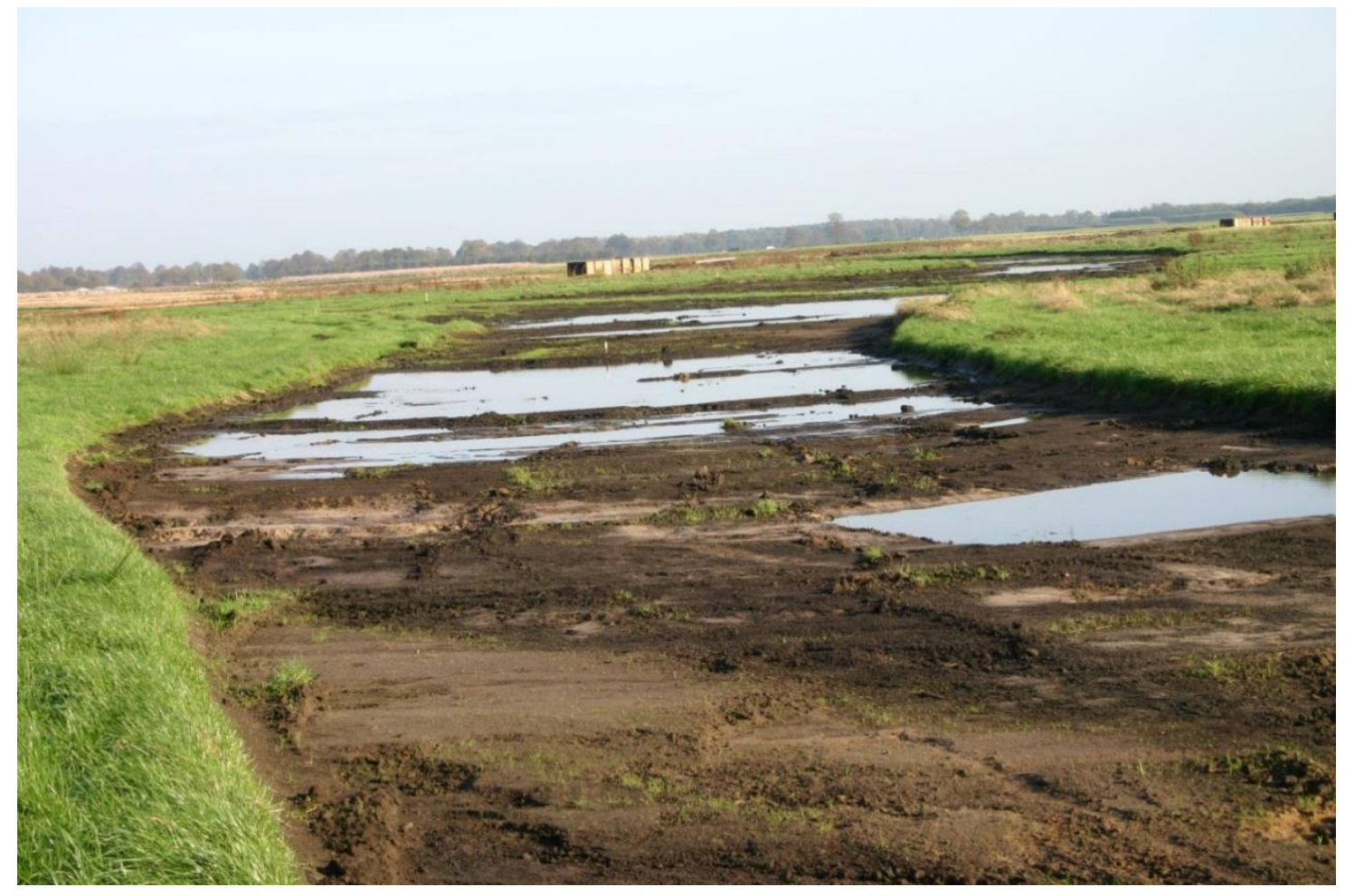

Foto 6: Herprofilering van de Geeserstroom. Er is gekozen voor een laagte met als doel moerasontwikkeling te stimuleren (Foto: Piet Verdonschot).

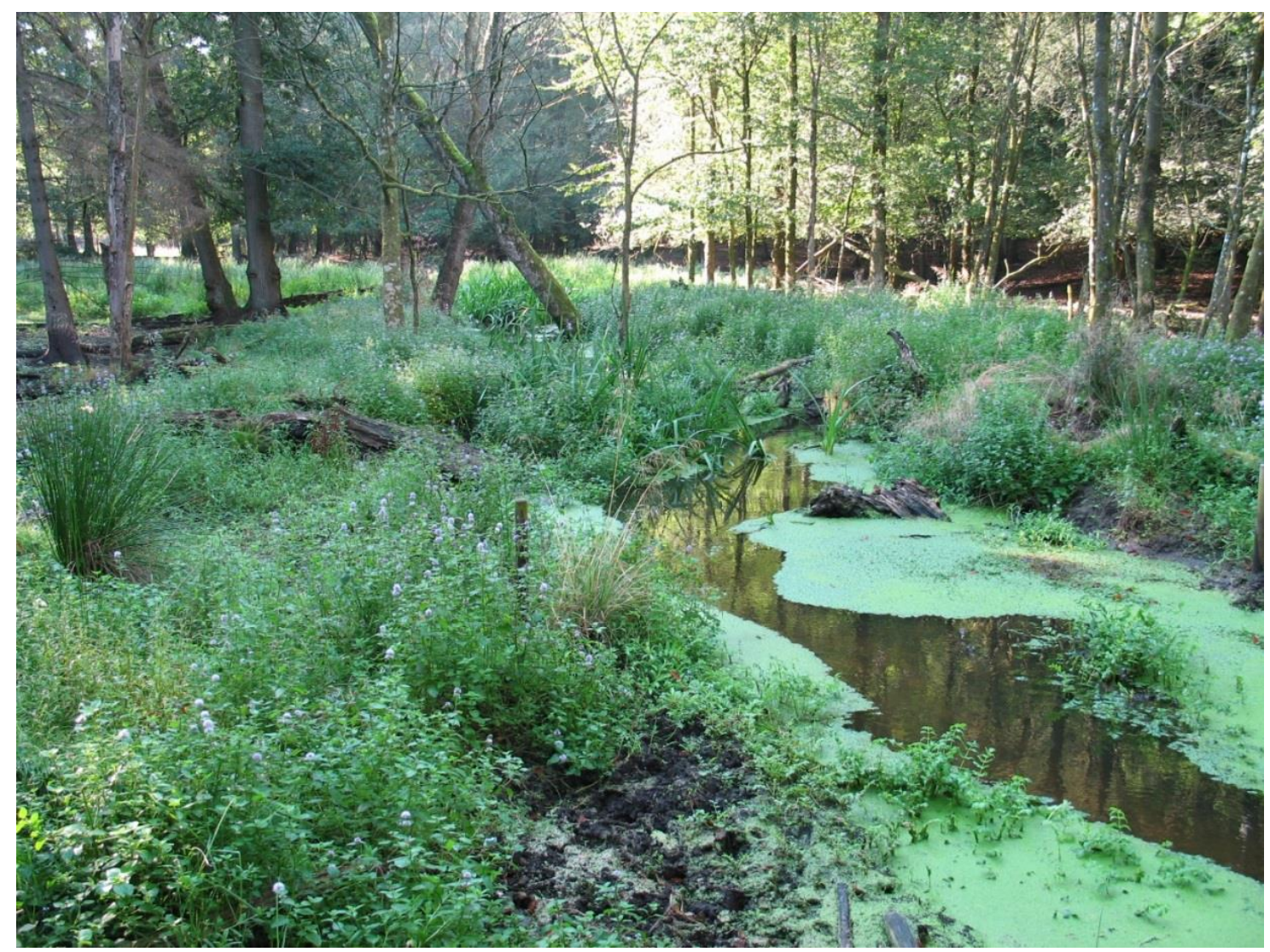

Foto 7: Vernatting van laagtes langs de Leuvenumse beek door houtinbreng en zandsuppletie leidt tot het ontstaan van moerasbeektrajecten. Er is zich een smal beekmoeras en een brede overstromingsvlakte aan het ontwikkelen. Foto: Ralf Verdonschot. 


\section{Aanpassingen macrofaunamaatlat}

Bij het toepassen van de macrofaunamaatlatten uit de 2016-notitie werd door de gebruikers geconstateerd dat het werken met losse indicatorlijsten voor beek en moeras en een aangepaste formule om de EKR te berekenen problemen opleverde, onder te verdelen in:

- De toetsing op basis van twee monsters is complexer en zal in de praktijk problemen kunnen opleveren (bijv in Aquo-kit: identificatie moeras- en loopmonsters).

- Onpraktisch bij het beoordelen van (oudere) monsters, die niet gescheiden zijn bemonsterd

- Kunstmatige scheiding water en moeras tijdens bemonstering, waarbij risico is dat de overgangszone niet voldoende wordt bemonsterd, terwijl die vaak juist interessant is

- Beeksoorten die in het moeras gevangen worden en vice versa tellen niet altijd mee.

- De invloed van DN en DP soorten en $\mathrm{K}$ soorten op het eindoordeel lijkt niet altijd goed in balans te zijn, waarbij de eerste groep onevenredig zwaar weegt ten opzichte van de andere twee groepen. Ook is de trefkans van een deel van de $\mathrm{K}$ soorten relatief gering.

Op basis van de bovenstaande constateringen is er besloten de indicatorlijsten voor het doorstroommoeras en de moerasbeek te herzien. Hierbij zijn de losse beeklijsten en de moeraslijst geaggregeerd tot één indicatorlijst per type. Dit maakt de beoordeling van doorstroommoerassen en moerasbeken eenvoudiger, zowel voor de monitoring als voor de analyse van de data. Voor de bepaling van de EKR zijn dus alle kenmerkende, positieve en negatieve soorten voor loop en moeras samengevoegd. Hiermee kan de formule die gangbaar is voor de KRW-watertypen R4 en R5 in het vervolg ook voor het doorstroommoeras en de moerasbeek gebruikt worden. Wel is voor beide typen een nieuwe waarde voor KMmax vastgesteld op basis van de beschikbare dataset.

\subsection{Aanpak}

\subsubsection{Aanpassingen indicatortaxalijst}

De indicatortaxalijst uit Verdonschot et al. (2016) is aangevuld met nieuwe gegevens en de losse beek en moeraslijsten zijn samengevoegd. Om tot geaggregeerde lijsten voor het doorstroommoeras en de moerasbeek te komen is een koppeling gemaakt tussen monitoringsdata en autoecologische informatie (Figuur 7). Er is een lijst opgesteld van soorten die voorkomen in beken met een moeraskarakter; in de loop en/of de moeraszone. Voor deze lijst vormden vier verschillende datasets de basis:

A. Bestand met monsters van locaties met een moeraskarakter (meetnet waterschappen vanaf 1991), niet opgenomen volgens moerasbekenmethodiek (onbekend of wateren in moerasdeel zijn bemonsterd) (doorstroommoeras: 159, moerasbeek: 203)

B. Referentiemonsters van Poolse laaglandbeken uit 1999, niet opgenomen volgens moerasbekenmethodiek (doorstroommoeras: 2, moerasbeek: 4)

C. Monsters aangeleverd naar aanleiding van de moerasbekenrapportage uit 2016. Voor het doorstroommoeras gaat het om 12 monsters, waarvan 7 monsters met aparte deelmonsters voor moeras en beekloop. Voor de moerasbeek gaat het om 19 monsters, waarvan 13 met een apart deelmonster voor moeras en beekloop. 
D. Lijsten met KRW-indicatoren voor R4 (herziene versie) en R5 (bestaande lijst).

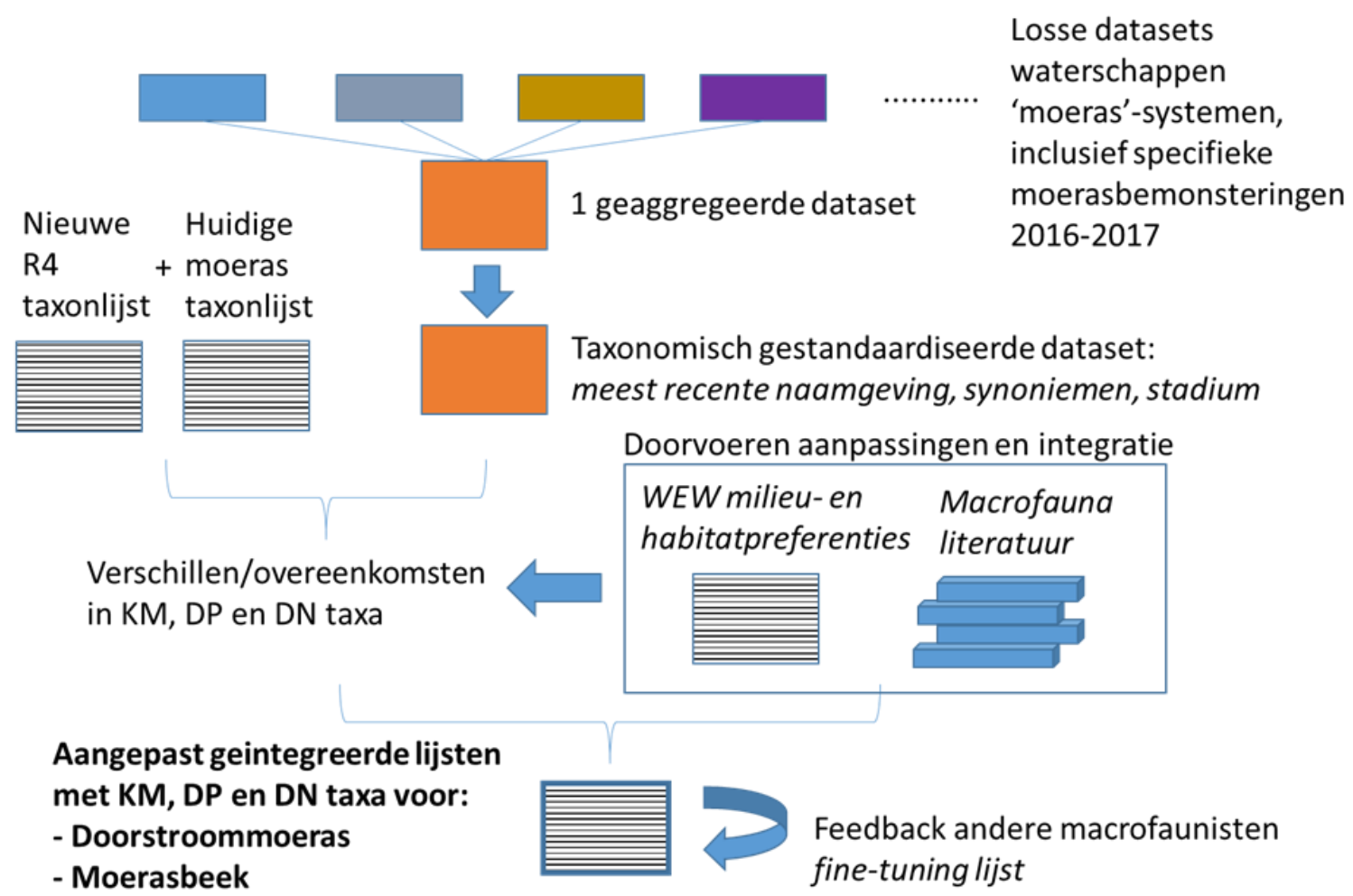

Figuur 7: Stappenplan herziening maatlatten doorstroommoeras en moerasbeek.

Voor de soorten in de complete dataset is de autoecologische informatie bekeken (milieu- en habitatpreferenties macrofauna (Verberk et al. 2012) en diverse literatuurbronnen) en op basis hiervan vastgesteld of deze soorten binding (in positieve of negatieve zin) hebben met a.) bovenlopen/ midden-benedenlopen + moerassystemen, b.) stressoren. Omdat in de verschillende bronnen veel variatie in terminologie bestaat wat betreft habitat en milieupreferenties, er is zelden gekwantificeerde informatie voorhanden, worden in box 1 voorbeelden gegevens van indicaties die voor ons aanleiding waren een soort te selecteren. In de praktijk bleek het vaak om combinaties van de verschillende termen te gaan.

\section{Box 1: voorbeelden van inschatting indeling op basis van literatuurbronnen}

Qua habitat passend bij de typen:

bronbeken, bovenlopen, moerasbeken, uittredingszones kwel (trickles), hygropetrisch, kleine beken, laaglandbeken, midden- en benedenlopen, overstromingsvlakten, moerassen, zeggenmoerassen, venen, veenmos, broekbossen, natte heiden, kwelgevoed.

Milieuindicatie +

Rheofiel/stroming, crenofiel/lage watertemperatuur, oligo- mesotroof, hoog zuurstofgehalte/lage organische belasting, helder water, natuurlijke bovenlopen, specifiek habitat (mos, hout, grind), specialist, typisch voor, bijzonder.

Milieuindicatie -

Verontreinigd, organisch belast, gekanaliseerd, genormaliseerd, zuurstofloos, ubiquist, weinig eisen, verstoring, gedegradeerd

Dominant

Talrijk in, veel voorkomend, hoge aantallen......... 


\subsubsection{Vaststellen belang beekloop en moeraszone t.b.v. beoordeling en aanpassingen bemonstering}

Speciaal voor het opstellen van de maatlatten voor doorstroommoerassen en moerasbeken zijn in verschillende in Nederland aanwezige doorstroommoerassen of moerasbeken (veelal herstelprojecten, dus systemen in ontwikkeling) monsters genomen in 2016-2017, waarbij zowel deelmonsters in het moeras als in de beekloop genomen zijn. In Verdonschot et al. (2017) werd het gebruik van losse deelmonsters voor beek en moeras aanbevolen, maar in de praktijk bleek dit niet altijd goed werkbaar. Problemen waar gebruikers tegenaan liepen waren dat het soms in het veld lastig was onderscheid te maken tussen beide delen, de berekening van een beekdeel en een moerasdeel niet goed recht deed aan de geleidelijke overgang tussen water en land etc.

De 7 doorstroommoerasmonsters en 12 moerasbeekmonsters met losse deelmonsters van de beekloop en het moeras zijn gebruikt om het belang van beide delen van het systeem te bepalen. Het is namelijk de vraag of in de loop een afspiegeling te zien is van de levensgemeenschap in het moeras of dat het losse onderdelen zijn met een verschillende soortensamenstelling. Deze informatie is tegelijkertijd nodig om de wijze van bemonsteren van doorstroommoerassen en moerasbeken definitief vast te stellen. Het streven was één mengmonster in plaats van aparte mengmonsters voor de moeraszone en voor de stroombaanzone te gebruiken. De apart verzamelde gegevens van het moerasdeel en het beekdeel worden gebruikt om deze aggregatie vorm te geven.

\subsubsection{Vaststellen grenswaarden aangepaste maatlat}

Nadat de nieuwe indicatorlijsten zijn opgesteld, is voor alle monsters het KM\% berekend. Dit is het aantal als kenmerkend aangeduide taxa gedeeld door het totaal aantal taxa. Dit percentage is belangrijk omdat dit voor een groot deel de uiteindelijke EKR score van een monster bepaalt. Het KM\% wordt per watertype geijkt aan een KMmax. Voor het watertype R4 bedraagt dit in de huidige situatie $26 \%$ en voor R5 33\%. Voor de aangepaste maatlatten moet de KMmax opnieuw worden vastgesteld. Een referentiesituatie voor doorstroommoerassen en moerasbeken is niet meer in Nederland aanwezig. Het vaststellen van deze toestand kan dan ook niet worden beschreven in dit project. Hiervoor is het noodzakelijk nog intacte natuurlijke locaties in het buitenland te bemonsteren, bijvoorbeeld in het oosten van Duitsland of Polen. Er is daarom gewerkt met de beste situatie die nu in Nederland aanwezig is als uitgangspunt. Voor de macrofauna zijn hiervoor de beste waarden voor de hierboven genoemde doorstroommoeras-/moerasbeekmonsters gebruikt. Deze gegevens geven op dit moment het beste beeld van de situatie. Van het KM\% van deze monsters is de KMmax voor in de formule voor het berekenen van de EKR afgeleid. Om de waarden in perspectief te zien zijn deze vergeleken met de standaardmonsters die ook in Verdonschot et al. 2016 zijn gebruikt van beken met eigenschappen van moerassystemen, inclusief doorstroommoeras en moerasbeekmonsters van referentiesituaties in Polen.

\subsection{Resultaten}

\subsubsection{Aanpassingen indicatortaxalijst}

$\mathrm{Er}$ is een aparte maatlat opgesteld voor doorstroommoerassen (op basis van de herziene R4 (Verdonschot \& Verdonschot 2018) + moerasindicatorlijst + aanvullingen op basis van verspreidingsgegevens en autoecologie) en voor moerasbeken (op basis van de huidige R5 + moerasindicatorlijst + aanvullingen op basis van verspreidingsgegevens en autoecologie). Omdat doorstroommoerassen en moerasbeken een hoge biodiversiteit kennen, immers er komen zowel soorten van stilstaande als stromende systemen voor, is het aantal kenmerkende taxa hoog (doorstroommoeras 414, moerasbeek 392). Daar komt nog bij dat 
het moerassen een grote ecologische differentiatie kennen, waardoor het aantal kenmerkende indicatoren hier ook hoog is. Het aantal positief dominante en negatief dominante taxa ligt lager (doorstroommoeras $P=60, N=31$; moerasbeek $P=83, N=32$ ). De complete lijst inclusief literatuurverwijzingen is te vinden in Bijlage 1.

\subsubsection{Vaststellen belang beekloop en moeraszone t.b.v. beoordeling en aanpassingen bemonstering}

Zowel de beekloop als het moeras zijn noodzakelijk om een goed beeld te krijgen van de levensgemeenschap, beide bevatten andere taxa (Tabel 1). Hierbij kan één mengmonster genomen worden waarbij het moeras en de beek worden gecombineerd. Gemiddeld genomen is het moerasdeel wel belangrijker voor het vangen van kenmerkende taxa: $75 \%$ van de kenmerkende taxa (doorstroommoeras) en 65\% (moerasbeek) komen uit het moerasdeel. Voor het doorstroommoeras geldt echter dat er in de meest natuurlijke situatie überhaupt niet goed onderscheid gemaakt kan worden tussen beek en moeras. Dit was het geval in het doorstroommoeras in de Strijper Aa (meetpunt 259844). Hier werd voor de doorstroommoerasmonsters overigens ook het hoogste aantal kenmerkende taxa aangetroffen (18). De monsterlengte voor dit monster bedroeg $5,5 \mathrm{~m}$, opgedeeld in: planten $(0,5 \mathrm{~m})$, wilgenmoeras $(0,5 \mathrm{~m})$, rietmoeras $(0,5 \mathrm{~m})$, takken $(0,5 \mathrm{~m}$, bladeren $(0,5 \mathrm{~m})$, wortels van bomen $(0,5 \mathrm{~m})$, fijne detritus $(0,5 \mathrm{~m})$, kwelvlies $(2 \mathrm{~m})$. Voor de bemonstering is het vooral belangrijk dat de diversiteit aan habitattypen (specifieke leefplekken voor macrofauna) in het systeem wordt meegenomen, waarbij zowel habitattypen in het moeras als in de beek worden bemonsterd. De aanpak staat uitgebreid beschreven in hoofdstuk 12 Macrofaunaachtergrondinformatie pagina 14-30 van het handboek Hydrobiologie, deze is ook goed bruikbaar in doorstroommoerassen en moerasbeken.

Tabel 1: Bijdrage deelmonsters aan totaal aantal aangetroffen kenmerkende $(K)$ taxa in doorstroommoerassen en moerasbeken.

\begin{tabular}{|c|c|c|c|c|c|c|c|}
\hline \multirow[t]{2}{*}{ Locatiecode } & \multirow[t]{2}{*}{ Locatienaam } & \multicolumn{4}{|c|}{ KM-taxa in deelmonsters (\#) } & \multicolumn{2}{|c|}{$\begin{array}{l}\text { Bijdrage } \\
\text { deelmonster } \\
\text { aan het totale } \\
\text { aantal KM-taxa } \\
(\%)\end{array}$} \\
\hline & & beek & moeras & totaal & overlap & beek & moeras \\
\hline \multicolumn{8}{|c|}{ Doorstroommoeras } \\
\hline 130006 & $\begin{array}{l}\text { Leij; bovenstrooms duiker } \\
\text { in Rielse Hoefke (Alphen) }\end{array}$ & 1 & 3 & 3 & 1 & 33 & 100 \\
\hline 130034 & $\begin{array}{l}\text { Leij; in de bocht (nieuwe) } \\
\text { waterloop }\end{array}$ & 3 & 6 & 9 & 0 & 33 & 67 \\
\hline 221322 & $\begin{array}{l}\text { Bijloop; benedenstrooms } \\
\text { Oosteindseweg Sprundel }\end{array}$ & 3 & 4 & 7 & 0 & 43 & 57 \\
\hline 221323 & $\begin{array}{l}\text { Bijloop; bovenstrooms } \\
\text { Sprundelsebaan } \\
\text { (Pannenhoef) }\end{array}$ & 1 & 6 & 6 & 1 & 17 & 100 \\
\hline 251118 & $\begin{array}{l}\text { Rosep, nabij Belversven } \\
\text { met moeraszone }\end{array}$ & 7 & 9 & 16 & 0 & 44 & 56 \\
\hline 259001 & $\begin{array}{l}\text { Rosep; nieuwe meander } \\
\text { bovenstrooms } \\
\text { Rosepdreef }\end{array}$ & 7 & 10 & 16 & 1 & 44 & 63 \\
\hline 259993 & $\begin{array}{l}\text { Rielloop, in het } \\
\text { moerasbos van Brabants } \\
\text { landschap }\end{array}$ & 4 & 8 & 10 & 2 & 40 & 80 \\
\hline \multicolumn{8}{|l|}{ Moerasbeek } \\
\hline 140268 & $\begin{array}{l}\text { Goorloop t.h.v. Jonker } \\
\text { Karellaan te Rixtel }\end{array}$ & 2 & 3 & 5 & 0 & 40 & 60 \\
\hline
\end{tabular}




\begin{tabular}{|c|c|c|c|c|c|c|c|}
\hline \multirow[t]{2}{*}{ Locatiecode } & \multirow[t]{2}{*}{ Locatienaam } & \multicolumn{4}{|c|}{ KM-taxa in deelmonsters (\#) } & \multicolumn{2}{|c|}{$\begin{array}{l}\text { Bijdrage } \\
\text { deelmonster } \\
\text { aan het totale } \\
\text { aantal KM-taxa } \\
\text { (\%) }\end{array}$} \\
\hline & & beek & moeras & totaal & overlap & beek & moeras \\
\hline 251092 & $\begin{array}{l}\text { Esschestroom, } \\
\text { Slingersloot. } \\
\text { Haarenseweg, Esch }\end{array}$ & 2 & 13 & 15 & 0 & 13 & 87 \\
\hline 251117 & $\begin{array}{l}\text { Reusel, Diessens Broek, } \\
\text { moeras bovenstrooms } \\
\text { kanaal }\end{array}$ & 7 & 8 & 15 & 0 & 47 & 53 \\
\hline 253090 & $\begin{array}{l}\text { Esschestroom, meanders } \\
\text { landgoed Bleijendijk }\end{array}$ & 6 & 7 & 13 & 0 & 46 & 54 \\
\hline 253500 & $\begin{array}{l}\text { Goorloop, zandvanger } \\
\text { Troprijt Bladel }\end{array}$ & 3 & 6 & 7 & 2 & 43 & 86 \\
\hline 258967 & $\begin{array}{l}\text { Beerze, Logstebaan, } \\
\text { bovenstroomse deel }\end{array}$ & 5 & 6 & 11 & 0 & 45 & 55 \\
\hline 258970 & $\begin{array}{l}\text { Beerze, Logstevelden, } \\
\text { bovenstrooms Brinksdijk }\end{array}$ & 7 & 9 & 16 & 0 & 44 & 56 \\
\hline 349999 & $\begin{array}{l}\text { Escharen, voor } \\
\text { uitmonding Graafse Raam }\end{array}$ & 1 & 3 & 4 & 0 & 25 & 75 \\
\hline $\begin{array}{l}\text { 8STHO8 } \\
\text { (voorjaar) }\end{array}$ & $\begin{array}{l}\text { Oude Diep Stadsrand; } \\
\text { verlanding }\end{array}$ & 9 & 5 & 9 & 5 & 100 & 56 \\
\hline $\begin{array}{l}\text { 8STHO8 } \\
\text { (najaar) }\end{array}$ & $\begin{array}{l}\text { Oude Diep Stadsrand; } \\
\text { verlanding }\end{array}$ & 2 & 5 & 7 & 0 & 29 & 71 \\
\hline 900022 & $\begin{array}{l}\text { Groote Wetering bij } \\
\text { Grolderseweg }\end{array}$ & 4 & 7 & 10 & 1 & 40 & 70 \\
\hline OAFLE750 & $\begin{array}{l}\text { Afleidingskanaal van } \\
\text { Smakterveldlossing }\end{array}$ & 10 & 10 & 18 & 2 & 56 & 56 \\
\hline OOOST425 & $\begin{array}{l}\text { Oostrumschebeek Leunse } \\
\text { Paes } 2\end{array}$ & 2 & 2 & 3 & 1 & 67 & 67 \\
\hline
\end{tabular}

\subsubsection{Vaststellen grenswaarden maatlatten}

\section{Doorstroommoeras}

Voor de doorstroommoerassen waren in totaal 12 monsters beschikbaar van de 'beste' locaties aanwezig in de provincies Noord-Brabant en Gelderland. Op basis hiervan bleek het monster van het doorstroommoeras Strijperheg, onderdeel van de Strijper Aa het hoogste $\mathrm{KM} \%$ te behalen (Tabel 2). Door de beheerder van het gebied werd de Strijper $\mathrm{Aa}$ voorafgaand aan de analyses ook al aangeduid als een goede locatie:

"De Strijper Aa is het traject met meeste bijzondere soorten van het onderzoek, zoals de zeldzame bosschaatsenrijder Gerris lateralis en de zeldzame steenvlieg Nemoura dubitans."

Om de waarde van de Strijper Aa in perspectief te plaatsen is deze vergeleken met een verlandend armpje van de Stobnika; hier werd in het voorjaar van 1999 een KM\% van 27 gehaald en in het najaar een waarde van 31. Het KM\% van 29 in de Strijper Aa ligt dus binnen de range van de Poolse situatie, met de kanttekening dat tijdens de bemonstering van de Poolse beek de nadruk op de loop lag en dus met de in Nederland gehanteerde methode nog hoger zou kunnen liggen. 
Tabel 2: Overzicht van de KM\% doorstroommoerasmonsters (eventuele loop en moeras deelmonsters gecombineerd).

\begin{tabular}{|c|c|c|c|c|c|c|}
\hline Locatiecode & Locatienaam & Waterschap & Monsterdatum & $\begin{array}{l}\text { Totaal } \\
\text { \# taxa }\end{array}$ & $\begin{array}{l}\text { KM (\# } \\
\text { taxa) }\end{array}$ & KM\% \\
\hline 259844 & $\begin{array}{l}\text { Strijper Aa, } \\
\text { Doorstroommoeras } \\
\text { Strijperheg }\end{array}$ & de Dommel & $19 / 4 / 2017$ & 62 & 18 & 29.0 \\
\hline KOGV2 & Koffijgoot punt 2 & Rijn \& IJssel & $30 / 3 / 2016$ & 38 & 7 & 18.4 \\
\hline 251118 & $\begin{array}{l}\text { Rosep, nabij } \\
\text { Belversven met } \\
\text { moeraszone }\end{array}$ & de Dommel & $3 / 4 / 2017$ & 95 & 16 & 16.8 \\
\hline KOGV4 & Koffijgoot punt 4 & Rijn \& IJssel & 6/4/2016 & 36 & 6 & 16.7 \\
\hline KOGV1 & Koffijgoot punt 1 & Rijn \& IJssel & $5 / 6 / 2015$ & 19 & 3 & 15.8 \\
\hline 259993 & $\begin{array}{l}\text { Rielloop, in het } \\
\text { moerasbos van } \\
\text { Brabants landschap }\end{array}$ & de Dommel & $3 / 4 / 2017$ & 65 & 10 & 15.4 \\
\hline 259001 & $\begin{array}{l}\text { Rosep; nieuwe } \\
\text { meander } \\
\text { bovenstrooms } \\
\text { Rosepdreef }\end{array}$ & de Dommel & $19 / 4 / 2017$ & 105 & 16 & 15.2 \\
\hline KOGV3 & Koffijgoot punt 3 & Rijn \& IJssel & $5 / 6 / 2015$ & 46 & 7 & 15.2 \\
\hline 130034 & $\begin{array}{l}\text { Leij; in de bocht } \\
\text { (nieuwe) waterloop }\end{array}$ & $\begin{array}{l}\text { Brabantse } \\
\text { Delta }\end{array}$ & $1 / 5 / 2017$ & 104 & 9 & 8.7 \\
\hline 221323 & $\begin{array}{l}\text { Bijloop; } \\
\text { bovenstrooms } \\
\text { Sprundelsebaan } \\
\text { (Pannenhoef) }\end{array}$ & $\begin{array}{l}\text { Brabantse } \\
\text { Delta }\end{array}$ & $1 / 5 / 2017$ & 71 & 6 & 8.5 \\
\hline 221322 & $\begin{array}{l}\text { Bijloop; } \\
\text { benedenstrooms } \\
\text { Oosteindseweg } \\
\text { Sprundel } \\
\end{array}$ & $\begin{array}{l}\text { Brabantse } \\
\text { Delta }\end{array}$ & $1 / 5 / 2017$ & 90 & 7 & 7.8 \\
\hline 130006 & $\begin{array}{l}\text { Leij; bovenstrooms } \\
\text { duiker in Rielse } \\
\text { Hoefke (Alphen) }\end{array}$ & $\begin{array}{l}\text { Brabantse } \\
\text { Delta }\end{array}$ & $1 / 5 / 2017$ & 90 & 3 & 3.3 \\
\hline
\end{tabular}

\section{Moerasbeek}

Voor de moerasbeek waren in totaal 34 monsters beschikbaar van de 'beste' locaties aanwezig in de provincies Limburg, Noord-Brabant, Gelderland en Overijssel. Op basis hiervan bleek een monster van een herstelproject in de Ramsbeek het hoogste KM\% te behalen: 22 (Tabel 3). Om deze waarde in perspectief te plaatsen is deze vergeleken met de moerasbeek de Gac in Polen, waar een oever/poel/moeras is bemonsterd; hier werd in het najaar van 1998 en het voorjaar van 1999 beide keren een KM\% van 22 gehaald. Het KM\% van de Ramsbeek is dus vergelijkbaar met de Poolse situatie, met de kanttekening dat tijdens de bemonstering van de Poolse beek de nadruk op de loop lag en dus met de in Nederland gehanteerde methode nog hoger zou kunnen liggen. 
Tabel 3: Overzicht van de KM\% moerasbeekmonsters (eventuele loop en moeras deelmonsters gecombineerd).

\begin{tabular}{|c|c|c|c|c|c|c|}
\hline Loccode & Locatienaam & Waterschap & $\begin{array}{l}\text { Monster } \\
\text { datum }\end{array}$ & $\begin{array}{l}\text { Totaal } \\
\text { \# taxa }\end{array}$ & $\begin{array}{l}\text { KM (\# } \\
\text { taxa) }\end{array}$ & KM\% \\
\hline RMB03 & $\begin{array}{l}\text { Ramsbeek } \\
\text { Emmausweg } \\
\text { Eibergen }\end{array}$ & Rijn \& IJssel & $15 / 4 / 2015$ & 78 & 17 & 21.8 \\
\hline Hierb & $\begin{array}{l}\text { Hierdense beek } \\
\text { moeras } \\
\text { bovenstrooms Z1 }\end{array}$ & $\begin{array}{l}\text { Vallei \& } \\
\text { Veluwe }\end{array}$ & 9/4/2018 & 63 & 13 & 20.6 \\
\hline RMB00 & $\begin{array}{l}\text { Ramsbeek, Grens } \\
\text { Eibergen }\end{array}$ & Rijn \& IJssel & $14 / 4 / 2011$ & 57 & 9 & 15.8 \\
\hline 253500 & $\begin{array}{l}\text { Goorloop, } \\
\text { zandvanger Troprijt } \\
\text { Bladel }\end{array}$ & de Dommel & $12 / 4 / 2017$ & 45 & 7 & 15.6 \\
\hline 258970 & $\begin{array}{l}\text { Beerze, } \\
\text { Logstevelden, } \\
\text { bovenstrooms } \\
\text { Brinksdijk }\end{array}$ & de Dommel & $3 / 4 / 2017$ & 107 & 16 & 15 \\
\hline DOB10 & $\begin{array}{l}\text { Dortherbeek, brug } \\
\text { Oxerweg bij } \\
\text { Oxerhoflaan } \\
\text { Deventer; } \\
\text { herinrichting met } \\
\text { meanders en } \\
\text { plasbermen 2013- } \\
2014\end{array}$ & Rijn \& IJssel & $4 / 6 / 2008$ & 29 & 4 & 13.8 \\
\hline RMB03 & $\begin{array}{l}\text { Ramsbeek } \\
\text { Emmausweg } \\
\text { Eibergen }\end{array}$ & Rijn \& IJssel & $12 / 4 / 2013$ & 58 & 8 & 13.8 \\
\hline RMB03 & $\begin{array}{l}\text { Ramsbeek } \\
\text { Emmausweg } \\
\text { Eibergen }\end{array}$ & Rijn \& IJssel & $21 / 4 / 2011$ & 82 & 11 & 13.4 \\
\hline 251117 & $\begin{array}{l}\text { Reusel, Diessens } \\
\text { Broek, Moeras } \\
\text { bovenstrooms } \\
\text { kanaal }\end{array}$ & de Dommel & $12 / 4 / 2017$ & 127 & 15 & 11.8 \\
\hline OAFLE750 & $\begin{array}{l}\text { Afleidingskanaal v. } \\
\text { Smakterveldlossing }\end{array}$ & Limburg & 9/5/2016 & 156 & 18 & 11.5 \\
\hline 258967 & $\begin{array}{l}\text { Beerze, } \\
\text { Logstebaan, } \\
\text { bovenstroomse } \\
\text { deel }\end{array}$ & de Dommel & $12 / 4 / 2017$ & 97 & 11 & 11.3 \\
\hline RMB03 & $\begin{array}{l}\text { Ramsbeek } \\
\text { Emmausweg } \\
\text { Eibergen }\end{array}$ & Rijn \& IJssel & $18 / 4 / 2014$ & 53 & 6 & 11.3 \\
\hline RMB00 & $\begin{array}{l}\text { Ramsbeek, Grens } \\
\text { Eibergen }\end{array}$ & Rijn \& IJssel & $18 / 10 / 2012$ & 73 & 8 & 11 \\
\hline 253090 & $\begin{array}{l}\text { Esschestroom, } \\
\text { meanders } \\
\text { landgoed } \\
\text { Bleijendijk }\end{array}$ & de Dommel & $26 / 4 / 2017$ & 120 & 13 & 10.8 \\
\hline
\end{tabular}




\begin{tabular}{|c|c|c|c|c|c|c|}
\hline Loccode & Locatienaam & Waterschap & $\begin{array}{l}\text { Monster } \\
\text { datum }\end{array}$ & $\begin{array}{l}\text { Totaal } \\
\text { \# taxa }\end{array}$ & $\begin{array}{l}\text { KM (\# } \\
\text { taxa) }\end{array}$ & KM\% \\
\hline RMB00 & $\begin{array}{l}\text { Ramsbeek, Grens } \\
\text { Eibergen }\end{array}$ & Rijn \& IJssel & $28 / 4 / 2013$ & 83 & 9 & 10.8 \\
\hline DOB00 & $\begin{array}{l}\text { Dortherbeek, brug } \\
\text { Oxerweg bij } \\
\text { Oxerhoflaan } \\
\text { Deventer; } \\
\text { herinrichting met } \\
\text { meanders en } \\
\text { plasbermen 2013- } \\
2014\end{array}$ & Rijn \& IJssel & $1 / 1 / 2017$ & 97 & 10 & 10.3 \\
\hline 251092 & $\begin{array}{l}\text { Esschestroom, } \\
\text { Slingersloot. } \\
\text { Haarenseweg, } \\
\text { Esch }\end{array}$ & de Dommel & $26 / 4 / 2017$ & 151 & 15 & 9.9 \\
\hline RMB00 & $\begin{array}{l}\text { Ramsbeek, Grens } \\
\text { Eibergen }\end{array}$ & Rijn \& IJssel & $15 / 5 / 2008$ & 56 & 5 & 8.9 \\
\hline 900022 & $\begin{array}{l}\text { Groote Wetering bij } \\
\text { Grolderseweg }\end{array}$ & Aa \& Maas & $17 / 5 / 2017$ & 114 & 10 & 8.8 \\
\hline 8STHO8 & $\begin{array}{l}\text { Oude Diep } \\
\text { Stadsrand; } \\
\text { verlanding }\end{array}$ & $\begin{array}{l}\text { Drents } \\
\text { Overijsselse } \\
\text { Delta }\end{array}$ & $21 / 4 / 2016$ & 103 & 9 & 8.7 \\
\hline RMB03 & $\begin{array}{l}\text { Ramsbeek } \\
\text { Emmausweg } \\
\text { Eibergen }\end{array}$ & Rijn \& IJssel & $30 / 9 / 2015$ & 71 & 6 & 8.5 \\
\hline DOB10 & $\begin{array}{l}\text { Dortherbeek, brug } \\
\text { Oxerweg bij } \\
\text { Oxerhoflaan } \\
\text { Deventer; } \\
\text { herinrichting met } \\
\text { meanders en } \\
\text { plasbermen 2013- } \\
2014\end{array}$ & Rijn \& IJssel & $23 / 5 / 2011$ & 48 & 4 & 8.3 \\
\hline 8STHO8 & $\begin{array}{l}\text { Oude Diep } \\
\text { Stadsrand; } \\
\text { verlanding }\end{array}$ & $\begin{array}{l}\text { Drents } \\
\text { Overijsselse } \\
\text { Delta }\end{array}$ & $12 / 10 / 2016$ & 85 & 7 & 8.2 \\
\hline BOSOP & $\begin{array}{l}\text { Bielheimerbeek; } \\
\text { Kipsweg }\end{array}$ & Rijn \& IJssel & $17 / 4 / 2013$ & 52 & 4 & 7.7 \\
\hline BOSOV & $\begin{array}{l}\text { Boven Slinge; } \\
\text { Vellengerdijk }\end{array}$ & Rijn \& IJssel & $16 / 4 / 2013$ & 56 & 4 & 7.1 \\
\hline DOB00 & $\begin{array}{l}\text { Dortherbeek, brug } \\
\text { Oxerweg bij } \\
\text { Oxerhoflaan } \\
\text { Deventer; } \\
\text { herinrichting met } \\
\text { meanders en } \\
\text { plasbermen 2013- } \\
2014\end{array}$ & Rijn \& IJssel & $5 / 5 / 2015$ & 71 & 5 & 7 \\
\hline RMB03 & $\begin{array}{l}\text { Ramsbeek } \\
\text { Emmausweg } \\
\text { Eibergen }\end{array}$ & Rijn \& IJssel & $22 / 5 / 2008$ & 45 & 3 & 6.7 \\
\hline RMB00 & $\begin{array}{l}\text { Ramsbeek, Grens } \\
\text { Eibergen }\end{array}$ & Rijn \& IJssel & $17 / 4 / 2014$ & 50 & 3 & 6 \\
\hline
\end{tabular}




\begin{tabular}{|c|c|c|c|c|c|c|}
\hline Loccode & Locatienaam & Waterschap & $\begin{array}{l}\text { Monster } \\
\text { datum }\end{array}$ & $\begin{array}{l}\text { Totaal } \\
\text { \# taxa }\end{array}$ & $\begin{array}{l}\text { KM (\# } \\
\text { taxa) }\end{array}$ & KM\% \\
\hline RMB00 & $\begin{array}{l}\text { Ramsbeek, Grens } \\
\text { Eibergen }\end{array}$ & Rijn \& IJssel & $12 / 5 / 2006$ & 73 & 4 & 5.5 \\
\hline 349999 & $\begin{array}{l}\text { Escharen, voor } \\
\text { uitmonding } \\
\text { Graafse Raam }\end{array}$ & Aa \& Maas & $17 / 5 / 2017$ & 91 & 4 & 4.4 \\
\hline DOB00 & $\begin{array}{l}\text { Dortherbeek, brug } \\
\text { Oxerweg bij } \\
\text { Oxerhoflaan } \\
\text { Deventer; } \\
\text { herinrichting met } \\
\text { meanders en } \\
\text { plasbermen 2013- } \\
2014\end{array}$ & Rijn \& IJssel & 7/10/2015 & 90 & 4 & 4.4 \\
\hline 140268 & $\begin{array}{l}\text { Goorloop t.h.v. } \\
\text { Jonker Karellaan te } \\
\text { Rixtel }\end{array}$ & de Dommel & $31 / 5 / 2017$ & 120 & 5 & 4.2 \\
\hline DOB10 & $\begin{array}{l}\text { Dortherbeek, brug } \\
\text { Oxerweg bij } \\
\text { Oxerhoflaan } \\
\text { Deventer; } \\
\text { herinrichting met } \\
\text { meanders en } \\
\text { plasbermen 2013- } \\
2014\end{array}$ & Rijn \& IJssel & $22 / 5 / 2007$ & 59 & 2 & 3.4 \\
\hline OOOST425 & $\begin{array}{l}\text { Oostrumschebeek } \\
\text { Leunse Paes } 2\end{array}$ & Limburg & $25 / 5 / 2016$ & 98 & 3 & 3.1 \\
\hline
\end{tabular}

\subsubsection{Maatlat}

De maatlat gaat uit van een gecombineerde bemonstering van de beekloop en de moeraszone waarin de diversiteit aan habitattypen is meegenomen, analoog aan de standaard KRW-bemonstering van beken. Waar beide delen gescheiden zijn gemonsterd, moeten deze voor de beoordeling worden opgeteld. Op basis van het monster worden de waarden voor drie parameters berekend met behulp van de indicatortaxalijsten in Bijlage 1 (analoog aan huidige R-maatlatten; Van der Molen et al. 2012):

- De parameter DN\%abun wordt berekend door de abundantie van de taxa die zowel in het monster als de lijsten negatief dominante indicatoren voorkomen om te zetten naar een abundantieklasse (Tabel 4) en te sommeren en vervolgens te delen door de som van alle abundantieklassen voor alle taxa.

- De parameter KM\%taxa wordt berekend door het aantal taxa dat zowel in het monster als de lijsten met kenmerkende taxa voorkomt te delen door het totaal aantal taxa in het monster.

- De parameter KM\%abun + DP\%abun wordt berekend door de abundanties van taxa die zowel in het monster als de lijsten kenmerkende taxa of positief dominante indicatoren voorkomen om te zetten naar een abundantieklasse en te sommeren en vervolgens te delen door de som van alle abundantieklassen voor alle taxa.

Voor indicatortaxa van hoger niveau worden de onderliggende taxa meegenomen in de berekening, waarbij de onderliggende taxa met hun abundanties worden opgeteld tot het niveau van het indicatortaxon. 
Als kwaliteitsijkpunt wordt de hierboven bepaalde KMmax gebruikt, het percentage kenmerkende taxa dat onder referentieomstandigheden kan worden verwacht in een monster. De term $\mathrm{KM}_{\operatorname{tax}} \% / \mathrm{KMmax}$ in de EKR-formule is gelimiteerd, als $\mathrm{KM}_{\operatorname{tax}} \% / \mathrm{KMmax}>1$ (oftewel een hoger aantal kenmerkende taxa dan onder referentieomstandigheden) dan wordt in de formule gerekend met 1.

Tabel 4: Omrekening van abundantie naar abundantieklasse voor gebruik in de EKRformule.

\begin{tabular}{|l|l|}
\hline Abundantie & Klasse \\
\hline 0 & 0 \\
\hline$>0,<1.5$ & 1 \\
\hline$\geq 1.5,<4.5$ & 2 \\
\hline$\geq 4.5,<12.5$ & 3 \\
\hline$\geq 12.5,<33.5$ & 4 \\
\hline$\geq 33.5,<90.5$ & 5 \\
\hline$\geq 90.5,<244.5$ & 6 \\
\hline$\geq 244.5,<665.5$ & 7 \\
\hline$\geq 665.5,<1808.5$ & 8 \\
\hline$\geq 1808.5$ & 9 \\
\hline
\end{tabular}

Met de scores van bovenstaande parameters wordt vervolgens in een formule de EKR uitgerekend. Deze formule is voor het doorstroommoeras en de moerasbeek gelijk aan de overige R-typen:

$E K R=\frac{200 *\left(K M \%_{\text {taxa }} / \mathrm{KMmax}\right)+2 *\left(100-\mathrm{DN} \%_{a b u n}\right)+\left(D P \%_{a b u n}+K M \%_{a b u n}\right)}{500}$

Voor doorstroommoerassen wordt KMmax $=29$ gehanteerd, voor moerasbeken KMmax $=$ 22.

\subsection{Discussie en aanbevelingen}

Omdat doorstroommoerassen en moerasbeken watertypen in ontwikkeling zijn als gevolg van recent uitgevoerde herstelmaatregelen, is het de vraag of de KMmax zoals nu gehanteerd wordt niet te laag wordt ingeschat. Er is daarom grote behoefte aan een referentieonderzoek om de waarden voor KM\%, DN\% en DP\% te vergelijken. Locaties in Oost-Duitsland of Polen zouden hier bijvoorbeeld geschikt voor zijn. 


\section{Macrofyten}

In de moerasbekenrapportage uit 2016 (Verdonschot et al. 2016) is een aanzet gedaan voor een vegetatiemaatlat voor doorstroommoerassen en moerasbeken. Deze maatlat was echter nog niet in de praktijk getest. In 2017 hebben verschillende waterschappen vegetatieopnamen gemaakt in doorstroommoerassen en moerasbeken, waarbij nadrukkelijk ook het moerasdeel betrokken is. Deze gegevens worden in dit hoofdstuk nader bekeken en gebruikt om de vegetatiemaatlat te verfijnen.

\subsection{Aanpak}

Door de waterschappen Aa en Maas, De Dommel, Rijn en IJssel en Drents Overijsselse Delta zijn opnamen aangeleverd (Tabel 5). Waterschap Aa en Maas en waterschap de Dommel hebben monsters uit 2017 aangeleverd. Beide andere waterschappen hebben oudere monsters uit de periode 2007-2016 aangeleverd. Het grootste deel van de monsters betreft moerasbeken. De vegetatiegegevens (meetpunten opgenomen volgens de moerasbekenmethodiek) zijn doorgerekend met de in de moerasbekenrapportage voorgestelde macrofyten-maatlatten (deelmaatlat soortensamenstelling en deelmaatlat abundantie). Het bleek dat alleen waterschap Rijn en IJssel totaal monsters had aangeleverd; de drie andere waterschappen hebben deelmonsters opgenomen, wat afwijkt van het voorschrift voor de moerasbekenmaatlat. Besloten is de analyse uit te voeren op totaalmonsters en eventuele deelmonsters samen te voegen.

\subsubsection{Deelmaatlat soortensamenstelling}

De deelmaatlat soortensamenstelling voor doorstroommoerassen en moerasbeken (Verdonschot et al. 2016) is toegepast op de aangeleverde dataset. Er zijn aan deze lijst enkele soorten toegevoegd en afgevoerd. De omschrijving en onderdelen van de herziene deelmaatlat worden gegeven in Bijlage 2.

\subsubsection{Deelmaatlat abundatie}

Binnen de deelmaatlat abundantie worden eisen gesteld aan de structuur van de vegetatie. Dit wordt afgeleid uit de relatieve verdeling van de aanwezige planten over groeivormen. $\mathrm{Er}$ wordt in vegetatieopnamen onderscheid gemaakt tussen ondergedoken vegetatie (S submers), vegetatie van drijfbladplanten ( $\mathrm{N}$ - nymphaeiden), emerse vegetatie beneden de laagwaterlijn ( $E$ - emers), oevervegetatie vooral tussen de laagwater- en hoogwaterlijn ( $O$ oeverplanten), drijvende kroosvegetatie (K - kroos) en draadalgen/flab (F). In een referentiesituatie bestaat het merendeel van een doorstroommoeras en een moerasbeek uit moerasvegetaties, waarvan met name bij moerasbeken een deel in het groeiseizoen droogvallend is (overstromingszone met natte ruigtekruiden, grote-zeggenvegetaties en moerasbos) en een deel permanent of zeer langdurig in ondiep dicht begroeid water staat (emerse vegetatie en bospoelen). Er is geen harde grens is tussen waterzone en oeverzone; beide zones gaan diffuus in elkaar over of kunnen door bijvoorbeeld hoogteverschillen in de overstromingszone als een mozaïek door elkaar voorkomen. Veel moerasplanten kunnen zowel voorkomen in ondiep open water (waar ze horen tot de emergente vegetatie, E) als op natte standplaatsen (waar ze deel uitmaken van de Oeverplanten, O). Er is daarom in Verdonschot et al. (2016) gekozen beide groeivormen samen te nemen tot één categorie, te weten moerasvegetaties $(E+O)$. Tot de moerasvegetaties behoren niet alleen niet alleen helofytenvegetaties en wilgenstruwelen in permanent of incidenteel droogvallend water, maar ook ruigtekruidenvegetaties, zeggenvegetaties en broekbossen op in de zomer 
droogvallende plekken. De deelmaatlat abundantie is in deze notitie aangepast ten opzichte van de eerste versie in Verdonschot et al. (2016) omdat bleek dat moerasvegetaties $(E+O)$ altijd zeer hoge abundanties haalden in de moerassystemen.Deze groeivorm is daarmee niet differentierend en is daarom niet meer meegenomen in de bepaling van de EKR. Verder is de percentuele schaal om abundanties in te schatten aangepast. Dit heeft twee redenen, ten eerste zijn in de nieuwe versie van de maatlat de bedekkingspercentages gegeven op basis van de STOWA-schaal (zie Handboek Hydrobiologie), zodat dit makkelijker te vertalen is naar de vegetatieopnamen zoals die in het veld gemaakt worden. Ten tweede zijn de ranges aangepast om een te groot effect van afwijkingen in de schattingen van bedekkingen van plantensoorten te verminderen. De nieuwe deelmaatlat is getest op de aangeleverde data. Ook is aandacht besteed aan de vraag of de aan- of afwezigheid van bomen invloed zou kunnen hebben op de bedekkingspercentages van de vegetatie.

\subsection{Resultaten}

\subsubsection{Deelmaatlat soortensamenstelling}

Voor de aangeleverde monsterpunten was het mogelijk de EKR voor de deelmaatlat soortensamenstelling te berekenen voor zowel doorstroommoerassen als moerasbeken (Tabel 5). Er bleek een aanzienlijke spreiding te zijn in de behaalde EKR scores, waarbij de locaties langs de Strijper Aa (doorstroommoeras) en de Esschestroom moeras Slingersloot. (moerasbeek) het beste beoordeeld werden. Het valt op dat meer natuurlijke of integraal herstelde beekdalen (bijv. Strijper Aa), al dan niet met broekbos, in het algemeen beter scoren dan beken met alleen natuurvriendelijke oevers, die vaak uit monotone vegetaties met bijvoorbeeld liesgras bestaan (bijv. Raam). Dit is volgens verwachting en in lijn met het referentiebeeld voor de vegetatie van moerassen. Daarnaast blijken systemen waarbij de verhouding smalle beekloop ten en opzichte van een brede moeraszone aanwezig is relatief beter te scoren. Ook dit is in lijn met de referentiesituatie.

Tabel 5. Overzicht van aangeleverde opnamen met locatiecode en -naam en datum, geordend per type. Per monster is de EKR-score gebaseerd op de deelmaatlat soortensamenstelling gegeven.

\begin{tabular}{|l|l|l|l|}
\hline Locatiecode & Locatienaam & Datum opname & $\begin{array}{l}\text { EKR } \\
\text { soortenrijkdom }\end{array}$ \\
\hline Doorstroommoeras & \multicolumn{2}{l|}{} \\
\hline 251118 & Rosep, nabij Belversven met moeraszone & $28 / 6 / 2017$ & 0.51 \\
\hline 259001 & $\begin{array}{l}\text { Rosep, nieuwe meander bovenstrooms } \\
\text { Rosepdreef }\end{array}$ & $28 / 6 / 2017$ & 0.40 \\
\hline 259844 & Strijper Aa, Doorstroommoeras Strijperheg & $3 / 7 / 2017$ & 0.59 \\
\hline 259993 & $\begin{array}{l}\text { Rielloop, in het moerasbos van Brabants } \\
\text { landschap }\end{array}$ & $24 / 7 / 2017$ & 0.45 \\
\hline Moerasbeek & \multicolumn{2}{|l|}{} \\
\hline 140268 & Goorloop t. h. v. Jonker Karellaan te Rixtel & $19 / 7 / 2017$ & 0.39 \\
\hline 251092 & $\begin{array}{l}\text { Esschestroom, Slingersloot. Haarenseweg, } \\
\text { Esch }\end{array}$ & $27 / 6 / 2017$ & 1.00 \\
\hline 251117 & $\begin{array}{l}\text { Reusel, Diessens Broek, moeras } \\
\text { bovenstrooms kanaal }\end{array}$ & $24 / 7 / 2017$ & 0.88 \\
\hline 253090 & $\begin{array}{l}\text { Essche stroom, meanders landgoed } \\
\text { Bleijendijk }\end{array}$ & $27 / 6 / 2017$ & 0.46 \\
\hline 253500 & Goorloop, zandvanger Troprijt Bladel & $3 / 7 / 2017$ & 0.55 \\
\hline 258967 & Beerze, Logstebaan, bovenstroomse deel & $21 / 6 / 2017$ & 0.49 \\
\hline
\end{tabular}




\begin{tabular}{|c|c|c|c|}
\hline Locatiecode & Locatienaam & Datum opname & $\begin{array}{l}\text { EKR } \\
\text { soortenrijkdom }\end{array}$ \\
\hline 258970 & $\begin{array}{l}\text { Beerze, Logstevelden, bovenstrooms } \\
\text { Brinksdijk }\end{array}$ & 28/6/2017 & 0.39 \\
\hline 349999 & Escharen, voor uitmonding Graafse Raam & $20 / 7 / 2017$ & 0.23 \\
\hline 900022 & Groote Wetering bij Grolderseweg & $17 / 7 / 2017$ & 0.40 \\
\hline BHBAD & Boven Slinge, Beunkdijk & $22 / 7 / 2008$ & 0.09 \\
\hline BHBAD & Boven Slinge, Beunkdijk & $21 / 7 / 2010$ & 0.06 \\
\hline BHBAD & Boven Slinge, Beunkdijk & $29 / 7 / 2013$ & 0.10 \\
\hline BHBAI & Bielheimerbeek, Bruggerweg & $21 / 7 / 2010$ & 0.11 \\
\hline BHBAI & Bielheimerbeek, Bruggerweg & $1 / 8 / 2013$ & 0.09 \\
\hline DOB00 & Dortherbeek, Oxerweg & $7 / 7 / 2011$ & 0.32 \\
\hline DOB00 & Dortherbeek, Oxerweg & $30 / 6 / 2015$ & 0.32 \\
\hline DOB01 & Dortherbeek, stadsrand Deventer & $7 / 7 / 2011$ & 0.31 \\
\hline DOB10 & Dortherbeek, Oxerweg & $22 / 5 / 2007$ & 0.14 \\
\hline DOB10 & Dortherbeek, Oxerweg & $1 / 6 / 2007$ & 0.11 \\
\hline DOB10 & Dortherbeek, Oxerweg & $4 / 6 / 2008$ & 0.01 \\
\hline DOBAU6 & Haarbeek, Jufferdijk & $1 / 6 / 2007$ & 0.11 \\
\hline DOBAU6 & Haarbeek, Jufferdijk & $7 / 7 / 2011$ & 0.31 \\
\hline DOBAU6 & Haarbeek, Jufferdijk & $30 / 6 / 2015$ & 0.40 \\
\hline DOBAV5 & Haarbeek, Bathmenseweg & $1 / 6 / 2007$ & 0.18 \\
\hline DOBAV5 & Haarbeek, Bathmenseweg & $7 / 7 / 2011$ & 0.34 \\
\hline DOBAV5 & Haarbeek, Bathmenseweg & $30 / 6 / 2015$ & 0.34 \\
\hline DOBAW4 & Dortherbeek, Hanninksdijk & $1 / 6 / 2007$ & 0.11 \\
\hline DOBAW4 & Dortherbeek, Hanninksdijk & 7/7/2011 & 0.28 \\
\hline DOBAW4 & Dortherbeek, Hanninksdijk & $30 / 6 / 2015$ & 0.29 \\
\hline DOBAX3 & Dortherbeek, Paddegatsteeg & $1 / 6 / 2007$ & 0.06 \\
\hline DOBAZ1 & Dortherbeek, Nijhofslaantje & $1 / 6 / 2007$ & 0.17 \\
\hline DOBAZ1 & Dortherbeek, Nijhofslaantje & $7 / 7 / 2011$ & 0.33 \\
\hline DOBAZ1 & Dortherbeek, Nijhofslaantje & $30 / 6 / 2015$ & 0.63 \\
\hline RMB03 & Ramsbeek, Emmausweg, Eibergen & $16 / 7 / 2011$ & 0.33 \\
\hline RMB03 & Ramsbeek, Emmausweg, Eibergen & $24 / 7 / 2014$ & 0.30 \\
\hline 8STHO8-1 & Oude Diep Stadsrand, verlanding & $22 / 6 / 2016$ & 0.30 \\
\hline 8STHO8-2 & Oude Diep Stadsrand, verlanding & $22 / 6 / 2016$ & 0.03 \\
\hline
\end{tabular}

\subsubsection{Deelmaatlat abundantie, toepassing op vegetatieopnamen}

De toepassing van de concept abundantie-deelmaatlat (Tabel 6, aangepast ten opzichte van Verdonschot et al. 2016, zie aanpak) op de aangeleverde vegetatieopnamen leverde een gedifferentieerde beoordeling op (Tabel 7). Er werd in de dataset geen verband gevonden tussen het bedekkingspercentage struik- en boomlaag en de bedekking van de watervegetatie; alle combinaties van bedekkingen bleken aanwezig. 
Tabel 6: Abundantie-deelmaatlat voor doorstroommoerassen en moerasbeken (aangepast naar Verdonschot et al. 2016). Afkortingen vegetatiegroeivormen: S: submers, N: drijfblad, K: kroos en kroosvaren, F: algen.

\begin{tabular}{|c|c|c|c|}
\hline \multirow[t]{2}{*}{ Kwaliteit (EKR) } & \multicolumn{3}{|c|}{ Groeivorm (\% bedekking proefvlak) } \\
\hline & $\begin{array}{l}\text { Watervegetatie } \\
(\mathrm{S}+\mathrm{N})^{\star}\end{array}$ & Kroos $(\mathrm{K})^{\star \star}$ & $\begin{array}{l}\text { Draadwier/flab } \\
(\mathrm{F})^{\star \star}\end{array}$ \\
\hline Slecht $(0.00)$ & $75-100$ & $75-100$ & $75-100$ \\
\hline Ontoereikend $(0.20)$ & $50-75$ & $25-75$ & $25-75$ \\
\hline Matig $(0.40)$ & $0-0.1 \& 25-50$ & $12-25$ & $12-25$ \\
\hline Goed (0.60) & $0.1-1 \& 12-25$ & $5-12$ & $5-12$ \\
\hline Zeer goed $(0.80)$ & $1-12$ & $0-5$ & $0-5$ \\
\hline Referentie (1.00) & 5 & 0 & 0 \\
\hline
\end{tabular}

Tabel 7. Percentage bedekking groeivormen en EKR scores op basis deelmaatlat abundantie Verdonschot et al. (2016). Afkortingen: $S+N$ watervegetatie submers en drijfblad, $\mathrm{E}$ : emers, O:oeverbegroeiing (boom- en struiklaag $\mathrm{O}_{1}$ of kruidlaag $\mathrm{O}_{2}$ ), $\mathrm{K}$ : kroos, $\mathrm{F}$ : draadwier/flab. De locatienamen horende bij de locatiecodes worden gegeven in tabel $5 . \mathrm{K}$ en $F$ wegen alleen mee in de eindbeoordeling vanaf categorie matig. De waarden zijn wanneer deelproefvlakken zijn gebruikt gecombineerd door het gemiddelde te nemen.

\begin{tabular}{|c|c|c|c|c|c|c|c|c|c|c|}
\hline \multirow{2}{*}{ Locatiecode } & \multicolumn{6}{|c|}{ Bedekking (\%) } & \multicolumn{3}{|c|}{$\begin{array}{l}\text { EKR } \\
\text { groeivormen }\end{array}$} & \multirow[t]{2}{*}{$\begin{array}{l}\text { EKR abundantie } \\
\text { (gemiddelde groeivormen) }\end{array}$} \\
\hline & $\mathrm{O}_{1}$ & $\mathrm{O}_{2}$ & $\mathbf{E}$ & $\mathrm{S}+\mathrm{N}$ & $\mathrm{K}$ & $\mathbf{F}$ & $\mathrm{S}+\mathrm{N}$ & $\mathrm{K}$ & $F$ & \\
\hline \multicolumn{11}{|c|}{ Doorstroommoeras } \\
\hline 251118 & 90 & 100 & 38 & 1 & 1 & 0 & 0.8 & & & 0.8 \\
\hline 259001 & 80 & 100 & 55 & 8 & 3 & 3 & 0.8 & & & 0.8 \\
\hline 259844 & 75 & 100 & 90 & 0 & 0 & 0 & 0.4 & & & 0.4 \\
\hline 259993 & 85 & 100 & 5 & 23 & 10 & 10 & 0.6 & & & 0.6 \\
\hline \multicolumn{11}{|l|}{ Moerasbeek } \\
\hline 140268 & 60 & 50 & 49 & 11 & 1 & 9 & 0.8 & & & 0.8 \\
\hline 251092 & 1 & 100 & 49 & 33 & 2 & 28 & 0.4 & & 0.2 & 0.3 \\
\hline 251117 & 5 & 10 & 85 & 6 & 0 & 1 & 0.8 & & & 0.8 \\
\hline 253090 & 0 & 100 & 49 & 7 & 4 & 3 & 0.8 & & & 0.8 \\
\hline 253500 & 30 & 100 & 41 & 16 & 0 & 15 & 0.6 & & 0.4 & 0.5 \\
\hline 258967 & 25 & 80 & 53 & 8 & 1 & 0 & 0.8 & & & 0.8 \\
\hline 258970 & 60 & 100 & 49 & 1 & 1 & 0 & 0.8 & & & 0.8 \\
\hline 349999 & 30 & 50 & 53 & 3 & 1 & 0 & 0.8 & & & 0.8 \\
\hline 900022 & 20 & 100 & 53 & 26 & 1 & 0 & 0.4 & & & 0.4 \\
\hline BHBAD & $?$ & 100 & 25 & 17 & 1 & 0 & 0.6 & & & 0.6 \\
\hline BHBAD & $?$ & 100 & 30 & 125 & 1 & 0 & 0.0 & & & 0.0 \\
\hline BHBAD & $?$ & 100 & 40 & 95 & 1 & 0 & 0.0 & & & 0.0 \\
\hline BHBAI & $?$ & 100 & 8 & 96 & 5 & 0 & 0.0 & & & 0.0 \\
\hline BHBAI & $?$ & 100 & 10 & 41 & 1 & 0 & 0.4 & & & 0.4 \\
\hline DOB00 & $?$ & 100 & 25 & 100 & 1 & 0 & 0.0 & & & 0.0 \\
\hline DOB00 & $?$ & 100 & 40 & 50 & 0 & 0 & 0.2 & & & 0.2 \\
\hline DOB01 & $?$ & 100 & 35 & 150 & 1 & 0 & 0.0 & & & 0.0 \\
\hline DOB10 & $?$ & 5 & 10 & 30 & 0 & 0 & 0.4 & & & 0.4 \\
\hline DOB10 & $?$ & 1 & 10 & 92 & 10 & 0 & 0.0 & & & 0.0 \\
\hline DOB10 & $?$ & 100 & 3 & 23 & 0 & 0 & 0.6 & & & 0.6 \\
\hline
\end{tabular}




\begin{tabular}{|l|l|l|l|l|l|l|l|l|l|l|}
\hline DOBAU6 & $?$ & 5 & 30 & 20 & 0 & 0 & 0.6 & & & 0.6 \\
\hline DOBAU6 & $?$ & 100 & 3 & 65 & 1 & 0 & 0.2 & & & 0.2 \\
\hline DOBAU6 & $?$ & 100 & 20 & 80 & 0 & 0 & 0.0 & & & 0.0 \\
\hline DOBAV5 & $?$ & 0 & 30 & 15 & 0 & 0 & 0.6 & & & 0.6 \\
\hline DOBAV5 & $?$ & 100 & 15 & 55 & 1 & 0 & 0.2 & & & 0.2 \\
\hline DOBAV5 & $?$ & 100 & 5 & 80 & 0 & 0 & 0.0 & & & 0.0 \\
\hline DOBAW4 & $?$ & 5 & 35 & 30 & 3 & 0 & 0.4 & & & 0.4 \\
\hline DOBAW4 & $?$ & 100 & 25 & 80 & 1 & 0 & 0.0 & & & 0.0 \\
\hline DOBAW4 & $?$ & 100 & 2 & 95 & 0 & 0 & 0.0 & & & 0.0 \\
\hline DOBAX3 & $?$ & 10 & 35 & 80 & 10 & 0 & 0.0 & & & 0.0 \\
\hline DOBAZ1 & $?$ & 3 & 10 & 55 & 1 & 0 & 0.2 & & & 0.2 \\
\hline DOBAZ1 & $?$ & 100 & 25 & 90 & 1 & 0 & 0.0 & & & 0.0 \\
\hline DOBAZ1 & $?$ & 100 & 50 & 85 & 0 & 0 & 0.0 & & & 0.0 \\
\hline RMB03 & 1 & 100 & 25 & 55 & 1 & 0 & 0.2 & & & 0.2 \\
\hline RMB03 & 1 & 100 & 10 & 16 & 1 & 0 & 0.6 & & & 0.6 \\
\hline 8STHO8-1 & $0-10$ & $?$ & $?$ & $?$ & $?$ & $?$ & $?$ & & & $?$ \\
\hline 8STHO8-2 & $10-40$ & $?$ & $?$ & $?$ & $?$ & $?$ & $?$ & & & $?$ \\
\hline
\end{tabular}

\subsubsection{Eindoordeel macrofyten}

De combinatie van de deelmaatlat soortensamenstelling en de deelmaatlat abundantie groeivormen geeft het eindoordeel per monster (Tabel 8). Hieruit blijkt dat het moerastraject van de Reusel in het Diessens broek de hoogste EKR heeft. Voor de doorstroommoerassen liggen de waarden relatief dicht bij elkaar en komt de moeraszone in de Rosep er als beste locatie uit. Wat opvalt is het grote contrast in scores tussen de deelmaatlatten. Vaak is er geen duidelijk verband tussen beide scores. Het is dan ook de vraag wat de toegevoegde waarde is van de abundantiemaatlat/groeivormen ten opzichte van de soortenmaatlat, gezien deze verschillen. Daarnaast is het inschatten van bedekkingen in het veld lastig, waardoor er een mogelijk een bron van fouten in de beoordeling wordt geïntroduceerd. Om in de huidige opzet alleen te toetsen op de soortensamenstelling levert mogelijk een betrouwbaarder oordeel op.

Tabel 8. Eindoordeel macrofyten, bestaande uit het gemiddelde van de EKR scores deelmaatlatten soortenrijkdom en abundantie groeivormen voor doorstroommoeras- en moerasbeeklocaties.

\begin{tabular}{|c|c|c|c|c|c|}
\hline \multirow[b]{2}{*}{ Locatiecode } & \multirow[b]{2}{*}{ Locatienaam } & \multirow{2}{*}{$\begin{array}{l}\text { Datum } \\
\text { opname }\end{array}$} & \multicolumn{2}{|l|}{ Deelmaatlat } & \multirow{2}{*}{$\begin{array}{l}\text { Eindoordeel } \\
\text { deelmaatlat } \\
\text { (gemiddelde) }\end{array}$} \\
\hline & & & Soortenrijkdom & $\begin{array}{l}\text { Abundantie } \\
\text { groeivormen }\end{array}$ & \\
\hline \multicolumn{6}{|c|}{ Doorstroommoeras } \\
\hline 251118 & $\begin{array}{l}\text { Rosep, nabij } \\
\text { Belversven met } \\
\text { moeraszone }\end{array}$ & $28 / 6 / 2017$ & 0.51 & 0.8 & 0.66 \\
\hline 259001 & $\begin{array}{l}\text { Rosep, nieuwe } \\
\text { meander } \\
\text { bovenstrooms } \\
\text { Rosepdreef }\end{array}$ & $28 / 6 / 2017$ & 0.40 & 0.8 & 0.60 \\
\hline 259844 & $\begin{array}{l}\text { Strijper } \mathrm{Aa}, \\
\text { Doorstroommoeras } \\
\text { Strijperheg }\end{array}$ & $3 / 7 / 2017$ & 0.59 & 0.4 & 0.50 \\
\hline
\end{tabular}




\begin{tabular}{|c|c|c|c|c|c|}
\hline 259993 & $\begin{array}{l}\text { Rielloop, in het } \\
\text { moerasbos van } \\
\text { Brabants } \\
\text { landschap }\end{array}$ & 24/7/2017 & 0.45 & 0.6 & 0.53 \\
\hline \multicolumn{6}{|c|}{ Moerasbeek } \\
\hline 140268 & $\begin{array}{l}\text { Goorloop t. h. v. } \\
\text { Jonker Karellaan } \\
\text { te Rixtel }\end{array}$ & $19 / 7 / 2017$ & 0.39 & 0.8 & 0.595 \\
\hline 251092 & $\begin{array}{l}\text { Esschestroom, } \\
\text { Slingersloot. } \\
\text { Haarenseweg, } \\
\text { Esch }\end{array}$ & 27/6/2017 & 1.00 & 0.3 & 0.65 \\
\hline 251117 & $\begin{array}{l}\text { Reusel, Diessens } \\
\text { Broek, moeras } \\
\text { bovenstrooms } \\
\text { kanaal }\end{array}$ & 24/7/2017 & 0.88 & 0.8 & 0.84 \\
\hline 253090 & $\begin{array}{l}\text { Essche stroom, } \\
\text { meanders } \\
\text { landgoed } \\
\text { Bleijendijk }\end{array}$ & 27/6/2017 & 0.46 & 0.8 & 0.63 \\
\hline 253500 & $\begin{array}{l}\text { Goorloop, } \\
\text { zandvanger } \\
\text { Troprijt Bladel }\end{array}$ & $3 / 7 / 2017$ & 0.55 & 0.5 & 0.53 \\
\hline 258967 & $\begin{array}{l}\text { Beerze, } \\
\text { Logstebaan, } \\
\text { bovenstroomse } \\
\text { deel }\end{array}$ & 21/6/2017 & 0.49 & 0.8 & 0.65 \\
\hline 258970 & $\begin{array}{l}\text { Beerze, } \\
\text { Logstevelden, } \\
\text { bovenstrooms } \\
\text { Brinksdijk }\end{array}$ & 28/6/2017 & 0.39 & 0.8 & 0.60 \\
\hline 349999 & $\begin{array}{l}\text { Escharen, voor } \\
\text { uitmonding } \\
\text { Graafse Raam }\end{array}$ & 20/7/2017 & 0.23 & 0.8 & 0.52 \\
\hline 900022 & $\begin{array}{l}\text { Groote Wetering } \\
\text { bij Grolderseweg }\end{array}$ & $17 / 7 / 2017$ & 0.40 & 0.4 & 0.40 \\
\hline BHBAD & $\begin{array}{l}\text { Boven Slinge, } \\
\text { Beunkdijk }\end{array}$ & 22/7/2008 & 0.09 & 0.6 & 0.35 \\
\hline BHBAD & $\begin{array}{l}\text { Boven Slinge, } \\
\text { Beunkdijk }\end{array}$ & $21 / 7 / 2010$ & 0.06 & 0.0 & 0.03 \\
\hline BHBAD & $\begin{array}{l}\text { Boven Slinge, } \\
\text { Beunkdijk }\end{array}$ & 29/7/2013 & 0.10 & 0.0 & 0.05 \\
\hline BHBAI & $\begin{array}{l}\text { Bielheimerbeek, } \\
\text { Bruggerweg }\end{array}$ & 21/7/2010 & 0.11 & 0.0 & 0.06 \\
\hline BHBAI & $\begin{array}{l}\text { Bielheimerbeek, } \\
\text { Bruggerweg }\end{array}$ & $1 / 8 / 2013$ & 0.09 & 0.4 & 0.25 \\
\hline DOB00 & $\begin{array}{l}\text { Dortherbeek, } \\
\text { Oxerweg }\end{array}$ & $7 / 7 / 2011$ & 0.32 & 0.0 & 0.16 \\
\hline DOB00 & $\begin{array}{l}\text { Dortherbeek, } \\
\text { Oxerweg }\end{array}$ & $30 / 6 / 2015$ & 0.32 & 0.2 & 0.26 \\
\hline DOB01 & $\begin{array}{l}\text { Dortherbeek, } \\
\text { stadsrand } \\
\text { Deventer }\end{array}$ & $7 / 7 / 2011$ & 0.31 & 0.0 & 0.16 \\
\hline DOB10 & $\begin{array}{l}\text { Dortherbeek, } \\
\text { Oxerweg }\end{array}$ & $22 / 5 / 2007$ & 0.14 & 0.4 & 0.27 \\
\hline DOB10 & $\begin{array}{l}\text { Dortherbeek, } \\
\text { Oxerweg }\end{array}$ & $1 / 6 / 2007$ & 0.11 & 0.0 & 0.06 \\
\hline DOB10 & $\begin{array}{l}\text { Dortherbeek, } \\
\text { Oxerweg }\end{array}$ & $4 / 6 / 2008$ & 0.01 & 0.6 & 0.31 \\
\hline
\end{tabular}




\begin{tabular}{|c|c|c|c|c|c|}
\hline DOBAU6 & $\begin{array}{l}\text { Haarbeek, } \\
\text { Jufferdijk }\end{array}$ & $1 / 6 / 2007$ & 0.11 & 0.6 & 0.36 \\
\hline DOBAU6 & $\begin{array}{l}\text { Haarbeek, } \\
\text { Jufferdijk }\end{array}$ & $7 / 7 / 2011$ & 0.31 & 0.2 & 0.26 \\
\hline DOBAU6 & $\begin{array}{l}\text { Haarbeek, } \\
\text { Jufferdijk }\end{array}$ & $30 / 6 / 2015$ & 0.40 & 0.0 & 0.20 \\
\hline DOBAV5 & $\begin{array}{l}\text { Haarbeek, } \\
\text { Bathmenseweg }\end{array}$ & $1 / 6 / 2007$ & 0.18 & 0.6 & 0.39 \\
\hline DOBAV5 & $\begin{array}{l}\text { Haarbeek, } \\
\text { Bathmenseweg }\end{array}$ & 7/7/2011 & 0.34 & 0.2 & 0.27 \\
\hline DOBAV5 & $\begin{array}{l}\text { Haarbeek, } \\
\text { Bathmenseweg }\end{array}$ & $30 / 6 / 2015$ & 0.34 & 0.0 & 0.17 \\
\hline DOBAW4 & $\begin{array}{l}\text { Dortherbeek, } \\
\text { Hanninksdijk }\end{array}$ & $1 / 6 / 2007$ & 0.11 & 0.4 & 0.26 \\
\hline DOBAW4 & $\begin{array}{l}\text { Dortherbeek, } \\
\text { Hanninksdijk }\end{array}$ & $7 / 7 / 2011$ & 0.28 & 0.0 & 0.14 \\
\hline DOBAW4 & $\begin{array}{l}\text { Dortherbeek, } \\
\text { Hanninksdijk }\end{array}$ & $30 / 6 / 2015$ & 0.29 & 0.0 & 0.15 \\
\hline DOBAX3 & $\begin{array}{l}\text { Dortherbeek, } \\
\text { Paddegatsteeg }\end{array}$ & $1 / 6 / 2007$ & 0.06 & 0.0 & 0.03 \\
\hline DOBAZ1 & $\begin{array}{l}\text { Dortherbeek, } \\
\text { Nijhofslaantje }\end{array}$ & $1 / 6 / 2007$ & 0.17 & 0.2 & 0.19 \\
\hline DOBAZ1 & $\begin{array}{l}\text { Dortherbeek, } \\
\text { Nijhofslaantje }\end{array}$ & $7 / 7 / 2011$ & 0.33 & 0.0 & 0.17 \\
\hline DOBAZ1 & $\begin{array}{l}\text { Dortherbeek, } \\
\text { Nijhofslaantje }\end{array}$ & $30 / 6 / 2015$ & 0.63 & 0.0 & 0.32 \\
\hline RMB03 & $\begin{array}{l}\text { Ramsbeek, } \\
\text { Emmausweg, } \\
\text { Eibergen }\end{array}$ & $16 / 7 / 2011$ & 0.33 & 0.2 & 0.27 \\
\hline RMB03 & $\begin{array}{l}\text { Ramsbeek, } \\
\text { Emmausweg, } \\
\text { Eibergen }\end{array}$ & $24 / 7 / 2014$ & 0.30 & 0.6 & 0.45 \\
\hline 8STHO8-1 & $\begin{array}{l}\text { Oude Diep } \\
\text { Stadsrand, } \\
\text { verlanding }\end{array}$ & 22/6/2016 & 0.30 & $?$ & $?$ \\
\hline 8STHO8-2 & $\begin{array}{l}\text { Oude Diep } \\
\text { Stadsrand, } \\
\text { verlanding }\end{array}$ & 22/6/2016 & 0.03 & $?$ & $?$ \\
\hline
\end{tabular}

\subsection{Discussie en aanbevelingen}

Omdat doorstroommoerassen en moerasbeken watertypen in ontwikkeling zijn als gevolg van recent uitgevoerde herstelmaatregelen, is het de vraag hoe dit zich verhoudt tot de bedekkingspercentages en voor referentiewaarde die gebruikt wordt voor het toekennen van het kwaliteitsoordeel aan de soortensamenstelling (nu 132 op basis van de locatie Holmers). Er is dan ook grote behoefte aan een referentieonderzoek om de Nederlandse situatie in perspectief te plaatsen. Locaties in het oosten van Duitsland of in Polen zouden hier geschikt voor zijn.

Op dit moment wordt er geen onderscheid gemaakt voor beschaduwde en onbeschaduwde moerassen. Beschaduwing is echter wel een belangrijk element. In de referentiesituatie komen in moerassen bomen voor, al kan (afhankelijk van de natheid van het gebied gedurende het jaar) de mate van beschaduwing wisselen. Van nature kunnen situaties van weinig tot volledig beschaduwd voorkomen met alle gradaties die hiertussen liggen. Bomen of beschaduwing zijn niet expliciet in de deelmaatlat abundantie opgenomen. De gedachte hierachter is dat wat betreft abundanties het weglaten van moerasvegetatie als scorend 
onderdeel en het wel opnemen van de watervegetatie in de deelmaatlat een groot deel van een beschaduwingseffect ondervangt. In een beschaduwde situatie is de bedekking watervegetatie relatief laag door gebrek aan licht (scoort hiermee goed), terwijl in een onbeschaduwde situatie bij goede kwaliteit het voedselarme water ervoor zorgt dat watervegetatie niet massaal optreedt en ook de hoeveelheid open water beperkt is (bijvoorbeeld kleine zeggenmoerassen). Een optie zou nog kunnen zijn de afwezigheid van bomen $(<5 \%$ of $10 \%)$ negatief te beoordelen. Echter in de deelmaatlat soortenrijkdom wordt de aanwezigheid van bepaalde moerasgebonden boomsoorten al positief beoordeeld, waardoor de noodzaak van zo'n toevoeging twijfelachtig is.

Helaas is er niets bekend over de breedte van de watergang en de breedte van de oever of het moerasgedeelte. Deze verhouding heeft invloed op de verhouding tussen de bedekkingspercentages van de water- en moerasvegetatie binnen de opname. Het is daarom belangrijk de afmetingen van de opnamevlakken en de verhouding water-oeverzone in de toekomst te vermelden bij de data. Omdat de beoordeling gaat over het begroeibare areaal (totale moeras: water tot gemiddelde hoogwaterlijn) is de consequentie immers dat een brede watergang met een smalle moeraszone slechter scoort dan een smalle watergang met een brede moeraszone

De deelmaatlat soortensamenstelling zou in theorie ook door beschaduwing beïnvloed kunnen worden, immers bij lagere vegetatiebedekkingen is de kans op het aantreffen van bepaalde scorende soorten ook lager. Echter in de geanalyseerde data scoorde ook de beschaduwde plekken relatief goed. Dit is verklaarbaar door de relatief open structuur van het bladerdak in moerassen, waardoor nog voldoende licht op de bosbodem kan doordringen waardoor veel plantensoorten zich kunnen handhaven, terwijl juist negetatief dominante soorten zich vaak massaal ontwikkelen wanneer er weinig beschaduwing aanwezig is. Daarnaast scoren boomsoorten in deze deelmaatlat wel, waardoor de aanwezigheid van bomen tot een hogere beoordeling leidt. Vaak is het aantal boomsoorten in een moeras echter beperkt (bijv. dominatie Els); misschien dat hoge bedekkingen van bomen via een hoger gewicht beter gewaardeerd kunnen worden ter compensatie. Er kan bijvoorbeeld een gedifferentieerde schaal gemaakt worden op basis van de abundantie. Dus als er veel bedekking is van karakteristieke bomen, telt dit zwaarder mee, dan als er slechts enkele kleine boompjes in het moeras staan. Bijvoorbeeld Salix cinerea: weinig aanwezig weegwaarde 1 , veel aanwezig weegwaarde 5.

In het algemeen wat betreft de macrofyten-deelmaatlatten voor de R-typen zouden deze niet gemiddeld moeten worden met het fytobenthos-oordeel, maar als twee aparte kwaliteitselementen gerapporteerd moeten worden. Het fytobenthos-oordeel is gebaseerd op andersoortige stressfactoren en heeft weinig samenhang met het voorkomen van macrofyten, zoals beschreven in Verdonschot et al. (2016).

\section{Vissen}

Er zijn de afgelopen jaren geen visbemonsteringen uitgevoerd in moerasbeken zoals dit voor macrofauna en vegetatie heeft plaatsgevonden. Van Herpen \& Jaarsma (2018) beschrijven de conceptmaatlat voor vissen in moerasbeken. Ze stellen de volgende aanpak voor:

Er worden in totaal 5 indicatoren gebruikt, 3 indicatoren gebaseerd op soortensamenstelling en 2 indicatoren op abundatie. Hierbij wordt er van uitgegaan dat voor deze systemen soortenrijkdom het beste kan worden uitgedrukt als het absolute aantal soorten. Verder wordt aangenomen dat het gilde reofiel en plantminnend gezamenlijk aanwezig zijn in moerasbeken en doorstroommoerassen in een ecologisch optimale situatie. De 
aanwezigheid volgt een optimumcurve, wat wil zeggen dat zowel hele hoge als hele lage abundanties van beide gilden een verstoring indiceren. Binnen de referentiesituatie is er ruimte voor $10-20 \%$ abundantie aan eurytope soorten. Tenslotte wordt de aanwezigheid van migrerende, reofiele en plantminnende soorten als positief beoordeeld.

Per indicator wordt de EKR score bepaald (Tabel 9), waarbij binnen een klasse lineair wordt geïnterpoleerd.

Soortensamenstelling

Voor de deelmaatlat soortensamenstelling worden bij het doorstroommoeras en de moerasbeek de volgende indicatoren gebruikt, op basis van de indeling in gilden of groepen die ook voor de andere KRW-typen wordt gehanteerd:

- Aantal reofiele soorten;

- Aantal plantminnende soorten;

- Aantal migrerende soorten;

Voor elk watertype is een beoordelingstabel opgesteld waaruit de score volgt uit het gevonden aandeel van deze soorten op basis van een ondergrens $(E K R=0)$ en een bovengrens $(E K R=1,0)$. Bij een aandeel dat tussen grenzen ligt wordt lineair geïnterpoleerd. Een waarde hoger dan de bovengrens leidt automatisch tot een EKR van 1,0 en een waarde beneden de ondergrens tot een EKR van 0.

Abundantie

Dit kenmerk wordt ingevuld door indicatoren die elk een deel van de visgemeenschap weerspiegelen.

Bij de moerasbeek en het doorstroommoeras worden de volgende indicatoren gebruikt:

- Relatieve abundantie reofiele soorten (\%) (aantalsaandeel);

- Relatieve abundantie plantminnende soorten (\%) (aantalsaandeel).

Hierbij wordt het aandeel van de individuen van de soorten die tot de groep reofielen en plantminnenden horen vergeleken met het totaal aantal gevangen vissen van alle soorten. Voor elk watertype is een tabel met klassengrenzen opgesteld (zie tekstvoorstellen in hoofdstuk 6), waaruit een score volgt die hoort bij het gevonden aandeel van deze soorten. Bij de moerasbeek en het doorstroommoeras betreft het voor de abundantie van de plantminnende en reofiele vissen een optimumcurve. Abundanties gelegen in dit optimum krijgen allemaal een waarde van EKR 1.0.

Tabel 9: Klassengrenzen vissenmaatlat moerasbeken en doorstroommoerassen (van Herpen \& Jaarsma, 2018).

\begin{tabular}{|l|l|l|l|l|l|}
\hline $\begin{array}{l}\text { Klasse } \\
\text { (EKR) }\end{array}$ & $\begin{array}{l}\text { aantal } \\
\text { reofiele } \\
\text { soorten } \\
\left(\mathbf{S}_{\text {reo }}\right)\end{array}$ & $\begin{array}{l}\text { aantal } \\
\text { plantminnende } \\
\left.\text { soorten } \mathbf{( S}_{\text {plant }}\right)\end{array}$ & $\begin{array}{l}\text { aantal } \\
\text { migrerende } \\
\text { soorten } \\
\left(\mathbf{S}_{\text {migr }}\right)\end{array}$ & $\begin{array}{l}\text { Relatieve } \\
\text { abundantie } \\
\text { reofiele } \\
\text { soorten } \\
\left(\mathbf{A}_{\text {reo }}\right)\end{array}$ & $\begin{array}{l}\text { Relatieve } \\
\text { abundantie } \\
\text { plantminnende } \\
\text { soorten }\left(\mathbf{A}_{\text {plant }}\right)\end{array}$ \\
\hline Slecht $(0.00)$ & 0 & 0 & 0 & $0 \%$ & $0 \%$ \\
\hline $\begin{array}{l}\text { Ontoereikend } \\
(0.20)\end{array}$ & 2 & 3 & 1 & $5 \%$ & $5 \%$ \\
\hline Matig $(0.40)$ & 3 & 4 & 2 & $10 \%$ & $10 \%$ \\
\hline
\end{tabular}




\begin{tabular}{|l|l|l|l|l|l|}
\hline Goed $(0.60)$ & 4 & 5 & 3 & $20 \%$ & $20 \%$ \\
\hline $\begin{array}{l}\text { Zeer goed } \\
(0.80)\end{array}$ & 5 & 6 & $40 \%$ & $30 \%$ \\
\hline $\begin{array}{l}\text { Referentie } \\
(1.00)\end{array}$ & 6 & 7 & 4 & $40-60 \%$ & $40-60 \%$ \\
\hline $\begin{array}{l}\text { Zeer goed } \\
(0.80)\end{array}$ & & & & $70 \%$ & $70 \%$ \\
\hline Goed (0.60) & & & & $80 \%$ & $80 \%$ \\
\hline Matig (0.40) & & & $90 \%$ & $90 \%$ \\
\hline $\begin{array}{l}\text { Ontoereikend } \\
-(0.20)\end{array}$ & & & $95 \%$ & $95 \%$ \\
\hline Slecht $(0.00)$ & & & $100 \%$ & $100 \%$ \\
\hline
\end{tabular}

\section{Eindoordeel}

Voor de toetsing met de vismaatlat in de doorstroommoeras en moerasbeek moet eerst de EKR per traject worden berekend. Als er sprake is van meerdere trajecten in één waterlichaam worden de EKR's (eventueel gewogen) gemiddeld tot een eind-EKR voor het totale waterlichaam.

Voor het bepalen van het eindoordeel wordt de EKR berekend door de scores van de vijf indicatoren te middelen:

$E K R=\frac{\text { Sreo }+ \text { Splant }+ \text { Smigr }+ \text { Areo }+ \text { Aplant }}{5}$

Bij het toepassen van de maatlat wordt een ondergrens geadviseerd van minimaal 30 gevangen vissen voor het toepassen van de maatlat. Het is ook mogelijk om bij minder dan 30 gevangen vissen een oordeel te bepalen, maar bij een gering aantal gevangen vissen is het risico groot dat de score geen representatief beeld geeft van de aanwezige visstand. 
6. Tekstherzieningen maatlatdocument 


\section{Doorstroommoeras (R19)}

\subsection{Globale referentiebeschrijving}

\section{Typologie}

De abiotische karakteristieken van het type R19 zijn weergegeven in tabel 1 . Het doorstroommoeras is niet opgenomen als natuurdoeltype (NDT); het is een mengvorm van de langzaam stromende bovenloop (3.6) met verschillende in beekdalen voorkomende NDT van moerassen, natte graslanden, struwelen en bossen (zie Bal et al., 2001).

Tabel 1: Karakterisering van het type gebaseerd op Elbersen et al. (2003) maar aangepast voor doorstroommoerassen.

\begin{tabular}{|c|c|c|}
\hline Parameter & Eenheid & Range \\
\hline Verhang & $\mathrm{m} / \mathrm{km}$ & $<0,5$ \\
\hline Stroomsnelheid* $^{\star}$ & $\mathrm{cm} / \mathrm{s}$ & $<20$ \\
\hline Geologie $>50 \%$ & & Kiezel \\
\hline Breedte loop & $\mathrm{m}$ & $\begin{array}{l}0-3 \text { (loop kan afwezig zijn } \\
\text { wanneer het water zich diffuus } \\
\text { over en door de ondergrond } \\
\text { verplaatst) }\end{array}$ \\
\hline $\begin{array}{l}\text { Oppervlak } \\
\text { stroomgebied** }^{*}\end{array}$ & $\mathrm{~km}^{2}$ & $<10$ \\
\hline Permanentie & - & $\begin{array}{l}\text { Permanent watervoerende } \\
\text { beekloop en/of beekmoeras (loop } \\
\text { vaak niet overal zichtbaar) } \\
\text { Geen of slechts een zeer smalle } \\
\text { overstromingszone door stabiele } \\
\text { afvoer }\end{array}$ \\
\hline Getijden & & n.v.t. \\
\hline
\end{tabular}

*Maximumwaarde gebaseerd op waarde waarbij start afname biomassa boven- en ondergronds bij water- en moerasplanten optreedt (Verdonschot et al., 2017).

**Waarschijnlijk te klein ingeschat voor natuurlijke beken, hier is meer onderzoek voor nodig (Elbersen et al., 2003).

\section{Geografie}

Het doorstroommoeras komt voor op plaatsen met een gering verhang op de hogere zandgronden: in uitgestoven laagten, glaciale erosiedalen en ingesneden beekdalen. Het betreft meestal halfopen tot beboste landschappen.

\section{Hydrologie}

Het doorstroommoeras is permanent watervoerend. De afvoer is laag en gelijkmatig; er is weinig dynamiek. De voeding is afkomstig van grond- en regenwater. Doorstroommoerassen komen optimaal ontwikkeld voor in natte, grondwater-gevoede laagtes in het oorspronggebied van beken, maar kunnen op kleinere schaal ook verder benedenstrooms in het stroomgebied voorkomen in de flanken van beekdalen op plekken waar een sterke aanvoer van grondwater vanuit de hoger gelegen delen optreedt.

\section{Structuren}

In een doorstroommoeras is de afvoer te laag om een duidelijk herkenbare en continue loop te vormen. Kleinschalige reliëf zorgt er echter voor dat er naar benedenstrooms telkens graduele overgangen zijn tussen relatief vlakke en steilere delen, waardoor er verschillen in stroomsnelheid optreden (Figuur 1). De sneller stromende delen zijn herkenbaar als een bovenloop (breedte tot $3 \mathrm{~m}$, analoog aan R4) in een relatief smal dal, terwijl de langzamer 
stromende delen een doorstroommoeras vormen: het beekdal is hier breder en het water stroomt over en door de bodem, vaak in slenken. De vegetatie heeft een belangrijke sturende rol voor het pad dat het water volgt in het doorstroommoeras. Het substraat bestaat uit een mozaïek van kale plekken met organisch materiaal en begroeide plekken met veel mossen en moerasplanten. Alleen in de loopjes is ook minerale bodem te vinden, naast organische substraten, zoals blad en takken. Boomgroei is verspreid in het moeras, waarbij wilg, els en berk als dominante boomsoorten kunnen optreden. Ook kan wilde gagel voorkomen. Wilgen komen vaak als struwelen in het doorstroommoeras voor. Zwaardere beschaduwing vanaf drogere delen aan de rand van het beekdal is mogelijk. De bodem bestaat uit zand en veen. Onder ongestoorde omstandigheden kunnen zich dikke pakketten zeggenveen vormen.
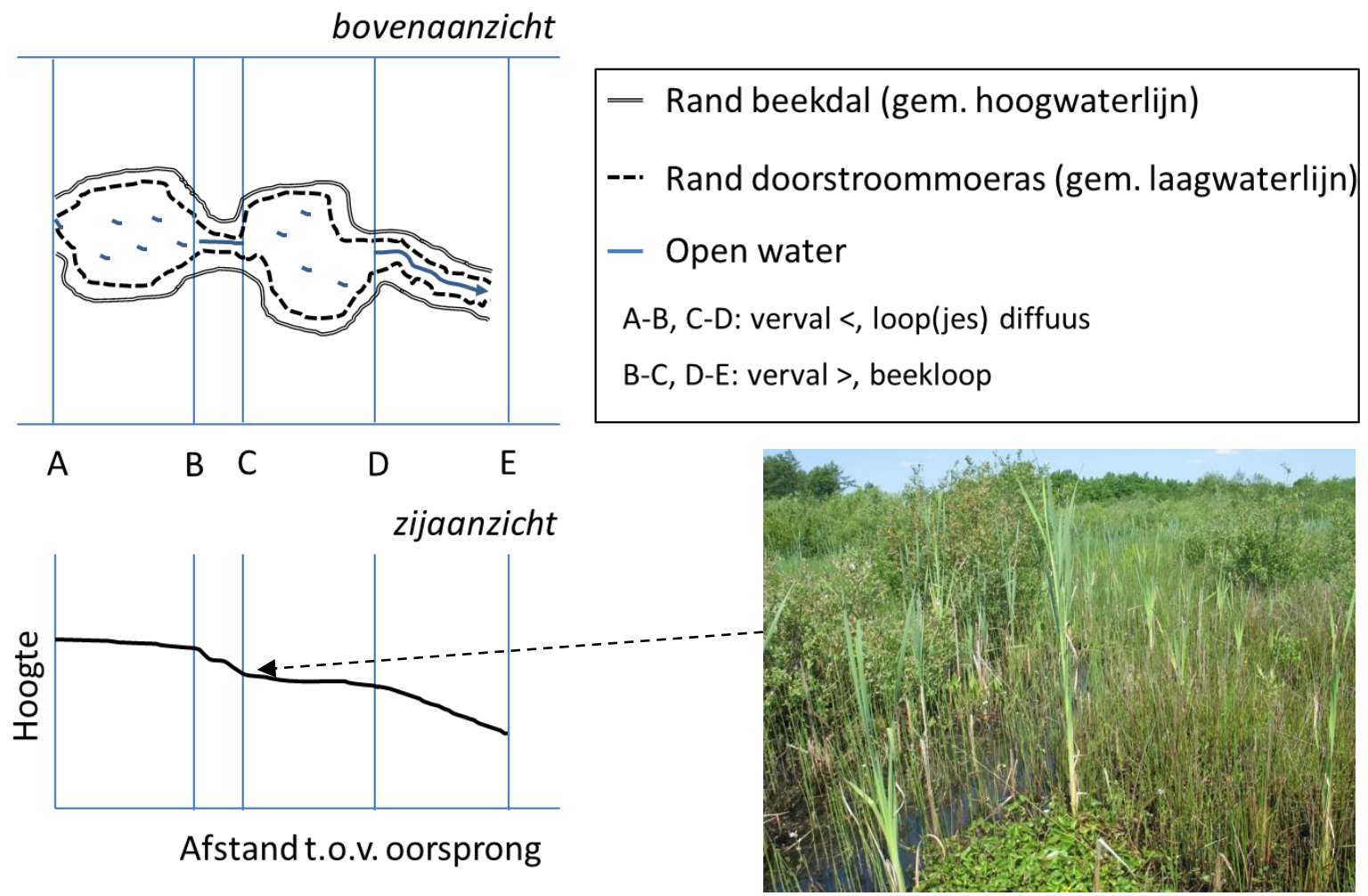

Figuur 1: Doorstroommoerassen ontstaan doordat er delen in het beekdal weinig verhang hebben, waardoor de beek als het ware uitwaaiert over het bredere dal (boven). Soms komen in het doorstroommoeras één of meer geultjes of geulen voor met duidelijke afvoer. Dit kan het gevolg zijn van steilere delen in de vervallijn (onder), of door de aanwezigheid van onregelmatigheden in de ondergrond, zoals ondoorlatende lagen.

\section{Chemie}

Het water is matig zuur tot neutraal en oligo- tot mesotroof. De ouderdom en de herkomst van het grondwater dat het doorstroommoeras voedt bepaalt de mineralenrijkdom van het water. Het water is oligo- tot $\beta$-mesosaproob en helder. In tabel 2 wordt op basis van de koppeling met de natuurdoeltypen een karakterisering van het type gegeven.

Tabel 2: Abiotische karakterisering van het doorstroommoeras gebaseerd op de indeling voor natuurdoeltypen, gebaseerd op Bal et al. (2001).

\begin{tabular}{|l|l|l|l|l|l|l|l|l|}
\hline Waterregime & open water & droogvallend & zeer nat & nat & matig nat & vochtig & matig droog & droog \\
\hline Zuurgraad & zuur & matig zuur & zwak zuur & neutraal & basisch \\
\hline Voedselrijkdom & oligotroof & mesotroof & zwak eutroof & matig eutroof & eutroof \\
\hline
\end{tabular}

\section{Biologie}


De kenmerkende macrofaunalevensgemeenschap bestaat uit enerzijds zuurstof- en/of stromingsminnende beeksoorten, die zich ophouden in de loopjes en leven op het minerale substraat, op hout of patches met organisch materiaal en anderzijds de moerassoorten, die zich ophouden tussen de mossen en de planten en tussen het opgehoopte organische materiaal op plekken waar het water diffuus afgevoerd wordt. Het betreft vertegenwoordigers van alle trofische niveau's. Onder mesotrofe mineralenrijke omstandigheden is de moerasvegetatie zeer soortenrijk, de watervegetatie in de loopjes is echter beperkt tot een klein aantal soorten. Vis komt zeer weinig voor als gevolg van isolatie (onderbroken loop) en een klein oppervlak aan open water.

\section{Fytobenthos}

Zowel in de loopjes als in het moerasdeel is fytobenthos op de meeste beschikbare substraten aanwezig. De hydrologische gradiënten in het doorstroommoeras kunnen bijzondere habitats voor met name diatomeeën en groenalgen bieden. Op plaatsen met weinig of geen stroming, waar slib accumuleert, zullen op de bodem de epipelische taxa domineren (diatomeeën die leven op slib). Waar meer stroming voorkomt, groeien epipsammische soorten (diatomeeën die leven op zandkorrels). Op dit substraat en op de in het water groeiende vegetatie kunnen soorten uit de geslachten Achnanthes s.I., Cymbella s.l., Diatoma, Eunotia, Fragilaria en Gomphonema worden gevonden.

\section{Macrofyten}

Vegetaties van doorstroommoerassen kunnen zeer soortenrijk zijn, maar door het verdwijnen van goed ontwikkelde doorstroommoerassen zijn veel soorten in Nederland zeer zeldzaam geworden of al langere tijd uitgestorven. De vegetatie bestaat overwegend uit zeggenvegetaties met daarin veel mossen, zoals het Rood schorpioenmos (Scorpidium scorpioides). Het gaat om plantengemeenschappen van oligo- tot mesotrofe, stikstof- en fosfaatarme, matige zure tot neutrale al dan niet kalkhoudende bodem. De vegetaties zijn laag productief en hebben dan ook een lage biomassa. Kenmerkend zijn het verbond van Zwarte zegge (9Aa) en het Draadzegge-verbond (10Ab). De vegetaties in beekdalen vertonen verwantschappen met trilvenen in het laagveengebied. In de slenken en loopjes wordt onder andere vlottende bies (Eleogiton fluitans), duizendknoopfonteinkruid (Potamogeton polygonifolius), kleinste egelskop (Sparganium natans) en plat blaasjeskruid (Utricularia intermedia) aangetroffen. Naast een groot aantal zeggensoorten bestaat de moerasvegetatie uit soorten zoals veenpluis (Eriophorum angustifolium), stijve moerasweegbree (Baldellia ranunculoides), moerasbastaardwederik (Epilobium palustre) slangewortel (Calla palustris), wateraardbei (Potentilla palustris) en waterdrieblad (Menyanthes trifoliata). Struwelen van wilgen kunnen voor beschaduwing zorgen (Salix aurita en Salix cinerea).

\section{Macrofauna}

De moerassoorten vertonen een duidelijke binding met organisch materiaal. De levensgemeenschap wordt gedomineerd door detritivoren (knippers van afgestorven plantenresten en blad, vergaarders van kleine organische deeltjes, bacteriën en schimmels). Belangrijke soorten of soortgroepen zijn de borstelwormen (diverse Tubificidae en Lumbriculidae), steenvliegen (Nemouriidae), haften (Leptophlebiidae), kokerjuffers (o.a. veel soorten van het genus Limnephilus), detritivore waterkevers (o.a. Hydrophilidae, Hydraenidae, Scirtidae). Daarnaast zijn vliegen en muggen (Diptera) zeer talrijk wat betreft aantallen en soortenrijkdom; er komen honderden soorten voor, variërend van moerassteekmuggen (Culicidae, o.a. de genera Aedes en Ochlerotatus), meniscusmuggen, (genus Dixella), knutten (Ceratopogonidae), motmugjes (Psychodidae), langpootmuggen (Tipulidae en Limoniidae) en vedermuggen (Chironomidae). Het relatief voedselarme en zure karakter zorgt ervoor dat slakken (Gastropoda), vlokreeften (Amphipoda) en bloedzuigers (Hirudinea) relatief schaars zijn. Tweekleppigen zijn beperkt tot vertegenwoordigers van de erwtenmosselen (Sphaeriidae). Naast detritivoren komen er ook veel predatoren voor, 
gedomineerd door een groot aantal soorten waterroofkevers (Dytiscidae, o.a. Hydroporus, Agabus, llybius), maar ook Diptera, o.a. dazen (Tabanidae) en water- en oppervlaktewantsen (Corixiidae, Gerris sp.). Tenslotte worden er veel watermijten (Hydracarina) aangetroffen, waaronder veel soorten die leven in de moslaag of grof organisch materiaal (zeggenstrooisel) en een aantal libellen (genera Sympecma en Leuccorhinia, karakteristiek is Nehalennia speciosa).

\section{Vissen}

De visfauna omvat slechts enkele soorten als gevolg van isolatie (onderbroken loop) en een klein oppervlak aan open water. Het meest aangetroffen wordt Tiendoornige stekelbaars (Pungitius pungitius) en waar een duidelijke loop aanwezig kan ook het bermpje (Barbatula barbatulus) gevonden worden. Tussen de moerasplanten kan de grote modderkruiper worden gevonden (Misgurnus fossilis).

\subsection{Waterflora}

\section{Abundantie}

Submerse vegetatie \& drijfbladplanten. In doorstroommoerassen speelt watervegetatie een ondergeschikte rol en bestaat een groot deel van de vegetatie uit emerse planten en oevervegetatie. De bedekking van submerse vegetatie \& drijfbladplanten is afhankelijk van de mate waarin stromende loopjes, slenken en andere plekken met open water aanwezig zijn. Samen zouden deze groeivormen 1-12\% van het begroeibare areaal moeten bedekken.

Emerse \& oevervegetatie. In doorstroommoerassen wordt géén onderscheid gemaakt tussen een waterzone en oeverzone, en het gehele gebied dat wordt begroeid door water- en moerasplanten (aan natte standplaatsen aangepaste soorten) wordt als één moeraszone beschouwd. Emerse vegetatie en oevervegetatie kunnen namelijk in een doorstroommoeras niet goed van elkaar gescheiden worden, omdat beide zones diffuus in elkaar overgaan of als een mozaïek door elkaar voor kunnen komen als gevolg van microreliëf. Omdat deze groeivormen in doorstroommoerassen altijd dominant zijn, worden ze niet beoordeeld omdat er te weinig differentiatie in voorkomt. Ook het bedekkingspercentage bos wordt niet apart beoordeeld, omdat dit zeer variabel kan zijn in doorstroommoerassen.

Kroos. Soms kan op plekken waar water stagneert kroos voorkomen, maar altijd in een zeer lage bedekking. Bedekking met kroos van het open water mag onder optimale omstandigheden slechts minimaal optreden $(<5 \%)$.

Draadwier/flab. Draadwier of flab kan onder optimale omstandigheden met een zeer lage bedekking $(<5 \%)$ voorkomen in het open water in het doorstroommoeras. Een hogere bedekking van het open water wijst op eutrofiëring.

De deelmaatlatscore voor abundantie wordt volgens tabel 3 afgeleid van de zeer goede toestand. Het bedekkingspercentage watervegetatie is uitgedrukt als het percentage van het totale proefvlak. Dit proefvlak omvat de zone tussen de gemiddelde hoogwaterlijnen. Voor kroos en draadwier/flab wordt alleen de bedekking van het open water gebruikt. 
Tabel 3: Deelmaatlat abundantie van groeivormen (bedekkingspercentage van het begroeibaar areaal) voor het doorstroommoeras.

\begin{tabular}{|c|c|c|c|c|c|c|}
\hline \multirow[b]{2}{*}{ Groeivorm } & \multirow[b]{2}{*}{ Referentie } & \multicolumn{5}{|c|}{ Bedekking proefvlak bij kwaliteitsklasse (\%) } \\
\hline & & $\begin{array}{l}\text { Zeer } \\
\text { goed }\end{array}$ & Goed & Matig & Ontoereikend & Slecht \\
\hline $\begin{array}{l}\text { Watervegetatie } \\
(\mathrm{S}+\mathrm{N})^{*}\end{array}$ & 5 & $1-12$ & $\begin{array}{l}0,1-1 \\
12-25\end{array}$ & $\begin{array}{l}0-0,1 \\
25-50\end{array}$ & $50-75$ & $\begin{array}{l}75- \\
100\end{array}$ \\
\hline $\operatorname{Kroos}(\mathrm{K})^{\star *}$ & 0 & $0-5$ & $5-12$ & $12-25$ & $25-75$ & $\begin{array}{l}75- \\
100\end{array}$ \\
\hline Draadwier/Flab $(F)^{\star *}$ & 0 & $0-5$ & $5-12$ & $12-25$ & $25-75$ & $\begin{array}{l}75- \\
100\end{array}$ \\
\hline
\end{tabular}

** Als percentage van permanent natte gedeelte.

\title{
Soortensamenstelling waterplanten
}

De scores voor de deelmaatlat soortensamenstelling worden gegenereerd op basis van de weegwaarden van de afzonderlijke soorten in appendix [ref. naar lijst]. De maatlatscore wordt aangegeven als percentage van de maximale score (referentie $=132$ ).

Overschrijdingen van de maximale score krijgen EKR $=1$.

\section{Eindoordeel macrofyten}

Om het eindoordeel te berekenen, wordt het gemiddelde genomen van de deelmaatlatscore soortenrijkdom en de deelmaatlatscore abudantie groeivormen.

\section{Fytobenthos}

Alleen de loop(jes) worden beoordeeld, niet het moerasdeel. De deelmaatlat voor fytobenthos bestaat uit een lijst met taxa, waarin aan elke soort twee getallen zijn toegekend: een gevoeligheidsgetal (s) en een indicatiewaarde (v). Deze lijst is gelijk aan type R4. De score wordt berekend met de IPS-methode.

\subsection{Macrofauna}

\begin{abstract}
Abundantie en soortensamenstelling
Voor de beschrijving van de ecologische toestand van het doorstroommoeras wordt gebruik gemaakt van kenmerkende (KM), positief dominante (DP) en negatief dominante (DN) indicatoren. Zowel de habitats in de aanwezige loop(jes) en het moeras worden gemonsterd volgens de multihabitatmethode volgens de voorschriften van het Handboek Hydrobiologie. Met de scores voor het relatief aandeel negatief dominante indicatoren (DN\%) en de kenmerkende en positief dominante indicatoren (KM\% + DP\%) en het percentage kenmerkende taxa (KM\%) wordt aan de hand van een formule de EKR uitgerekend zoals beschreven in hoofdstuk 2. De lijst met indicatoren voor het doorstroommoeras is opgenomen in de bijlage. Voor het doorstroommoeras geldt een KMmax van 29.
\end{abstract}

\subsection{Vis (overgenomen uit van Herpen \& Jaarsma, 2018)}

Doorstroommoerassen bevatten weinig open water en deze wateren zijn ook nog eens sterk geïsoleerd. Het doorstroommoeras is daarom voor de meeste, vooral de wat grotere vissoorten, geen geschikt habitat. Voor het bepalen van de kwaliteit voor de vissen kan de voorlopige maatlat voor vissen uit de moerasbeek worden gebruikt.

Indien het niet mogelijk is om het doorstroommoeras conform de voorschriften te bemonsteren (met electrovisserij in de open stroomgeulen), wat vaak onder natuurlijke 
omstandigheden het geval zal zijn, dan kan de beoordeling van vis in het doorstroommoeras beter achterwege blijven.

\section{Abundantie en soortensamenstelling}

De ecologische toestand van het doorstroommoeras op basis van de visstand wordt beoordeeld aan de hand van een combinatie van de soortensamenstelling en de abundantie van reofiele, migrerende en plantminnnende soorten in de beekloop (Tabel 4). De toewijzing van de soorten tot beide groepen wordt gegeven in bijlage [X]. Voor de soortensamenstelling wordt het aantal reofiele, het aantal migrerende en het aantal plantminnende soorten in de levensgemeenschap bepaald. Tenslotte wordt de relatieve aantalsabundantie reofiele soorten, om het stromende karakter expliciet te beoordelen, bepaald, net zoals de relatieve abundantie plantminnende soorten, om de moeraszone te beoordelen. De EKR vis voor de moerasbeek kan worden berekend met de formule gegeven in hoofdstuk 2 .

Tabel 4: Voorlopige maatlat soortensamenstelling en abundantie vis voor de moerasbeek, welke in sommige gevallen ook bruikbaar is voor het doorstroommoeras.

\begin{tabular}{|l|l|l|l|l|l|}
\hline $\begin{array}{l}\text { Klasse } \\
(\text { EKR) }\end{array}$ & $\begin{array}{l}\text { aantal } \\
\text { reofiele } \\
\text { soorten } \\
\left(\mathbf{S}_{\text {reo }}\right)\end{array}$ & $\begin{array}{l}\text { aantal } \\
\text { plantminnende } \\
\text { soorten }\left(\mathbf{S}_{\text {plant }}\right)\end{array}$ & $\begin{array}{l}\text { aantal } \\
\text { migrerende } \\
\text { soorten } \\
\left(\mathbf{S}_{\text {migr }}\right)\end{array}$ & $\begin{array}{l}\text { Relatieve } \\
\text { abundantie } \\
\text { reofiele } \\
\text { soorten } \\
\left(\mathbf{A}_{\text {reo }}\right.\end{array}$ & $\begin{array}{l}\text { Relatieve } \\
\text { abundantie } \\
\text { plantminnende } \\
\text { soorten }\left(\mathbf{A}_{\text {plant }}\right)\end{array}$ \\
\hline Slecht $(0.00)$ & 0 & 0 & 0 & $0 \%$ & $0 \%$ \\
\hline $\begin{array}{l}\text { Ontoereikend } \\
(0.20)\end{array}$ & 2 & 3 & 1 & $5 \%$ & $5 \%$ \\
\hline Matig (0.40) & 3 & 4 & 2 & $10 \%$ & $10 \%$ \\
\hline Goed (0.60) & 4 & 5 & 3 & $20 \%$ & $20 \%$ \\
\hline $\begin{array}{l}\text { Zeer goed } \\
(0.80)\end{array}$ & 5 & 6 & & $30 \%$ & $30 \%$ \\
\hline $\begin{array}{l}\text { Referentie } \\
(1.00)\end{array}$ & 6 & 7 & 4 & $40-60 \%$ & $40-60 \%$ \\
\hline $\begin{array}{l}\text { Zeer goed } \\
(0.80)\end{array}$ & & & & $70 \%$ & $70 \%$ \\
\hline Goed (0.60) & & & & $80 \%$ & $80 \%$ \\
\hline Matig (0.40) & & & & $90 \%$ & $90 \%$ \\
\hline $\begin{array}{l}\text { Ontoereikend } \\
-(0.20)\end{array}$ & & & & $100 \%$ & $100 \%$ \\
\hline Slecht (0.00) & & & & & \\
\hline
\end{tabular}

\subsection{Algemene fysisch-chemische kwaliteitselementen}

De maatlat voor de algemene fysisch-chemische kwaliteitselementen is weergegeven in tabel 5 en is overgenomen van R4 met enkele kleine aanpassingen in verband met overlappende waarden tussen klassen. Deze waarden moeten nog worden gevalideerd aan de hand van nader onderzoek in onder andere referentiegebieden. Een belangrijk verschil met R4 is bijvoorbeeld dat heterogeniteit in omstandigheden kenmerkend is voor een moeras, bijvoorbeeld door de aanwezigheid van regenwaterlenzen, poeltjes met veel organisch materiaal etc. Fysisch-chemische bemonsteringen moeten daarom worden uitgevoerd in de aanwezige loopjes om een zo veel mogelijk gestandaardiseerd beeld te krijgen van de fysisch-chemische toestand.

Tabel 5: Maatlat voor de algemene fysisch-chemische kwaliteitselementen voor het doorstroommoeras. 


\begin{tabular}{|l|l|l|l|l|l|l|l|}
\hline Kwaliteitselement & $\begin{array}{l}\text { Indicato } \\
\mathbf{r}\end{array}$ & $\begin{array}{l}\text { Eenhei } \\
\mathbf{d}\end{array}$ & $\begin{array}{l}\text { Zeer } \\
\text { goed }\end{array}$ & Goed & Matig & $\begin{array}{l}\text { Ontoereike } \\
\text { nd }\end{array}$ & Slecht \\
\hline $\begin{array}{l}\text { Thermische } \\
\text { omstandigheden }\end{array}$ & $\begin{array}{l}\text { Dagwaar } \\
\text { de }\end{array}$ & ${ }^{\circ} \mathrm{C}$ & $<14$ & $14-18$ & $18-20$ & $20-22,5$ & $>22,5$ \\
\hline Zuurstofhuishouding & $\begin{array}{l}\text { Verzadig } \\
\text { ing }\end{array}$ & $\%$ & $60-90$ & $\begin{array}{l}50-60 \\
90-100\end{array}$ & $\begin{array}{l}40-50 \\
100-110\end{array}$ & $\begin{array}{l}30-40 \\
110-120\end{array}$ & $\begin{array}{l}<30 \\
>120\end{array}$ \\
\hline Zoutgehalte & $\mathrm{chloride}$ & $\mathrm{mg} \mathrm{Cl} / \mathrm{L}$ & $\leq 20$ & $\leq 40$ & $40-75$ & $75-100$ & $>100$ \\
\hline Zuurgraad & $\mathrm{pH}$ & - & $5,5-7,0$ & $\begin{array}{l}4,5-5,5 \\
7,0-8,0\end{array}$ & $\begin{array}{l}8,0-8,5 \\
<4,5\end{array}$ & $8,5-9,0$ & $>9,0$ \\
\hline Nutriënten & Totaal-P & $\mathrm{mg} \mathrm{P/L}$ & $\leq 0,05$ & $\leq 0,11$ & $\begin{array}{l}0,11- \\
0,22\end{array}$ & $0,22-0,33$ & $>0,33$ \\
\hline Nutriënten & Totaal-N & $\mathrm{mg} \mathrm{N} / \mathrm{L}$ & $\leq 2,0$ & $\leq 2,3$ & $2,3-4,6$ & $4,6-6,9$ & $>6,9$ \\
\hline
\end{tabular}

\subsection{Hydromorfologie}

De ranges van de parameters behorend bij de zeer goede toestand van het kwaliteitselement hydrologisch regime zijn weergegeven in tabel 6 . De waarden van de overige hydromorfologische parameters zijn beschreven in de tabel met algemene $R$ parameters.

Tabel 6: Waarden doorstroommoeras in zeer goede toestand voor de hydromorfologische kwaliteitselementen.

\begin{tabular}{|l|l|l|l|l|l|}
\hline Parameter & Code & Eenheid & Minimum & Maximum & Verantwoording \\
\hline Stroomsnelheid & $\mathrm{V}$ & $\mathrm{m} \mathrm{s}^{-1}$ & $>0$ & 20 & 1 \\
\hline Afvoer & $\mathrm{Q}$ & $\mathrm{m}^{3} \mathrm{~s}^{-1}$ & $>0$ & $<1,125$ & 2 \\
\hline
\end{tabular}
1. Maximumwaarde gebaseerd op waarde waarbij start afname biomassa boven en ondergronds bij water-en moerasplanten optreedt
(Verdonschot et al., 2017)
2. Relatie doorstroommoeras afvoer niet bekend. Omdat de afvoerdynamiek sterk bepalend is of zich een doorstroommoeras of een beekloop
ontwikkelt, zal deze dus lager zijn dan de hier van R4 overgenomen berekende waarde.




\section{Maatlat Moerasbeek (R20)}

\subsection{Globale referentiebeschrijving}

\section{Typologie}

De abiotische karakteristieken van het type R20 zijn weergegeven in tabel 1. De moerasbeek is niet opgenomen als NDT; het is een mengvorm van de langzaam stromende midden- en benedenloop (3.7) met verschillende in beekdalen voorkomende NDT van moerassen, natte graslanden, struwelen en bossen (zie Bal et al., 2001).

Tabel 12.1a: Karakterisering van het type gebaseerd op Elbersen et al. (2003) maar aangepast voor moerasbeken.

\begin{tabular}{|l|l|l|}
\hline Parameter & Eenheid & Range \\
\hline Verhang & $\mathrm{m} / \mathrm{km}$ & $<0,5$ \\
\hline Stroomsnelheid & $\mathrm{cm} / \mathrm{s}$ & $>0-20$ \\
\hline Geologie $>50 \%$ & $\mathrm{~m}$ & Kiezel \\
\hline Breedte loop & $\mathrm{km}^{2}$ & $3-8$ \\
\hline $\begin{array}{l}\text { Oppervlak } \\
\text { stroomgebied }\end{array}$ & - & $10-100$ \\
\hline Permanentie & - & $\begin{array}{l}\text { Permanent watervoerende beekloop } \\
\text { en beekmoeras. Droogval in } \\
\text { overstromingszone bij lage afvoer }\end{array}$ \\
\hline Getijden & - & n.v.t. \\
\hline
\end{tabular}

*Maximumwaarde gebaseerd op waarde waarbij start afname biomassa boven en ondergronds bij water-en moerasplanten optreedt (Verdonschot et al., 2017).

${ }^{* *}$ Waarschijnlijk te klein ingeschat voor natuurlijke beken, hier is meer onderzoek voor nodig (Elbersen et al., 2003).

\section{Geografie}

De moerasbeek komt voor op plaatsen met een gering verhang op de hogere zandgronden: in uitgestoven laagten, glaciale erosiedalen en ingesneden beekdalen. Het betreft meestal halfopen tot beboste landschappen, waarbij wilg en els meestal als dominante boomsoorten optreden. Wilgen komen vaak als struwelen in het moeras voor.

\section{Hydrologie}

De moerasbeek wordt gevoed door een doorstroommoeras of een bovenloop. In vergelijking met het doorstroommoeras is er ter hoogte van de midden- of benedenloop een dusdanige afvoer - ondanks het geringe verval en de daardoor lage stroomsnelheid - dat het water voldoende erosieve kracht heeft om een duidelijke loop te vormen in de moerassige laagte in het beekdal. De herkomst van het water bestaat uit zowel regen-, grond- als oppervlaktewater. Ten opzichte van het doorstroommoeras is er een veel grotere dynamiek, met name in het winterhalfjaar komen inundaties van het beekdal voor. In tegenstelling tot het doorstroommoeras bestaat het water in het moerasdeel van de moerasbeek meestal uit eutroof oppervlaktewater en is de invloed van grondwater geringer. Naast waterbeweging in benedenstroomse richting treedt er uitwisseling van oppervlaktewater op tussen de beekloop, het beekmoeras en bij hoog water de overstromingszone (Figuur 1). Deze laterale uitwisseling van water is onderscheidend ten opzichte van het doorstroommoeras, waarbij de waterbeweging overwegend in stroomafwaarste richting plaatsvindt. 

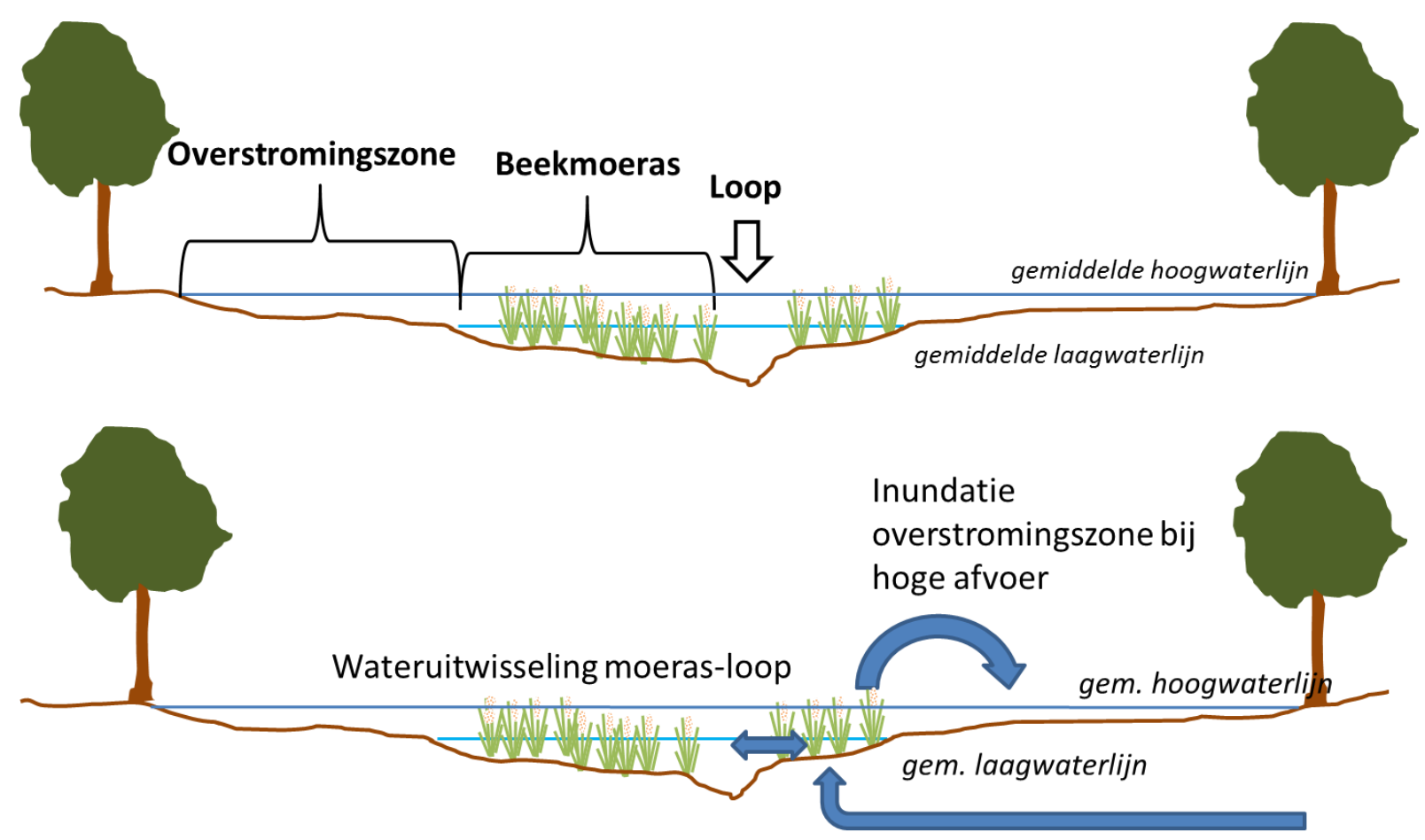

Grondwatervoeding moeras en loop

Figuur 1: Dwarsdoorsnede van een moerasbeek (boven) en schematische weergave van de hydrologie (onder). Naast een naar benedenstrooms gerichte stroming is ook wateruitwisseling in de dwarsrichting tussen de beekloop, het beekmoeras en bij hoge waterstanden de overstromingszone kenmerkend voor de moerasbeek.

\section{Structuren}

Het dwarsprofiel van een moerasbeek bevat de loop, de moerasbeek, geflankeerd door een beekmoeras, wat weer overgaat in een overstromingszone (Figuur 1). De overgang tussen de loop en het beekmoeras is door de aanwezige moerasvegetatie diffuus. De overstromingszone valt in de zomer droog; hiermee onderscheidt deze zone (waar ook moerasplanten staan) zich van het beekmoeras, dat permanent nat is. De maximale waterdiepte van de met moerasplanten begroeide zones bedraagt enkele decimeters. In de lengterichting is de loop van een moerasbeek vrijwel altijd continu. Echter, na een periode van hoge afvoer kunnen stukken moerasvegetatie (drijftillen) losraken en een obstructie in de loop vormen. Deze onderbrekingen in de loop zijn altijd tijdelijk, dit in tegenstelling tot een doorstroommoeras waarin zones voorkomen waar het water zich diffuus door de bodem verplaatst en geen loop zichtbaar is, omdat het water ofwel een weg om de obstructie heen vindt of de obstructie na verloop van tijd erodeert. In de beekloop is een mozaïek van kaal zand en dood organisch materiaal (blad, hout, fijn organisch materiaal) aanwezig, gestuurd door de verschillen in stroomsnelheid in de loop. Het systeem is half beschaduwd, waarbij stukken met bomen afgewisseld worden door onbeschaduwde moerasvegetatie. De aanwezigheid van bomen wordt met name gestuurd door de waterstand. Zwaardere beschaduwing door elzenbroek- of alluviaal bos vanaf drogere delen (overstromingszone of droger) is mogelijk. In het beekmoeras is, naast moerasplanten, vooral organisch materiaal te vinden. Het organisch materiaal mineraliseert snel, waardoor veenvorming weinig optreedt.

\section{Chemie}

Het water is zwak zuur tot neutraal en meso- tot eutroof. De hoeveelheid, ouderdom en de herkomst van het grondwater dat de moerasbeek voedt bepaalt de mineralenrijkdom van het water. Het water in de loop is meestal $\beta$-mesosaproob tot $\alpha$-mesosaproob en het is helder. In 
tabel 2 wordt op basis van de koppeling met de natuurdoeltypen een karakterisering van het type gegeven.

Tabel 2: Abiotische karakterisering van de moerasbeek, gebaseerd op de indeling voor natuurdoeltypen, gebaseerd op Bal et al. (2001).

\begin{tabular}{|l|l|l|l|l|l|l|l|l|}
\hline Waterregime & open water & droogvallend & zeer nat & nat & matig nat & vochtig & matig droog & droog \\
\hline Zuurgraad & zuur & matig zuur & zwak zuur & neutraal & basisch & \\
\hline Voedselrijkdom & oligotroof & mesotroof & zwak eutroof & matig eutroof & eutroof \\
\hline
\end{tabular}

\section{Biologie}

De soortensamenstelling van zowel de flora als de fauna is zeer divers, een zogenoemde 'biodiversiteits-hotspot', door de nat-droog gradiënt in het beekdal en het daarbij horende mozaïek van habitats. Het onderscheid tussen de flora en fauna van het doorstroommoeras en de moerasbeek is vaag en vooral gestuurd door de voedselrijkdom (herkomst water) van het systeem, zeker wanneer in een moerasbeek langs de flanken van het beekdal kleine doorstroommoeras-situaties voorkomen. Er zijn migratiemogelijkheden door verbinding met grotere wateren benedenstrooms, waarvan bijvoorbeeld vis kan profiteren. De visstand zal daardoor diverser zijn en in die zin wel duidelijk afwijken van het doorstroommoeras.

\section{Fytobenthos}

Zowel in de loop als in het beekmoeras is fytobenthos op de meeste beschikbare substraten aanwezig. De hydrologische gradiënt in het beekdal kan bijzondere habitats voor met name diatomeeën en groenalgen bieden. Op plaatsen met weinig of geen stroming, waar slib accumuleert, zullen op de bodem de epipelische taxa domineren (diatomeeën die leven op slib). Waar meer stroming voorkomt, groeien epipsammische soorten (diatomeeën die leven op zandkorrels). Op dit substraat en op de in het water groeiende vegetatie kunnen soorten uit de geslachten Achnanthes s.I., Cymbella s.I., Diatoma, Eunotia, Fragilaria en Gomphonema worden gevonden.

\section{Macrofyten}

Kenmerkend voor de beekmoerassen zijn hoog productieve opgaande moerasvegetaties, bestaande uit emerse waterplanten (riet, lisdodde, liesgras, egelskop, gele lis e.d.) van relatief voedselrijke omstandigheden, grote-zeggenvegetaties en elzen- en wilgenbroekbos. Typische plantengemeenschappen van het moeras omvatten het Bultkroos-verbond (Lemnion minoris), Waterlelie-verbond (Nymphaeion), Kikkerbeet-verbond (Hydrocharition morsus-ranae), Vlotgras-verbond (Sparganio-Glycerion), Waterscheerling-verbond (Cicution virosae), Riet-verbond (Phragmition australis), verbond van Scherpe zegge (Caricion gracilis) en het verbond van Stijve zegge (Caricion elatae). In de beekloop zijn waterplantenvegetaties aan te treffen, zoals van de orde van Haaksterrekroos en Grote waterranonkel (Callitricho-Potametalia). Beekbegeleidend bos en struweel op de natte plekken bestaat uit vegetaties van het verbond der wilgenbroekstruwelen (Salicion cinereae) en het verbond der elzenbroekbossen (Alnion glutinosae). In de overstromingszone komt alluviaal bos voor.

\section{Macrofauna}

Vertegenwoordigers van alle macrofauna-hoofdgroepen zijn in moerasbeken aan te treffen en er is veel overlap met het doorstroommoeras. Hier wordt vooral ingegaan op de voedselrijkere situaties. Er is een duidelijke tweedeling tussen zuurstof- en/of stromingsminnende beeksoorten, die zich ophouden in de beekloop en leven op het minerale substraat, op hout of plekken met organisch materiaal en de moerassoorten, die zich ophouden op de planten en tussen het opgehoopte organische materiaal in de stromingsluwe delen. De moerassoorten vertonen een duidelijke binding met organisch materiaal en veel soorten hebben aanpassingen aan het voorkomen op plekken met een lage zuurstofbeschikbaarheid, zoals de mogelijkheid tot luchtademhaling (adembuis, opslaan 
van lucht in een luchtbel). Detritivoren domineren de moerassystemen: knippers van afgestorven plantenresten en blad, vergaarders van kleine organische deeltjes, bacterieën en schimmels. Belangrijke soorten of soortgroepen zijn de borstelwormen (diverse Tubificidae, Lumbriculus variegatus), waterpissebedden (Asellus aquaticus, Proasellus), steenvliegen (Nemoura cinerea en N. dubitans), haften (naast Baetidae een aantal vertegenwoordigers van de Leptophlebiidae), kokerjuffers (o.a. veel soorten van het genus Limnephilus, Glypothaelius pellicidulus, Trichostegia minor), detritivore waterkevers (zoals familie Hydrophilidae, o.a. Anacaena; Scirtidae, Hydraenidae). Daarnaast zijn vliegen en muggen (Diptera) zeer talrijk wat betreft aantallen en soortenrijkdom; er komen honderden soorten voor, variërend van moerassteekmuggen (Culicidae, o.a. de genera Aedes en Ochlerotatus), meniscusmuggen, (genus Dixella), knutten (Ceratopogonidae), motmugjes (Psychodidae), langpootmuggen (Tipulidae en Limoniidae), en vedermuggen (Chironomidae; o.a. Chironomus, Polypedilum, Telmatopelopia nemorum, Paralimnophyes longiseta, Xenopelopia, Limnophyes). Tweekleppigen zijn relatief schaars en beperkt tot vertegenwoordigers van de erwtenmosselen (Pisidium, Sphaerium). Grazers komen voor in de vorm van diverse slakkensoorten; de poelslakken Lymnaeidae en schijfhoornslakken Planorbidae. Met name onder voedselrijke omstandigheden komen deze talrijk voor. Binnen het voedselweb wordt het segment van de predatoren gedomineerd door een groot aantal soorten waterroofkevers (Dytiscidae, o.a. Hydroporus, Agabus, llybius), maar ook Diptera, o.a. dazen Tabanidae, bloedzuigers (in het beekmoeras, o.a. Helobdella stagnalis, Erpobdella, Glossiphonia) en water- en oppervlaktewantsen (Nepa cinerea, Corixiidae, Gerris sp.). Relatief weinig voorkomend in het voedselrijke beekmoeras zijn libellen (vooral Pyrrhosoma nymphula en Aeshna cyanea) en vlokreeften. Deze laatste komen wel weer veel voor in de beekloop. Tenslotte worden er in het moerasdeel veel watermijten (Hydracarina) aangetroffen, waaronder veel soorten die leven onder plas-dras omstandigheden.

\begin{abstract}
Vissen
Voor stromingsminnende en algemene vissen is de moerasbeek een belangrijker habitat dan een doorstroommoeras, omdat er sprake is van een continue loop en meer open water. De visstand van een moerasbeek wordt gevormd door een beperkt aantal reofiele soorten, zoals bermpje, riviergrondel en winde. In de moeraszone worden juist plantenminnende en zuurstoftolerante soorten aangetroffen, zoals kleine modderkruiper, ruisvoorn, snoek, tiendoornige stekelbaars, vetje en zeelt. Twee uitgesproken soorten van moeraszones, de kroeskarper en grote modderkruiper zijn zeer karakteristiek voor deze systemen. De overstromingszone kan dienst doen als opgroeihabitat, bijvoorbeeld voor de kwabaal.
\end{abstract}

\title{
1.2 Waterflora
}

\begin{abstract}
Abundantie
Submerse vegetatie \& drijfbladplanten. In moerasbeken speelt watervegetatie een ondergeschikte rol en bestaat een groot deel van de vegetatie uit emerse planten en oevervegetatie. De bedekking van submerse vegetatie \& drijfbladplanten is afhankelijk van de breedte van de beekloop ten opzichte van het beekmoeras en de overstromingszone, waarbij een brede moeraszone tot een hogere waardering van het systeem leidt. Samen zouden deze groeivormen 1-12\% van het begroeibare areaal moeten bedekken.
\end{abstract}

Emerse \& oevervegetatie. In moerasbeken wordt géén onderscheid gemaakt tussen een waterzone en oeverzone, en het gehele gebied dat wordt begroeid door water- en moerasplanten (aan natte standplaatsen aangepaste soorten) wordt als één moeraszone beschouwd. Emerse vegetatie en oevervegetatie kunnen namelijk in een moerasbeek niet goed van elkaar gescheiden worden, omdat beide zones diffuus in elkaar overgaan of als een mozaïek door elkaar voor kunnen komen als gevolg van laagtes in bijvoorbeeld de overstromingszone. Omdat deze groeivormen in moerassen altijd dominant zijn, worden ze 
niet beoordeeld omdat er te weinig differentiatie in voorkomt. Ook het bedekkingspercentage bos wordt niet apart beoordeeld, omdat dit zeer variabel kan zijn langs moerasbeken.

Kroos. Op plekken waar water stagneert kan wat kroos aangetroffen worden. Echter bedekking met kroos van het open water mag slechts minimaal optreden $(<5 \%$ onder optimale omstandigheden).

Draadwier/flab. Draadwier of flab komt onder optimale omstandigheden met een zeer lage bedekking $(<5 \%)$ voor in het open water in de moerasbeek. Een hogere bedekking van het open water wijst op eutrofiëring.

De deelmaatlatscore voor abundantie wordt volgens tabel 3 afgeleid van de zeer goede toestand. Het bedekkingspercentage watervegetatie is uitgedrukt als het percentage van het totale proefvlak. Dit proefvlak omvat de zone tussen de gemiddelde hoogwaterlijnen. Voor kroos en draadwier/flab wordt alleen de bedekking van het open water gebruikt.

Tabel 3: Deelmaatlat abundantie van groeivormen (bedekkingspercentage van het begroeibaar areaal) voor het doorstroommoeras.

\begin{tabular}{|c|c|c|c|c|c|c|}
\hline \multirow[b]{2}{*}{ Groeivorm } & \multirow[b]{2}{*}{ Referentie } & \multicolumn{5}{|c|}{ Bedekking proefvlak bij kwaliteitsklasse (\%) } \\
\hline & & $\begin{array}{l}\text { Zeer } \\
\text { goed }\end{array}$ & Goed & Matig & Ontoereikend & Slecht \\
\hline \multirow{2}{*}{$\begin{array}{l}\text { Watervegetatie } \\
(\mathrm{S}+\mathrm{N})^{*}\end{array}$} & \multirow[b]{2}{*}{5} & \multirow{2}{*}{$1-12$} & $0,1-1$ & $0-0,1$ & \multirow{2}{*}{$50-75$} & \multirow{2}{*}{$\begin{array}{l}75- \\
100\end{array}$} \\
\hline & & & $12-25$ & $25-50$ & & \\
\hline Kroos $(\mathrm{K})^{\star *}$ & 0 & $0-5$ & $5-12$ & $12-25$ & $25-75$ & $\begin{array}{l}75- \\
100\end{array}$ \\
\hline Draadwier/Flab $(F)^{\star *}$ & 0 & $0-5$ & $5-12$ & $12-25$ & $25-75$ & $\begin{array}{l}75- \\
100\end{array}$ \\
\hline
\end{tabular}

** Als percentage van permanent natte gedeelte.

\section{Soortensamenstelling waterplanten}

De scores voor de deelmaatlat soortensamenstelling worden gegenereerd op basis van de weegwaarden van de afzonderlijke soorten in appendix [ref. naar lijst]. De maatlatscore wordt aangegeven als percentage van de maximale score (referentie $=132$ ).

Overschrijdingen van de maximale score krijgen EKR $=1$.

\section{Eindoordeel macrofyten}

Om het eindoordeel te berekenen, wordt het gemiddelde genomen van de deelmaatlatscore soortenrijkdom en de deelmaatlatscore abudantie groeivormen.

\section{Fytobenthos}

Alleen de beekloop worden beoordeeld, niet het moerasdeel. De deelmaatlat voor fytobenthos bestaat uit een lijst met taxa, waarin aan elke soort twee getallen zijn toegekend: een gevoeligheidsgetal (s) en een indicatiewaarde (v). Deze lijst is gelijk aan type R5. De score wordt berekend met de IPS-methode.

\subsection{Macrofauna}

\section{Abundantie en soortensamenstelling}

Voor de beschrijving van de ecologische toestand van de moerasbeek wordt gebruik gemaakt van kenmerkende (KM), positief dominante (DP) en negatief dominante (DN) 
indicatoren. Zowel de habitats in de beekloop, het beekmoeras en eventueel de overstromingsvlakte (wanneer geïnundeerd) worden gemonsterd volgens de multihabitatmethode. Met de scores voor het relatief aandeel negatief dominante indicatoren (DN\%) en de kenmerkende en positief dominante indicatoren (KM\% + DP\%) en het percentage kenmerkende taxa (KM\%) wordt aan de hand van een formule de EKR uitgerekend zoals beschreven in hoofdstuk 2. De lijst met indicatoren voor de moerasbeek is opgenomen in de bijlage. Voor de moerasbeek geldt een KMmax van 22. Deze KMmax is relatief laag om recht te doen aan het grote aantal soorten dat in deze systemen kan worden aangetroffen; het gevolg is dat er ook veel soorten gevonden worden die niet per se kenmerkend zijn voor het systeem waardoor $\mathrm{KM} \%$ vaak relatief laag is.

\subsection{Vis (overgenomen uit van Herpen \& Jaarsma 2018)}

\section{Abundantie en soortensamenstelling}

De ecologische toestand van de moerasbeek op basis van de visstand wordt beoordeeld aan de hand van een combinatie van de soortensamenstelling en de abundantie van reofiele, migrerende en plantminnnende soorten in de beekloop (Tabel 4). De toewijzing van de soorten tot beide groepen wordt gegeven in bijlage [X]. Voor de soortensamenstelling wordt het aantal reofiele, het aantal migrerende en het aantal plantminnende soorten in de levensgemeenschap bepaald. Tenslotte wordt de relatieve aantalsabundantie reofiele soorten, om het stromende karakter expliciet te beoordelen bepaald, net zoals de relatieve aantalsabundantie plantminnende soorten, om de moeraszone te beoordelen. De EKR vis voor de moerasbeek kan worden berekend met de formule gegeven in hoofdstuk 2 .

Tabel 4: Voorlopige maatlat soortensamenstelling en abundantie vis voor de moerasbeek, welke in sommige gevallen ook bruikbaar is voor het doorstroommoeras.

\begin{tabular}{|l|l|l|l|l|l|}
\hline $\begin{array}{l}\text { Klasse } \\
(\text { EKR) }\end{array}$ & $\begin{array}{l}\text { aantal } \\
\text { reofiele } \\
\text { soorten } \\
\left(\mathbf{S}_{\text {reo }}\right)\end{array}$ & $\begin{array}{l}\text { aantal } \\
\text { plantminnende } \\
\text { soorten }\left(\mathbf{S}_{\text {plant }}\right)\end{array}$ & $\begin{array}{l}\text { aantal } \\
\text { migrerende } \\
\text { soorten } \\
\left(\mathbf{S}_{\text {migr }}\right)\end{array}$ & $\begin{array}{l}\text { Relatieve } \\
\text { abundantie } \\
\text { reofiele } \\
\text { soorten } \\
\mathbf{( A}_{\text {reo }}\end{array}$ & $\begin{array}{l}\text { Relatieve } \\
\text { abundantie } \\
\text { plantminnende } \\
\text { soorten }\left(\mathbf{A}_{\text {plant }}\right)\end{array}$ \\
\hline Slecht $(0.00)$ & 0 & 0 & 0 & $0 \%$ & $0 \%$ \\
\hline $\begin{array}{l}\text { Ontoereikend } \\
(0.20)\end{array}$ & 2 & 3 & 1 & $5 \%$ & $5 \%$ \\
\hline Matig (0.40) & 3 & 4 & 2 & $10 \%$ & $10 \%$ \\
\hline Goed (0.60) & 4 & 5 & 3 & $20 \%$ & $20 \%$ \\
\hline $\begin{array}{l}\text { Zeer goed } \\
(0.80)\end{array}$ & 5 & 6 & 4 & $30 \%$ & $30 \%$ \\
\hline $\begin{array}{l}\text { Referentie } \\
(1.00)\end{array}$ & 6 & 7 & & $40-60 \%$ & $40-60 \%$ \\
\hline $\begin{array}{l}\text { Zeer goed } \\
(0.80)\end{array}$ & & & & $70 \%$ & $70 \%$ \\
\hline Goed (0.60) & & & & $80 \%$ & $80 \%$ \\
\hline Matig (0.40) & & & & $90 \%$ & $90 \%$ \\
\hline $\begin{array}{l}\text { Ontoereikend } \\
-(0.20)\end{array}$ & & & & $100 \%$ & $100 \%$ \\
\hline Slecht (0.00) & & & & & \\
\hline
\end{tabular}

1.5 Algemene fysisch-chemische kwaliteitselementen 
De maatlat voor de algemene fysisch-chemische kwaliteitselementen is weergegeven in tabel 5 en is overgenomen van R5. Deze waarden moeten nog worden gevalideerd aan de hand van nader onderzoek in onder andere referentiegebieden. Een belangrijk verschil met $\mathrm{R} 5$ is bijvoorbeeld dat heterogeniteit in omstandigheden kenmerkend is voor een moeras, bijvoorbeeld door zones met veel organisch materiaal etc. Fysisch-chemische bemonsteringen moeten daarom worden uitgevoerd in de beekloop om een zo veel mogelijk gestandaardiseerd beeld te krijgen van de fysisch-chemische toestand.

Tabel 5: Maatlat voor de algemene fysisch-chemische kwaliteitselementen voor de moerasbeek.

\begin{tabular}{|l|l|l|l|l|l|l|l|}
\hline Kwaliteitselement & Indicator & Eenheid & Zeer goed & Goed & Matig & $\begin{array}{l}\text { Ontoereiken } \\
\text { d }\end{array}$ & Slecht \\
\hline $\begin{array}{l}\text { Thermische } \\
\text { omstandigheden }\end{array}$ & dagwaarde & ${ }^{\circ} \mathrm{C}$ & $\leq 23$ & $\leq 25$ & $25-27,5$ & $27,5-30$ & $>30$ \\
\hline Zuurstofhuishouding & verzadiging & $\%$ & $70-90$ & $90-120$ & $\begin{array}{l}60-70 \\
120-130\end{array}$ & $\begin{array}{l}50-60 \\
130-140\end{array}$ & $\begin{array}{l}<50 \\
>140\end{array}$ \\
\hline Zoutgehalte & chloriditeit & $\mathrm{mg} \mathrm{Cl} / \mathrm{L}$ & $\leq 20$ & $\leq 150$ & $150-200$ & $200-250$ & $>250$ \\
\hline Zuurgraad & $\mathrm{pH}$ & - & $5,5-7,0$ & $\begin{array}{l}4,5-5,5 \\
7,0-8,5\end{array}$ & $\begin{array}{l}8,5-9,0 \\
<5,5\end{array}$ & $9,0-9,5$ & $>9,5$ \\
\hline Nutriënten & totaal-P & $\mathrm{mg} \mathrm{P/L}$ & $\leq 0,06$ & $\leq 0,11$ & $\begin{array}{l}0,11- \\
0,22\end{array}$ & $0,22-0,33$ & $>0,33$ \\
\hline Nutriënten & totaal-N & $\mathrm{mg} \mathrm{N} / \mathrm{L}$ & $\leq 2,0$ & $\leq 2,3$ & $2,3-4,6$ & $4,6-6,9$ & $>6,9$ \\
\hline
\end{tabular}

\subsection{Hydromorfologie}

De ranges van de parameters behorend bij de zeer goede toestand van het kwaliteitselement hydrologisch regime en morfologische parameters zijn weergegeven in tabel 6. De waarden van de overige hydromorfologische parameters zijn beschreven in de tabel met algemene $\mathrm{R}$ parameters.

Tabel 6: Waarden doorstroommoeras in zeer goede toestand voor de hydromorfologische kwaliteitselementen.

\begin{tabular}{|l|l|l|l|l|l|}
\hline Parameter & Code & Eenheid & Laag & Hoog & Verantwoording \\
\hline Stroomsnelheid & $\mathrm{v}$ & $\mathrm{m} \mathrm{s}^{-1}$ & $>0$ & 20 & 1 \\
\hline Afvoer & $\mathrm{Q}$ & $\mathrm{m}^{3} \mathrm{~s}^{-1}$ & 0,024 & 3,08 & 2 \\
\hline
\end{tabular}

1. Maximumwaarde gebaseerd op waarde waarbij start afname biomassa boven- en ondergronds bij water- en moerasplanten optreedt (Verdonschot et al., 2017)

2. Relatie moerasbeek afvoer niet bekend. Voorlopig berekende waarden R5 gebruikt. 


\section{Literatuur}

Aggenbach,C.J.S., Verdonschot, R.C.M., Vries, H.H. de, Groenendijk, D., Dijkstra, J.P., Diggelen, R. van (2014) Effecten van maaibeheer op kleine zeggenmoerassen in beekdalen; effecten op vegetatiestructuur, microtopografie en faunagemeenschappen.Rapport nr. Rapport nr. 2014/OBN183-BE. Directie Agrokennis, Ministerie van Economische Zaken, Den Haag. 137 pp.

Bal, D., Beije, H.M., Fellinger, M., Haveman, R., Opstal, A.J.F.M. van, Zadelhoff, F.J. van (2001) Handboek natuurdoeltypen; 2e geheel herz. ed. Rapport / Expertisecentrum LNV 2001/020. Expertisecentrum LNV, Wageningen.

Blackwell, M.S.A., Pilgrim, E.S. (2011) Ecosystem services delivered by small-scale wetlands, Hydrological Sciences Journal, 56:1467-1484.

Elbersen, J.W.H.; Verdonschot, P.F.M.; Roels, B.; Hartholt, J.G. (2003) Definitiestudie Kaderichtlijn Water (KRW); I. typologie Nederlandse oppervlaktewateren. Alterra-rapport 669, Alterra, Wageningen.

Gurnell, A. (2014) Plants as river system engineers. Earth Surf. Process. Landforms 39: 4-25.

van Herpen, F., Jaarsma, N. (2018) Maatlatten vissen moerasbeek en doorstroommoeras. Rapport BG1384WATRP1808030941, Royal Haskoning DHV, Eindhoven.

van der Molen, D.T., Pot, R., Evers, C.H.M., Nieuwerburgh, L.L.J. van, (2012) Referenties en maatlatten voor natuurlijke watertypen voor de Kaderrichtlijn Water 2015-2021. Rapport 201231. STOWA, Amersfoort. ( $2^{\mathrm{e}}$ druk 2016)

Verdonschot, R.C.M., Verdonschot P.F.M. (2018) Herziening macrofaunamaatlat R4. Notitie Zoetwatersystemen, Wageningen Environmental Research, Wageningen UR, Wageningenerdonschot, R.C.M., Verdonschot P.F.M. (2018) Herziening macrofaunamaatlat R4. Notitie Zoetwatersystemen, Wageningen Environmental Research, Wageningen UR, Wageningen.

Verdonschot, P., Verdonschot, R., Bauwens, J., Brugmans, B., Dees, A., Kits, M., Moeleker, M., Hoog, J. de, Scheepens, M., Barten, I., Coenen, D., Vught, A. van, Roovers, S. (2017) Kennisoverzicht kleinschalige maatregelen in Brabantse beken. STOWA rapport 2017-16, STOWA, Amersfoort.

Verdonschot, R.C.M., Verdonschot, P.F.M. (2017) Relatie KRW-doelen en macrofauna in beken in Noord-Brabant. Wageningen Environmental Research, Wageningen UR, Wageningen.

Verdonschot, R., Runhaar, H., Buijse, T., Bijkerk, R., Verdonschot, P. (2016) Doorstroommoerassen en moerasbeken. Typebeschrijvingen en ontwikkeling maatlatten voor de biologische kwaliteitselementen. Notitie Zoetwatersystemen, Alterra Wageningen UR, Wageningen.

Verdonschot, P.F.M. (2000) Natuurlijke levensgemeenschappen van de Nederlandse binnenwateren deel 2, Beken. Achtergronddocument bij het 'Handboek Natuurdoeltypen in Nederland'. Rapport EC-LNV nr. AS-02. Expertisecentrum LNV, Wageningen.

Mactaggart, B., Bauer, J., Goldney, D., Rawson, A. (2008) Problems in naming and defining the swampy meadow - An Australian perspective. Journal of Environmental Management 87: 461-473. 
Mitsch, W.J. Gosselink, J.G. (2007) Wetlands. 4th edition. John Wiley \& Sons, Inc. Hoboken, New Yersey.

Verberk, W.C.E.P., Verdonschot, P.F.M., van Haaren, T., van Maanen, B. (2012) Milieu- en habitatpreferenties van Nederlandse zoetwatermacrofauna. WEW Themanummer 23, Van de Garde-Jémé, Eindhoven. 


\section{Bijlage 1: Indicatorlijst macrofauna}

Herziene maatlatten voor doorstroommoerassen (R19) en moerasbeken (R20). Indicatiewaarden $1=\mathrm{KM}, 2=\mathrm{DP}, 3=\mathrm{DN}$.

\begin{tabular}{|l|l|l|l|l|l|}
\hline Taxonnaam TWN & Hoofdgroep & Familie & R19 & R20 & lit \\
\hline Erpobdella octoculata & APHIR & Erpobdellidae & 3 & 3 & van Haaren et al. 2004 \\
\hline Erpobdella vilnensis & APHIR & Erpobdellidae & 1 & 1 & van Haaren et al. 2004 \\
\hline Glossiphonia concolor & APHIR & Glossiphoniidae & 1 & 1 & van Haaren et al. 2004 \\
\hline Helobdella stagnalis & APHIR & Glossiphoniidae & 3 & 3 & van Haaren et al. 2004 \\
\hline Placobdella costata & APHIR & Glossiphoniidae & 1 & 1 & van Haaren et al. 2004 \\
\hline Hirudo medicinalis & APHIR & Hirudinidae & & 1 & van Haaren et al. 2004 \\
\hline Haplotaxis gordioides & APOLI & Haplotaxidae & 1 & 1 & van Haaren \& Soors 2013 \\
\hline Lumbriculus variegatus & APOLI & Lumbriculidae & 2 & 2 & van Haaren \& Soors 2013 \\
\hline Rhynchelmis limosella & APOLI & Lumbriculidae & 1 & 1 & van Haaren \& Soors 2013 \\
\hline Rhynchelmis tetratheca & APOLI & Lumbriculidae & 1 & 1 & van Haaren \& Soors 2013 \\
\hline Stylodrilus brachystylus & APOLI & Lumbriculidae & 1 & 1 & van Haaren \& Soors 2013 \\
\hline Stylodrilus heringianus & APOLI & Lumbriculidae & 2 & 2 & van Haaren \& Soors 2013 \\
\hline Trichodrilus & APOLI & Lumbriculidae & 1 & 1 & van Haaren \& Soors 2013 \\
\hline Dero digitata & APOLI & Naididae & 3 & 3 & van Haaren \& Soors 2013 \\
\hline Dero nivea & APOLI & Naididae & & 1 & van Haaren \& Soors 2013 \\
\hline Dero obtusa & APOLI & Naididae & 1 & 1 & van Haaren \& Soors 2013 \\
\hline Haemonais waldvogeli & APOLI & Naididae & 1 & 1 & van Haaren \& Soors 2013 \\
\hline Nais barbata & APOLI & Naididae & & 2 & van Haaren \& Soors 2013 \\
\hline Nais bretscheri & APOLI & Naididae & & 1 & van Haaren \& Soors 2013 \\
\hline Nais communis & APOLI & Naididae & 3 & 3 & van Haaren \& Soors 2013 \\
\hline Nais elinguis & APOLI & Naididae & 3 & 3 & van Haaren \& Soors 2013 \\
\hline Nais pseudobtusa & APOLI & Naididae & 1 & 1 & van Haaren \& Soors 2013 \\
\hline Nais variabilis & APOLI & Naididae & & 2 & van Haaren \& Soors 2013 \\
\hline
\end{tabular}




\begin{tabular}{|c|c|c|c|c|c|}
\hline Taxonnaam TWN & Hoofdgroep & Familie & R19 & $\mathbf{R 2 0}$ & lit \\
\hline Ophidonais serpentina & APOLI & Naididae & 3 & 3 & van Haaren \& Soors 2013 \\
\hline Ripistes parasita & APOLI & Naididae & & 1 & van Haaren \& Soors 2013 \\
\hline Slavina appendiculata & APOLI & Naididae & 2 & 2 & van Haaren \& Soors 2013 \\
\hline Specaria josinae & APOLI & Naididae & 1 & 1 & van Haaren \& Soors 2013 \\
\hline Stylaria lacustris & APOLI & Naididae & 3 & 3 & van Haaren \& Soors 2013 \\
\hline Vejdovskyella comata & APOLI & Naididae & 1 & & van Haaren \& Soors 2013 \\
\hline Aulodrilus limnobius & APOLI & Tubificidae & 2 & 2 & van Haaren \& Soors 2013 \\
\hline Bothrioneurum vejdovskyanum & APOLI & Tubificidae & 2 & 2 & van Haaren \& Soors 2013 \\
\hline Embolocephalus velutinus & APOLI & Tubificidae & 1 & & van Haaren \& Soors 2013 \\
\hline Bdellocephala punctata & APTUR & Dendrocoelidae & & 1 & Den Hartog 1962 \\
\hline Dugesia gonocephala & APTUR & Dugesiidae & 1 & & Den Hartog 1962 \\
\hline Planaria torva & APTUR & Planariidae & 1 & 1 & Den Hartog 1962 \\
\hline Polycelis felina & APTUR & Planariidae & 1 & & Reynoldson \& Young 2000 \\
\hline Arrenurus affinis & ARACH & Arrenuridae & 1 & & Gerecke et al. 2016 \\
\hline Arrenurus bicuspidator & ARACH & Arrenuridae & 1 & 1 & Gerecke et al. 2016 \\
\hline Arrenurus bifidicodulus & ARACH & Arrenuridae & 1 & 1 & Gerecke et al. 2016 \\
\hline Arrenurus bruzelii & ARACH & Arrenuridae & 1 & 1 & Gerecke et al. 2016 \\
\hline Arrenurus buccinator & ARACH & Arrenuridae & 1 & 1 & Gerecke et al. 2016 \\
\hline Arrenurus claviger & ARACH & Arrenuridae & 1 & 1 & Gerecke et al. 2016 \\
\hline Arrenurus cylindratus & ARACH & Arrenuridae & 1 & 1 & Smit \& van der Hammen 2000 \\
\hline Arrenurus falciger & $\mathrm{ARACH}$ & Arrenuridae & 1 & 1 & Gerecke et al. 2016 \\
\hline Arrenurus globator & ARACH & Arrenuridae & 3 & 3 & Gerecke et al. 2016 \\
\hline Arrenurus inexploratus & ARACH & Arrenuridae & 1 & 1 & Gerecke et al. 2016 \\
\hline Arrenurus knauthei & ARACH & Arrenuridae & 1 & 1 & Gerecke et al. 2016 \\
\hline Arrenurus leuckarti & ARACH & Arrenuridae & 1 & 1 & Gerecke et al. 2016 \\
\hline Arrenurus neumani & ARACH & Arrenuridae & 1 & & Gerecke et al. 2016 \\
\hline
\end{tabular}




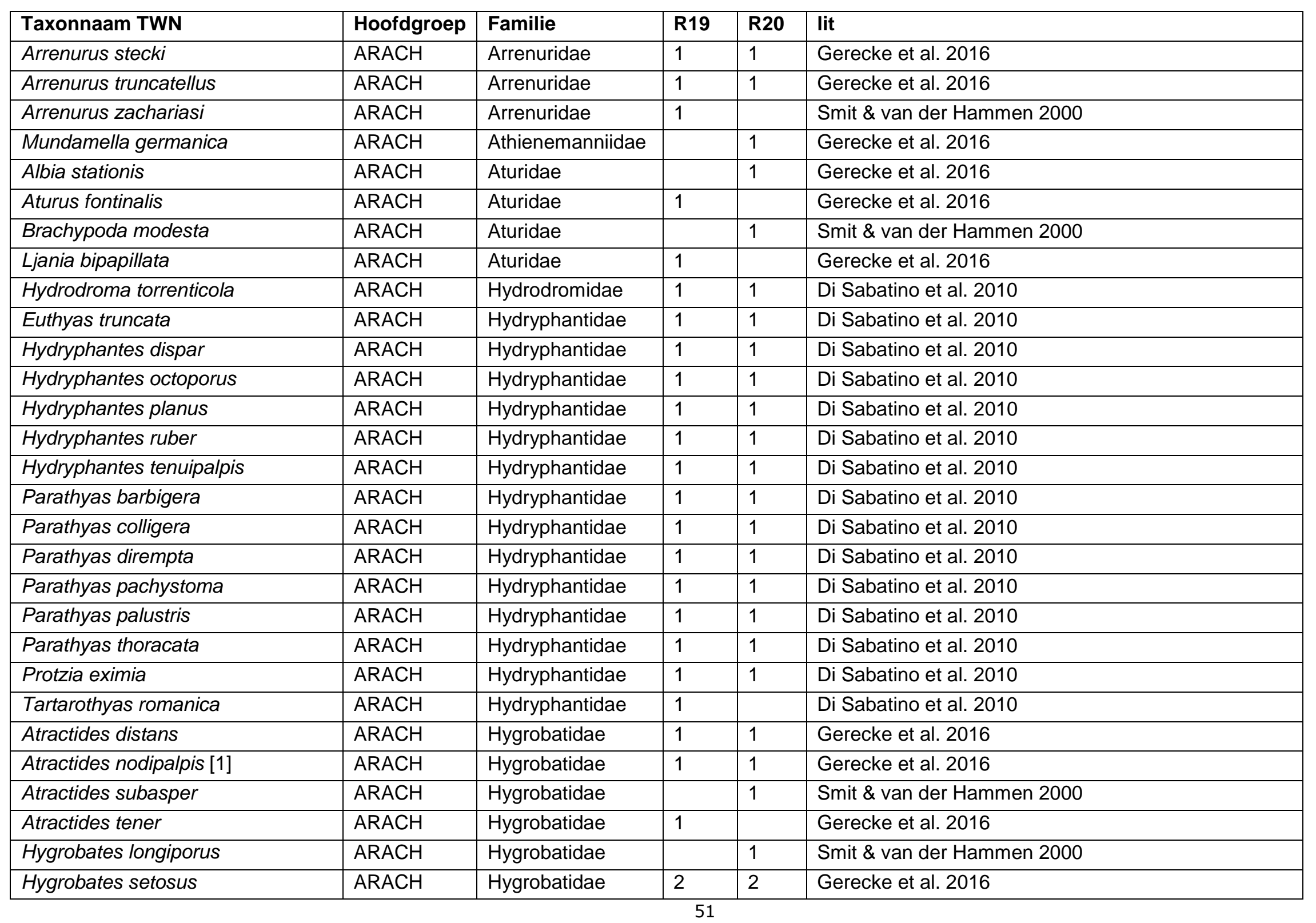




\begin{tabular}{|c|c|c|c|c|c|}
\hline Taxonnaam TWN & Hoofdgroep & Familie & R19 & $\mathbf{R 2 0}$ & lit \\
\hline Hygrobates trigonicus & ARACH & Hygrobatidae & 2 & 2 & Gerecke et al. 2016 \\
\hline Lebertia bracteata & ARACH & Lebertiidae & 1 & & Di Sabatino et al. 2010 \\
\hline Lebertia cognata & ARACH & Lebertiidae & 1 & & Di Sabatino et al. 2010 \\
\hline Lebertia dubia & ARACH & Lebertiidae & 1 & & Di Sabatino et al. 2010 \\
\hline Lebertia fimbriata & ARACH & Lebertiidae & 1 & 1 & Di Sabatino et al. 2010 \\
\hline Lebertia glabra & ARACH & Lebertiidae & 1 & & Di Sabatino et al. 2010 \\
\hline Lebertia insignis & ARACH & Lebertiidae & 1 & 1 & Di Sabatino et al. 2010 \\
\hline Lebertia minutipalpis & ARACH & Lebertiidae & 1 & & Di Sabatino et al. 2010 \\
\hline Lebertia porosa & ARACH & Lebertiidae & 1 & 1 & Di Sabatino et al. 2010 \\
\hline Lebertia rivulorum & $\mathrm{ARACH}$ & Lebertiidae & 1 & 1 & Di Sabatino et al. 2010 \\
\hline Lebertia stigmatifera & $\mathrm{ARACH}$ & Lebertiidae & 1 & & Di Sabatino et al. 2010 \\
\hline Limnesia koenikei & ARACH & Limnesiidae & 2 & 2 & Smit \& van der Hammen 2000 \\
\hline Limnesia maculata [1] & $\mathrm{ARACH}$ & Limnesiidae & & 2 & Smit \& van der Hammen 2000 \\
\hline Limnochares aquatica & ARACH & Limnocharidae & & 1 & Bartsch et al. 2007 \\
\hline Mideopsis crassipes & $\mathrm{ARACH}$ & Mideopsidae & 1 & 1 & Gerecke et al. 2016 \\
\hline Mideopsis roztoczensis & ARACH & Mideopsidae & 1 & & Gerecke et al. 2016 \\
\hline Oxus ovalis & $\mathrm{ARACH}$ & Oxidae & 1 & 1 & Di Sabatino et al. 2010 \\
\hline Oxus setosus & ARACH & Oxidae & 1 & 1 & Smit \& van der Hammen 2000 \\
\hline Forelia liliacea & ARACH & Pionidae & & 1 & Smit \& van der Hammen 2000 \\
\hline Forelia longipalpis & ARACH & Pionidae & & 1 & Smit \& van der Hammen 2000 \\
\hline Forelia variegator & ARACH & Pionidae & & 1 & Gerecke et al. 2016 \\
\hline Hydrochoreutes krameri & ARACH & Pionidae & & 1 & Smit \& van der Hammen 2000 \\
\hline Nautarachna crassa & $\mathrm{ARACH}$ & Pionidae & 1 & 1 & Gerecke et al. 2016 \\
\hline Piona clavicornis & ARACH & Pionidae & 1 & 1 & Gerecke et al. 2016 \\
\hline Piona longipalpis & ARACH & Pionidae & & 2 & Smit \& van der Hammen 2000 \\
\hline Piona nodata / laminata & ARACH & Pionidae & 1 & 1 & Smit \& van der Hammen 2000 \\
\hline
\end{tabular}




\begin{tabular}{|c|c|c|c|c|c|}
\hline Taxonnaam TWN & Hoofdgroep & Familie & R19 & $\mathbf{R 2 0}$ & lit \\
\hline Pionacercus vatrax & ARACH & Pionidae & & 1 & Gerecke et al. 2016 \\
\hline Pionopsis lutescens & ARACH & Pionidae & 1 & 1 & Gerecke et al. 2016 \\
\hline Tiphys latipes & $\mathrm{ARACH}$ & Pionidae & 1 & 1 & Smit \& van der Hammen 2000 \\
\hline Tiphys torris & $\mathrm{ARACH}$ & Pionidae & 1 & 1 & Smit \& van der Hammen 2000 \\
\hline Sperchon clupeifer & ARACH & Sperchontidae & 1 & 1 & Di Sabatino et al. 2010 \\
\hline Sperchon compactilis & ARACH & Sperchontidae & 1 & 1 & Di Sabatino et al. 2010 \\
\hline Sperchon setiger [1] & $\mathrm{ARACH}$ & Sperchontidae & 1 & 1 & Di Sabatino et al. 2010 \\
\hline Sperchon squamosus & $\mathrm{ARACH}$ & Sperchontidae & 1 & & Di Sabatino et al. 2010 \\
\hline Sperchon thienemanni & $\mathrm{ARACH}$ & Sperchontidae & 1 & & Di Sabatino et al. 2010 \\
\hline Sperchon turgidus & $\mathrm{ARACH}$ & Sperchontidae & 1 & 1 & Di Sabatino et al. 2010 \\
\hline Sperchon vaginosus & ARACH & Sperchontidae & 1 & 1 & Di Sabatino et al. 2010 \\
\hline Sperchonopsis verrucosa & ARACH & Sperchontidae & 1 & 1 & Di Sabatino et al. 2010 \\
\hline Teutonia cometes & ARACH & Teutoniidae & 1 & & Smit \& van der Hammen 2000 \\
\hline Neumania imitata & ARACH & Unionicolidae & 1 & 1 & Gerecke et al. 2016 \\
\hline Neumania limosa & $\mathrm{ARACH}$ & Unionicolidae & 2 & 2 & Smit \& van der Hammen 2000 \\
\hline Neumania vernalis & ARACH & Unionicolidae & 1 & 1 & Gerecke et al. 2016 \\
\hline Wettina podagrica & ARACH & Wettinidae & 1 & 1 & Gerecke et al. 2016 \\
\hline Crangonyx pseudogracilis & CRAMP & Crangonyctidae & 3 & 3 & $\mathrm{x}$ \\
\hline Echinogammarus berilloni & CRAMP & Gammaridae & & 1 & $\mathrm{x}$ \\
\hline Gammarus fossarum & CRAMP & Gammaridae & 2 & 2 & $x$ \\
\hline Gammarus pulex & CRAMP & Gammaridae & 2 & 2 & $\mathrm{x}$ \\
\hline Gammarus roeseli & CRAMP & Gammaridae & 2 & 2 & $x$ \\
\hline Astacus astacus & CRDEC & Astacidae & & 1 & $\mathrm{x}$ \\
\hline Chironomus & IDCHI & Chironomini & 3 & 3 & Moller Pillot 2009 \\
\hline Demicryptochironomus vulneratus & IDCHI & Chironomini & & 1 & Moller Pillot 2009 \\
\hline Dicrotendipes nervosus & IDCHI & Chironomini & 3 & 3 & Moller Pillot 2009 \\
\hline
\end{tabular}




\begin{tabular}{|c|c|c|c|c|c|}
\hline Taxonnaam TWN & Hoofdgroep & Familie & R19 & $\mathbf{R} 20$ & lit \\
\hline Glyptotendipes barbipes & IDCHI & Chironomini & 3 & 3 & Moller Pillot 2009 \\
\hline Harnischia & IDCHI & Chironomini & & 1 & Moller Pillot 2009 \\
\hline Lauterborniella agrayloides & IDCHI & Chironomini & 1 & 1 & Moller Pillot 2009 \\
\hline Paracladopelma camptolabis & IDCHI & Chironomini & 1 & 1 & Moller Pillot 2013 \\
\hline Paracladopelma nigritulum & IDCHI & Chironomini & 1 & 1 & Moller Pillot 2013 \\
\hline Paralauterborniella nigrohalteralis & IDCHI & Chironomini & & 1 & Moller Pillot 2009 \\
\hline Paratendipes nudisquama & IDCHI & Chironomini & 1 & & Moller Pillot 2009 \\
\hline Phaenopsectra & IDCHI & Chironomini & 2 & 2 & Moller Pillot 2009 \\
\hline Polypedilum albicorne & IDCHI & Chironomini & 1 & & Moller Pillot 2009 \\
\hline Polypedilum bicrenatum & IDCHI & Chironomini & 2 & 2 & Moller Pillot 2009 \\
\hline Polypedilum convictum & IDCHI & Chironomini & 1 & 1 & Moller Pillot 2009 \\
\hline Polypedilum cultellatum & IDCHI & Chironomini & & 2 & Moller Pillot 2009 \\
\hline Polypedilum laetum & IDCHI & Chironomini & 1 & 1 & Moller Pillot 2009 \\
\hline Polypedilum pedestre & IDCHI & Chironomini & 1 & 1 & Moller Pillot 2009 \\
\hline Polypedilum scalaenum & IDCHI & Chironomini & 2 & 2 & Moller Pillot 2009 \\
\hline Polypedilum sordens & IDCHI & Chironomini & & 2 & Moller Pillot 2009 \\
\hline Polypedilum uncinatum agg. & $\mathrm{IDCHI}$ & Chironomini & 2 & 2 & Moller Pillot 2009 \\
\hline Pseudochironomus prasinatus & IDCHI & Chironomini & 1 & 1 & Moller Pillot 2009 \\
\hline Stenochironomus & IDCHI & Chironomini & 1 & 1 & Moller Pillot 2009 \\
\hline Stictochironomus maculipennis & IDCHI & Chironomini & 1 & 1 & Moller Pillot 2009 \\
\hline Stictochironomus pictulus & IDCHI & Chironomini & 1 & 1 & Moller Pillot 2009 \\
\hline Potthastia gaedii & IDCHI & Diamesinae & 1 & 1 & Moller Pillot 2009 \\
\hline Potthastia longimanus & IDCHI & Diamesinae & 1 & 1 & Moller Pillot 2009 \\
\hline Brillia bifida & IDCHI & Orthocladiinae & 1 & 1 & Moller Pillot 2013 \\
\hline Brillia longifurca & IDCHI & Orthocladiinae & 1 & 1 & Moller Pillot 2013 \\
\hline Chaetocladius femineus & IDCHI & Orthocladiinae & 1 & & Moller Pillot 2013 \\
\hline
\end{tabular}




\begin{tabular}{|c|c|c|c|c|c|}
\hline Taxonnaam TWN & Hoofdgroep & Familie & R19 & $\mathbf{R} 20$ & lit \\
\hline Chaetocladius melaleucus & IDCHI & Orthocladiinae & 1 & & Moller Pillot 2013 \\
\hline Chaetocladius piger agg. & IDCHI & Orthocladiinae & 2 & 2 & Moller Pillot 2013 \\
\hline Chaetocladius vitellinus gr. & $\mathrm{IDCHI}$ & Orthocladiinae & 1 & & Moller Pillot 2013 \\
\hline Corynoneura coronata & $\mathrm{IDCHI}$ & Orthocladiinae & 1 & 1 & Moller Pillot 2013 \\
\hline Corynoneura lobata agg. & $\mathrm{IDCHI}$ & Orthocladiinae & 1 & 1 & Moller Pillot 2013 \\
\hline Cricotopus bicinctus & IDCHI & Orthocladiinae & 3 & 3 & Moller Pillot 2013 \\
\hline Cricotopus sylvestris gr. & IDCHI & Orthocladiinae & 3 & 3 & Moller Pillot 2013 \\
\hline Cricotopus tibialis & $\mathrm{IDCHI}$ & Orthocladiinae & 1 & 1 & Moller Pillot 2013 \\
\hline Cricotopus triannulatus & IDCHI & Orthocladiinae & & 1 & Moller Pillot 2013 \\
\hline Diplocladius cultriger & IDCHI & Orthocladiinae & 1 & 1 & Moller Pillot 2013 \\
\hline Epoicocladius ephemerae & IDCHI & Orthocladiinae & 1 & 1 & Moller Pillot 2013 \\
\hline Eukiefferiella brevicalcar & IDCHI & Orthocladiinae & 1 & 1 & Moller Pillot 2013 \\
\hline Eukiefferiella claripennis & IDCHI & Orthocladiinae & & 1 & Moller Pillot 2013 \\
\hline Heleniella ornaticollis & IDCHI & Orthocladiinae & 1 & & Moller Pillot 2013 \\
\hline Heterotanytarsus apicalis & $\mathrm{IDCHI}$ & Orthocladiinae & 1 & & Moller Pillot 2013 \\
\hline Heterotrissocladius marcidus & IDCHI & Orthocladiinae & 1 & 1 & Moller Pillot 2013 \\
\hline Hydrobaenus lugubris & IDCHI & Orthocladiinae & & 1 & Moller Pillot 2013 \\
\hline Hydrobaenus pilipes & IDCHI & Orthocladiinae & 1 & 1 & Moller Pillot 2013 \\
\hline Limnophyes & IDCHI & Orthocladiinae & 2 & 2 & Moller Pillot 2013 \\
\hline Metriocnemus hirticollis agg. & IDCHI & Orthocladiinae & 2 & 2 & Moller Pillot 2013 \\
\hline Metriocnemus hygropetricus agg. & IDCHI & Orthocladiinae & 2 & 2 & Moller Pillot 2013 \\
\hline Nanocladius rectinervis & IDCHI & Orthocladiinae & 1 & 1 & Moller Pillot 2013 \\
\hline Orthocladius (Euorthocladius) & IDCHI & Orthocladiinae & 1 & 1 & Moller Pillot 2013 \\
\hline Orthocladius frigidus & IDCHI & Orthocladiinae & 1 & 1 & Moller Pillot 2013 \\
\hline Orthocladius lignicola & $\mathrm{IDCHI}$ & Orthocladiinae & 1 & 1 & Moller Pillot 2013 \\
\hline Orthocladius oblidens & $\mathrm{IDCHI}$ & Orthocladiinae & 1 & 1 & Moller Pillot 2013 \\
\hline
\end{tabular}




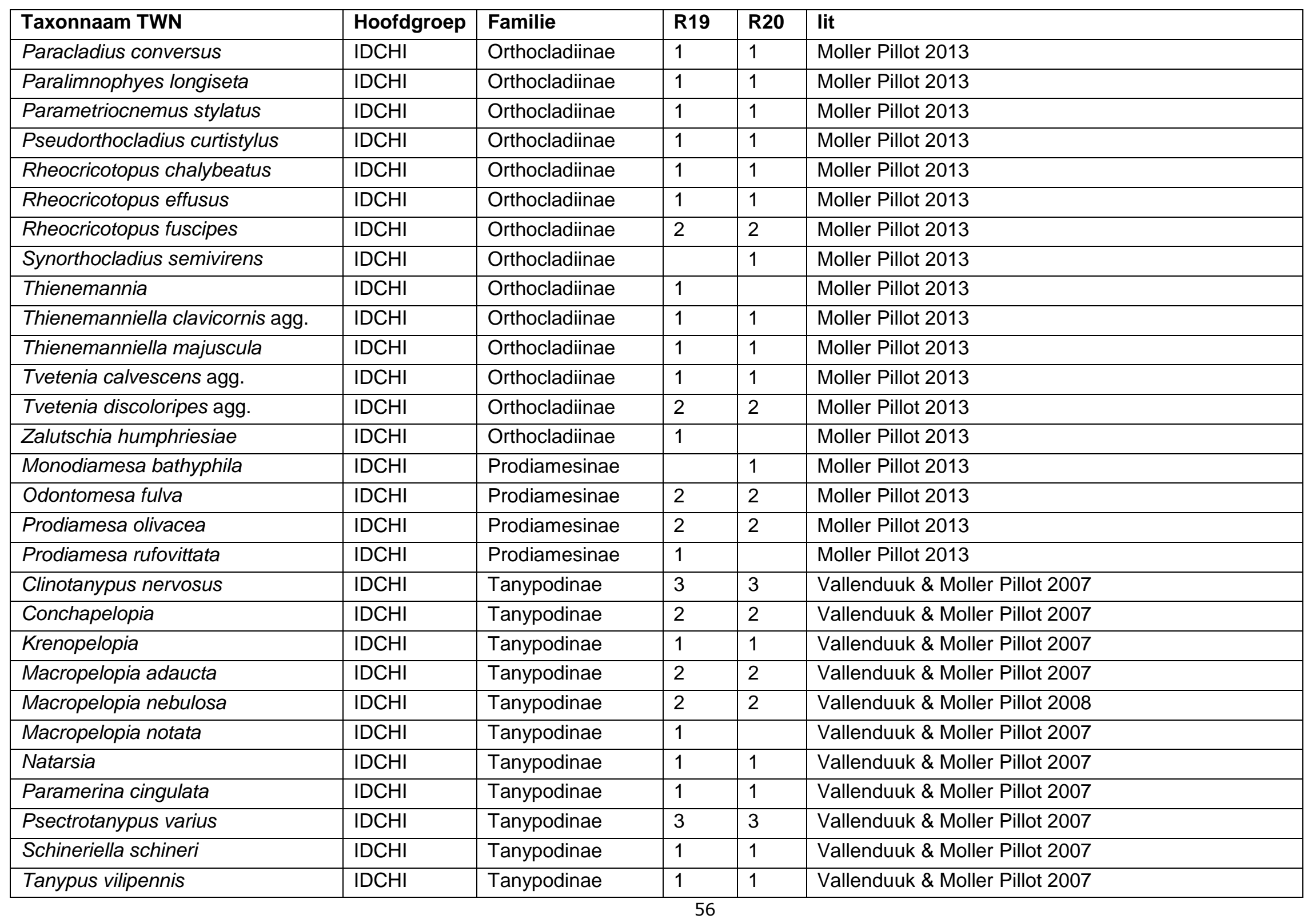




\begin{tabular}{|c|c|c|c|c|c|}
\hline Taxonnaam TWN & Hoofdgroep & Familie & R19 & $\mathbf{R 2 0}$ & lit \\
\hline Telmatopelopia nemorum & IDCHI & Tanypodinae & 1 & 1 & Vallenduuk \& Moller Pillot 2007 \\
\hline Trissopelopia longimanus & IDCHI & Tanypodinae & 1 & & Vallenduuk \& Moller Pillot 2007 \\
\hline Xenopelopia & IDCHI & Tanypodinae & 2 & 2 & Vallenduuk \& Moller Pillot 2007 \\
\hline Zavrelimyia & IDCHI & Tanypodinae & 1 & 1 & Vallenduuk \& Moller Pillot 2007 \\
\hline Cladotanytarsus mancus gr. & $\mathrm{IDCHI}$ & Tanytarsini & & 2 & Klink \& Moller Pillot 1996 \\
\hline Micropsectra apposita & IDCHI & Tanytarsini & 2 & 2 & Klink \& Moller Pillot 1996 \\
\hline Micropsectra junci & IDCHI & Tanytarsini & 1 & & Klink \& Moller Pillot 1996 \\
\hline Micropsectra notescens & IDCHI & Tanytarsini & 1 & & Klink \& Moller Pillot 1996 \\
\hline Micropsectra recurvata & IDCHI & Tanytarsini & & 2 & Klink \& Moller Pillot 1996 \\
\hline Micropsectra roseiventris & IDCHI & Tanytarsini & 1 & 1 & Cuppen et al. 2015 \\
\hline Paratanytarsus austriacus & IDCHI & Tanytarsini & & 2 & Klink \& Moller Pillot 1996 \\
\hline Paratanytarsus dissimilis & IDCHI & Tanytarsini & & 2 & Klink \& Moller Pillot 1996 \\
\hline Paratanytarsus grimmii & IDCHI & Tanytarsini & & 2 & Klink \& Moller Pillot 1996 \\
\hline Rheotanytarsus & IDCHI & Tanytarsini & 2 & 2 & Klink \& Moller Pillot 1996 \\
\hline Stempellina & IDCHI & Tanytarsini & & 1 & Klink \& Moller Pillot 1996 \\
\hline Stempellinella brevis & IDCHI & Tanytarsini & 1 & 1 & Ekrem 2007 \\
\hline Stempellinella edwardsi & $\mathrm{IDCHI}$ & Tanytarsini & 1 & 1 & Ekrem 2007 \\
\hline Tanytarsus buchonius & IDCHI & Tanytarsini & 1 & & Cuppen et al. 2015 \\
\hline Tanytarsus ejuncidus & IDCHI & Tanytarsini & 2 & 2 & Cuppen et al. 2015 \\
\hline Tanytarsus eminulus & IDCHI & Tanytarsini & 1 & & Cuppen et al. 2015 \\
\hline Tanytarsus heusdensis & IDCHI & Tanytarsini & 2 & 2 & Cuppen et al. 2015 \\
\hline Tanytarsus lactescens & IDCHI & Tanytarsini & 1 & & Cuppen et al. 2015 \\
\hline Tanytarsus lestagei & IDCHI & Tanytarsini & & 2 & Cuppen et al. 2015 \\
\hline Tanytarsus medius & IDCHI & Tanytarsini & & 2 & Cuppen et al. 2015 \\
\hline Tanytarsus palettaris & IDCHI & Tanytarsini & 1 & & Cuppen et al. 2015 \\
\hline Tanytarsus pallidicornis & IDCHI & Tanytarsini & 2 & 2 & Cuppen et al. 2015 \\
\hline
\end{tabular}




\begin{tabular}{|c|c|c|c|c|c|}
\hline Taxonnaam TWN & Hoofdgroep & Familie & R19 & $\mathbf{R 2 0}$ & lit \\
\hline Zavrelia pentatoma & IDCHI & Tanytarsini & 1 & 1 & Klink \& Moller Pillot 1996 \\
\hline Atherix ibis & IDREM & Athericidae & & 1 & Faasch 2015 \\
\hline Atrichops crassipes & IDREM & Athericidae & & 1 & Faasch 2015 \\
\hline Chaoborus pallidus & IDREM & Chaoboridae & 1 & 1 & $\mathrm{x}$ \\
\hline Mochlonyx velutinus & IDREM & Chaoboridae & 1 & & $x$ \\
\hline Culicidae & IDREM & Culicidae & 3 & 3 & $x$ \\
\hline Dixella & IDREM & Dixidae & 2 & 2 & Disney 1999 \\
\hline Limoniidae & IDREM & Limoniidae & 2 & 2 & $x$ \\
\hline Dicranota & IDREM & Pediciidae & 2 & 2 & $x$ \\
\hline Pedicia & IDREM & Pediciidae & 1 & 1 & $\mathrm{x}$ \\
\hline Chrysops caecutiens & IDREM & Tabanidae & 1 & 1 & Zeegers \& van haaren 2000 \\
\hline Simulium angustipes & IDSIM & Simuliidae & 1 & 1 & Lock \& van Maanen 2014 \\
\hline Simulium aureum & IDSIM & Simuliidae & 1 & & Lock \& van Maanen 2014 \\
\hline Simulium cryophilum & IDSIM & Simuliidae & 1 & & Lock \& van Maanen 2014 \\
\hline Simulium equinum & IDSIM & Simuliidae & & 1 & Lock \& van Maanen 2014 \\
\hline Simulium erythrocephalum & IDSIM & Simuliidae & 2 & 2 & Lock \& van Maanen 2014 \\
\hline Simulium lundstromi & IDSIM & Simuliidae & 1 & 1 & Lock \& van Maanen 2014 \\
\hline Simulium morsitans & IDSIM & Simuliidae & 1 & 1 & Lock \& van Maanen 2014 \\
\hline Simulium noelleri & IDSIM & Simuliidae & 2 & 2 & Lock \& van Maanen 2014 \\
\hline Simulium ornatum gr. & IDSIM & Simuliidae & 2 & 2 & Lock \& van Maanen 2014 \\
\hline Simulium vernum & IDSIM & Simuliidae & 1 & & Lock \& van Maanen 2014 \\
\hline Dryops anglicanus & INCOL & Dryopidae & 1 & 1 & Drost et al. 1992 \\
\hline Dryops auriculatus & INCOL & Dryopidae & 1 & 1 & Drost et al. 1992 \\
\hline Pomatinus substriatus & INCOL & Dryopidae & 1 & 1 & med. Barend van Maanen \\
\hline Acilius canaliculatus & INCOL & Dytiscidae & 1 & 1 & Drost et al. 1992 \\
\hline Agabus affinis & INCOL & Dytiscidae & 1 & & Drost et al. 1992 \\
\hline
\end{tabular}




\begin{tabular}{|c|c|c|c|c|c|}
\hline Taxonnaam TWN & Hoofdgroep & Familie & R19 & $\mathbf{R 2 0}$ & lit \\
\hline Agabus didymus & INCOL & Dytiscidae & 1 & 1 & Drost et al. 1992 \\
\hline Agabus guttatus & INCOL & Dytiscidae & 1 & & Drost et al. 1992 \\
\hline Agabus labiatus & INCOL & Dytiscidae & 1 & & Drost et al. 1992 \\
\hline Agabus paludosus & INCOL & Dytiscidae & 1 & 1 & Drost et al. 1992 \\
\hline Agabus striolatus & INCOL & Dytiscidae & 1 & 1 & Drost et al. 1992 \\
\hline Agabus uliginosus & INCOL & Dytiscidae & 1 & 1 & Drost et al. 1992 \\
\hline Bidessus grossepunctatus & INCOL & Dytiscidae & 1 & 1 & Drost et al. 1992 \\
\hline Bidessus unistriatus & INCOL & Dytiscidae & 1 & 1 & Drost et al. 1992 \\
\hline Deronectes latus & INCOL & Dytiscidae & 1 & 1 & Drost et al. 1992 \\
\hline Dytiscus dimidiatus & INCOL & Dytiscidae & 1 & 1 & Drost et al. 1992 \\
\hline Dytiscus semisulcatus & INCOL & Dytiscidae & 1 & 1 & Drost et al. 1992 \\
\hline Graptodytes granularis & INCOL & Dytiscidae & 1 & 1 & Drost et al. 1992 \\
\hline Hydaticus transversalis & INCOL & Dytiscidae & 1 & 1 & Drost et al. 1992 \\
\hline Hydroporus elongatulus & INCOL & Dytiscidae & 1 & 1 & Drost et al. 1992 \\
\hline Hydroporus glabriusculus & INCOL & Dytiscidae & 1 & & Drost et al. 1992 \\
\hline Hydroporus incognitus & INCOL & Dytiscidae & 1 & 1 & Drost et al. 1992 \\
\hline Hydroporus longulus & INCOL & Dytiscidae & 1 & & Drost et al. 1992 \\
\hline Hydroporus melanarius & INCOL & Dytiscidae & 1 & 1 & Drost et al. 1992 \\
\hline Hydroporus memnonius & INCOL & Dytiscidae & 1 & 1 & Drost et al. 1992 \\
\hline Hydroporus morio & INCOL & Dytiscidae & 1 & & Drost et al. 1992 \\
\hline Hydroporus neglectus & INCOL & Dytiscidae & 1 & 1 & Drost et al. 1992 \\
\hline Hydroporus nigrita & INCOL & Dytiscidae & 1 & 1 & Drost et al. 1992 \\
\hline Hydroporus notatus & INCOL & Dytiscidae & 1 & 1 & Drost et al. 1992 \\
\hline Hydroporus obscurus & INCOL & Dytiscidae & 1 & & Drost et al. 1992 \\
\hline Hydroporus pubescens & INCOL & Dytiscidae & 1 & & Drost et al. 1992 \\
\hline Hydroporus rufifrons & INCOL & Dytiscidae & 1 & 1 & Drost et al. 1992 \\
\hline
\end{tabular}




\begin{tabular}{|c|c|c|c|c|c|}
\hline Taxonnaam TWN & Hoofdgroep & Familie & R19 & $\mathbf{R 2 0}$ & lit \\
\hline Hydroporus striola & INCOL & Dytiscidae & 1 & 1 & Drost et al. 1992 \\
\hline Hydroporus umbrosus & INCOL & Dytiscidae & 1 & 1 & Drost et al. 1992 \\
\hline Hygrotus decoratus & INCOL & Dytiscidae & 1 & 1 & Drost et al. 1992 \\
\hline Ilybius aenescens & INCOL & Dytiscidae & 1 & & Drost et al. 1992 \\
\hline Ilybius chalconatus & INCOL & Dytiscidae & 1 & 1 & Drost et al. 1992 \\
\hline Ilybius guttiger & INCOL & Dytiscidae & 1 & 1 & Drost et al. 1992 \\
\hline Ilybius quadriguttatus & INCOL & Dytiscidae & 1 & 1 & Drost et al. 1992 \\
\hline Ilybius subaeneus & INCOL & Dytiscidae & 1 & 1 & Drost et al. 1992 \\
\hline Laccornis oblongus & INCOL & Dytiscidae & 1 & 1 & Drost et al. 1992 \\
\hline Liopterus haemorrhoidalis & INCOL & Dytiscidae & 1 & 1 & Drost et al. 1992 \\
\hline Nebrioporus elegans & INCOL & Dytiscidae & 1 & 1 & Drost et al. 1992 \\
\hline Oreodytes sanmarkii & INCOL & Dytiscidae & 1 & & Drost et al. 1992 \\
\hline Platambus maculatus & INCOL & Dytiscidae & 1 & 1 & Drost et al. 1992 \\
\hline Rhantus grapii & INCOL & Dytiscidae & 1 & 1 & Drost et al. 1992 \\
\hline Rhantus suturellus & INCOL & Dytiscidae & 1 & & Drost et al. 1992 \\
\hline Scarodytes halensis & INCOL & Dytiscidae & 1 & 1 & med. Barend van Maanen \\
\hline Stictotarsus duodecimpustulatus & INCOL & Dytiscidae & 1 & 1 & Drost et al. 1992 \\
\hline Suphrodytes dorsalis & INCOL & Dytiscidae & 1 & 1 & Scheers et al. 2014 \\
\hline Suphrodytes figuralis & INCOL & Dytiscidae & 1 & 1 & Scheers et al. 2014 \\
\hline Yola bicarinata & INCOL & Dytiscidae & & 1 & Drost et al. 1992 \\
\hline Elmis aenea & INCOL & Elmidae & 1 & 1 & Drost et al. 1992 \\
\hline Limnius volckmari & INCOL & Elmidae & 1 & 1 & Drost et al. 1992 \\
\hline Oulimnius rivularis & INCOL & Elmidae & & 1 & Drost et al. 1992 \\
\hline Oulimnius tuberculatus & INCOL & Elmidae & 1 & 1 & Drost et al. 1992 \\
\hline Gyrinus aeratus & INCOL & Gyrinidae & & 1 & Drost et al. 1992 \\
\hline Gyrinus distinctus & INCOL & Gyrinidae & & 1 & Drost et al. 1992 \\
\hline
\end{tabular}




\begin{tabular}{|c|c|c|c|c|c|}
\hline Taxonnaam TWN & Hoofdgroep & Familie & R19 & $\mathbf{R 2 0}$ & lit \\
\hline Gyrinus paykulli & INCOL & Gyrinidae & 1 & 1 & Drost et al. 1992 \\
\hline Gyrinus suffriani & INCOL & Gyrinidae & 1 & 1 & Drost et al. 1992 \\
\hline Orectochilus villosus & INCOL & Gyrinidae & 1 & 1 & Drost et al. 1992 \\
\hline Brychius elevatus & INCOL & Haliplidae & 1 & 1 & Drost et al. 1992 \\
\hline Haliplus flavicollis & INCOL & Haliplidae & & 1 & Drost et al. 1992 \\
\hline Haliplus fluviatilis & INCOL & Haliplidae & & 2 & Drost et al. 1992 \\
\hline Haliplus fulvus & INCOL & Haliplidae & & 1 & Drost et al. 1992 \\
\hline Haliplus laminatus & INCOL & Haliplidae & 1 & 1 & Drost et al. 1992 \\
\hline Haliplus lineolatus & INCOL & Haliplidae & & 1 & Drost et al. 1992 \\
\hline Haliplus sibiricus & INCOL & Haliplidae & 1 & 1 & Drost et al. 1992 \\
\hline Helophorus arvernicus & INCOL & Helophoridae & 1 & 1 & Drost et al. 1992 \\
\hline Helophorus flavipes & INCOL & Helophoridae & 1 & & Drost et al. 1992 \\
\hline Helophorus granularis & INCOL & Helophoridae & 1 & 1 & Drost et al. 1992 \\
\hline Helophorus pumilio & INCOL & Helophoridae & 1 & 1 & Drost et al. 1992 \\
\hline Helophorus strigifrons & INCOL & Helophoridae & 1 & 1 & Drost et al. 1992 \\
\hline Hydraena assimilis & INCOL & Hydraenidae & 1 & & Drost et al. 1992 \\
\hline Hydraena britteni & INCOL & Hydraenidae & 1 & 1 & Drost et al. 1992 \\
\hline Hydraena excisa & INCOL & Hydraenidae & 1 & 1 & Drost et al. 1992 \\
\hline Hydraena melas & INCOL & Hydraenidae & 1 & 1 & Drost et al. 1992 \\
\hline Hydraena palustris & INCOL & Hydraenidae & 1 & 1 & Drost et al. 1992 \\
\hline Hydraena riparia & INCOL & Hydraenidae & 1 & 1 & Drost et al. 1992 \\
\hline Hydraena testacea & INCOL & Hydraenidae & 1 & 1 & Drost et al. 1992 \\
\hline Limnebius aluta & INCOL & Hydraenidae & 1 & 1 & Drost et al. 1992 \\
\hline Limnebius nitidus & INCOL & Hydraenidae & 1 & 1 & Drost et al. 1992 \\
\hline Limnebius papposus & INCOL & Hydraenidae & 1 & 1 & Drost et al. 1992 \\
\hline Limnebius truncatellus & INCOL & Hydraenidae & 1 & 1 & Drost et al. 1992 \\
\hline
\end{tabular}




\begin{tabular}{|c|c|c|c|c|c|}
\hline Taxonnaam TWN & Hoofdgroep & Familie & R19 & $\mathbf{R 2 0}$ & lit \\
\hline Ochthebius minimus & INCOL & Hydraenidae & 1 & 1 & Drost et al. 1992 \\
\hline Hydrochus angustatus & INCOL & Hydrochidae & 1 & 1 & Drost et al. 1992 \\
\hline Hydrochus brevis & INCOL & Hydrochidae & 1 & 1 & Drost et al. 1992 \\
\hline Hydrochus carinatus & INCOL & Hydrochidae & 1 & 1 & Drost et al. 1992 \\
\hline Hydrochus elongatus & INCOL & Hydrochidae & 1 & 1 & Drost et al. 1992 \\
\hline Hydrochus ignicollis & INCOL & Hydrochidae & 1 & 1 & Drost et al. 1992 \\
\hline Berosus luridus & INCOL & Hydrophilidae & 1 & 1 & Drost et al. 1992 \\
\hline Berosus signaticollis & INCOL & Hydrophilidae & 1 & 1 & Drost et al. 1992 \\
\hline Cercyon & INCOL & Hydrophilidae & 1 & 1 & Drost et al. 1992 \\
\hline Chaetarthria seminulum & INCOL & Hydrophilidae & 1 & 1 & Drost et al. 1992 \\
\hline Chaetarthria similis & INCOL & Hydrophilidae & 1 & 1 & med. Barend van Maanen \\
\hline Coelostoma orbiculare & INCOL & Hydrophilidae & 1 & 1 & Drost et al. 1992 \\
\hline Enochrus affinis & INCOL & Hydrophilidae & 1 & 1 & Drost et al. 1992 \\
\hline Enochrus fuscipennis & INCOL & Hydrophilidae & 1 & 1 & Drost et al. 1992 \\
\hline Enochrus ochropterus & INCOL & Hydrophilidae & 1 & 1 & Drost et al. 1992 \\
\hline Enochrus quadripunctatus & INCOL & Hydrophilidae & 1 & 1 & Drost et al. 1992 \\
\hline Helochares lividus & INCOL & Hydrophilidae & & 1 & Drost et al. 1992 \\
\hline Helochares punctatus & INCOL & Hydrophilidae & 1 & & Drost et al. 1992 \\
\hline Hydrochara caraboides & INCOL & Hydrophilidae & 1 & 1 & Drost et al. 1992 \\
\hline Laccobius atratus & INCOL & Hydrophilidae & 1 & & Drost et al. 1992 \\
\hline Laccobius sinuatus & INCOL & Hydrophilidae & 1 & 1 & Drost et al. 1992 \\
\hline Laccobius striatulus & INCOL & Hydrophilidae & 1 & 1 & Drost et al. 1992 \\
\hline Limnoxenus niger & INCOL & Hydrophilidae & 1 & 1 & Drost et al. 1992 \\
\hline Paracymus scutellaris & INCOL & Hydrophilidae & 1 & & Drost et al. 1992 \\
\hline Scirtidae & INCOL & Scirtidae & 2 & 2 & Drost et al. 1992 \\
\hline Metreletus balcanicus & INEPH & Ameletidae & 1 & & Drukker in prep. \\
\hline
\end{tabular}




\begin{tabular}{|c|c|c|c|c|c|}
\hline Taxonnaam TWN & Hoofdgroep & Familie & R19 & R20 & lit \\
\hline Baetis fuscatus & INEPH & Baetidae & 1 & 1 & Drukker in prep. \\
\hline Baetis niger & INEPH & Baetidae & 1 & 1 & Drukker in prep. \\
\hline Baetis rhodani & INEPH & Baetidae & 1 & 1 & Drukker in prep. \\
\hline Baetis tracheatus & INEPH & Baetidae & & 1 & Drukker in prep. \\
\hline Baetis vernus & INEPH & Baetidae & 2 & 2 & Drukker in prep. \\
\hline Centroptilum Iuteolum & INEPH & Baetidae & 1 & 1 & Drukker in prep. \\
\hline Procloeon bifidum & INEPH & Baetidae & 1 & 1 & Drukker in prep. \\
\hline Brachycercus harrisella & INEPH & Caenidae & 1 & 1 & Drukker in prep. \\
\hline Caenis lactea & INEPH & Caenidae & & 1 & Drukker in prep. \\
\hline Caenis pseudorivulorum & INEPH & Caenidae & 1 & 1 & Drukker in prep. \\
\hline Serratella ignita & INEPH & Ephemerellidae & 1 & 1 & Drukker in prep. \\
\hline Ephemera danica & INEPH & Ephemeridae & 1 & 1 & Drukker in prep. \\
\hline Ephemera vulgata & INEPH & Ephemeridae & 1 & 1 & Drukker in prep. \\
\hline Heptagenia flava & INEPH & Heptageniidae & & 1 & Drukker in prep. \\
\hline Heptagenia sulphurea & INEPH & Heptageniidae & & 1 & Drukker in prep. \\
\hline Kageronia fuscogrisea & INEPH & Heptageniidae & & 1 & Drukker in prep. \\
\hline Habrophlebia fusca & INEPH & Leptophlebiidae & 1 & 1 & Drukker in prep. \\
\hline Leptophlebia marginata & INEPH & Leptophlebiidae & 1 & 1 & Drukker in prep. \\
\hline Leptophlebia vespertina & INEPH & Leptophlebiidae & 1 & & Drukker in prep. \\
\hline Paraleptophlebia submarginata & INEPH & Leptophlebiidae & 1 & 1 & Drukker in prep. \\
\hline Siphlonurus aestivalis & INEPH & Siphlonuridae & 1 & 1 & Drukker in prep. \\
\hline Siphlonurus armatus & INEPH & Siphlonuridae & 1 & 1 & Drukker in prep. \\
\hline Aphelocheirus aestivalis & INHET & Aphelocheiridae & & 1 & Aukema et al. 2002; Tempelman \& van Haaren 2009 \\
\hline Micronecta poweri & INHET & Corixidae & 1 & 1 & Aukema et al. 2002; Tempelman \& van Haaren 2009 \\
\hline Sigara fossarum & INHET & Corixidae & 1 & 1 & Aukema et al. 2002; Tempelman \& van Haaren 2009 \\
\hline Sigara hellensii & INHET & Corixidae & 1 & 1 & Aukema et al. 2002; Tempelman \& van Haaren 2009 \\
\hline Sigara limitata & INHET & Corixidae & 1 & & Aukema et al. 2002; Tempelman \& van Haaren 2009 \\
\hline Sigara striata & INHET & Corixidae & 3 & 3 & Aukema et al. 2002; Tempelman \& van Haaren 2009 \\
\hline Aquarius najas & INHET & Gerridae & 1 & 1 & Aukema et al. 2002; Tempelman \& van Haaren 2009 \\
\hline
\end{tabular}




\begin{tabular}{|c|c|c|c|c|c|}
\hline Taxonnaam TWN & Hoofdgroep & Familie & R19 & $\mathbf{R 2 0}$ & lit \\
\hline Gerris gibbifer & INHET & Gerridae & 1 & & Aukema et al. 2002; Tempelman \& van Haaren 2009 \\
\hline Gerris lateralis & INHET & Gerridae & 1 & 1 & Aukema et al. 2002; Tempelman \& van Haaren 2009 \\
\hline Hebrus pusillus & INHET & Hebridae & 1 & 1 & Aukema et al. 2002; Tempelman \& van Haaren 2009 \\
\hline Hebrus ruficeps & INHET & Hebridae & 1 & 1 & Aukema et al. 2002; Tempelman \& van Haaren 2009 \\
\hline Hydrometra gracilenta & INHET & Hydrometridae & 1 & 1 & Aukema et al. 2002; Tempelman \& van Haaren 2009 \\
\hline Notonecta maculata & INHET & Notonectidae & 1 & 1 & Aukema et al. 2002; Tempelman \& van Haaren 2009 \\
\hline Notonecta obliqua & INHET & Notonectidae & 1 & 1 & Aukema et al. 2002; Tempelman \& van Haaren 2009 \\
\hline Microvelia buenoi & INHET & Veliidae & 1 & 1 & Aukema et al. 2002; Tempelman \& van Haaren 2009 \\
\hline Velia caprai & INHET & Veliidae & 1 & 1 & Aukema et al. 2002; Tempelman \& van Haaren 2009 \\
\hline Velia saulii & INHET & Veliidae & 1 & 1 & Aukema et al. 2002; Tempelman \& van Haaren 2009 \\
\hline Aeshna affinis & INODO & Aeshnidae & & 1 & www.libellennet.nl \\
\hline Aeshna isoceles & INODO & Aeshnidae & & 1 & www.libellennet.nl \\
\hline Aeshna juncea & INODO & Aeshnidae & 1 & & www.libellennet.nl \\
\hline Brachytron pratense & INODO & Aeshnidae & & 1 & www.libellennet.nl \\
\hline Calopteryx splendens & INODO & Calopterygidae & 2 & 2 & www.libellennet.nl \\
\hline Calopteryx virgo & INODO & Calopterygidae & 1 & 1 & www.libellennet.nl \\
\hline Ceriagrion tenellum & INODO & Coenagrionidae & 1 & & www.libellennet.nl \\
\hline Coenagrion hastulatum & INODO & Coenagrionidae & 1 & 1 & www.libellennet.nl \\
\hline Coenagrion mercuriale & INODO & Coenagrionidae & 1 & & www.libellennet.nl \\
\hline Erythromma lindenii & INODO & Coenagrionidae & & 1 & www.libellennet.nl \\
\hline Ischnura pumilio & INODO & Coenagrionidae & 1 & 1 & www.libellennet.nl \\
\hline Nehalennia speciosa & INODO & Coenagrionidae & 1 & & www.libellennet.nl \\
\hline Cordulegaster boltonii & INODO & Cordulegastridae & 1 & & www.libellennet.nl \\
\hline Cordulia aenea & INODO & Corduliidae & & 1 & www.libellennet.nl \\
\hline Epitheca bimaculata & INODO & Corduliidae & & 1 & www.libellennet.nl \\
\hline Oxygastra curtisii & INODO & Corduliidae & & 1 & www.libellennet.nl \\
\hline Somatochlora arctica & INODO & Corduliidae & 1 & & www.libellennet.nl \\
\hline Somatochlora flavomaculata & INODO & Corduliidae & 1 & 1 & www.libellennet.nl \\
\hline Somatochlora metallica & INODO & Corduliidae & & 1 & www.libellennet.nl \\
\hline
\end{tabular}




\begin{tabular}{|c|c|c|c|c|c|}
\hline Taxonnaam TWN & Hoofdgroep & Familie & R19 & $\mathbf{R} 20$ & lit \\
\hline Gomphus pulchellus & INODO & Gomphidae & & 1 & www.libellennet.nl \\
\hline Gomphus vulgatissimus & INODO & Gomphidae & & 1 & www.libellennet.nl \\
\hline Sympecma fusca & INODO & Lestidae & 1 & & www.libellennet.nl \\
\hline Sympecma paedisca & INODO & Lestidae & 1 & 1 & www.libellennet.nl \\
\hline Leucorrhinia caudalis & INODO & Libellulidae & & 1 & www.libellennet.nl \\
\hline Leucorrhinia pectoralis & INODO & Libellulidae & 1 & 1 & www.libellennet.nl \\
\hline Libellula fulva & INODO & Libellulidae & & 1 & www.libellennet.nl \\
\hline Orthetrum brunneum & INODO & Libellulidae & 1 & 1 & www.libellennet.nl \\
\hline Orthetrum coerulescens & INODO & Libellulidae & 1 & & www.libellennet.nl \\
\hline Sympetrum depressiusculum & INODO & Libellulidae & 1 & 1 & www.libellennet.nl \\
\hline Sympetrum pedemontanum & INODO & Libellulidae & 1 & 1 & www.libellennet.nl \\
\hline Platycnemis pennipes & INODO & Platycnemididae & 1 & 1 & www.libellennet.nl \\
\hline Leuctra fusca & INREM & Leuctridae & 1 & 1 & Koese 2008 \\
\hline Amphinemura standfussi & INREM & Nemouridae & 1 & 1 & Koese 2008 \\
\hline Amphinemura sulcicollis & INREM & Nemouridae & & 1 & Koese 2008 \\
\hline Nemoura avicularis & INREM & Nemouridae & 1 & 1 & Koese 2008 \\
\hline Nemoura cinerea & INREM & Nemouridae & 2 & 2 & Koese 2008 \\
\hline Nemoura dubitans & INREM & Nemouridae & 1 & 1 & Koese 2008 \\
\hline Nemurella pictetii & INREM & Nemouridae & 1 & 1 & Koese 2008 \\
\hline Isoperla grammatica & INREM & Perlodidae & 1 & 1 & Koese 2008 \\
\hline Taeniopteryx nebulosa & INREM & Taeniopterygidae & & 1 & Koese 2008 \\
\hline Osmylus fulvicephalus & INREM & Osmylidae & 1 & 1 & Elliott 2009 \\
\hline Sialis fuliginosa & INREM & Sialidae & 1 & 1 & Elliott 2009 \\
\hline Beraea maurus & INTRI & Beraeidae & 1 & & Higler 2008 \\
\hline Beraea pullata & INTRI & Beraeidae & 1 & 1 & Higler 2008 \\
\hline Beraeodes minutus & INTRI & Beraeidae & 1 & 1 & Higler 2008 \\
\hline
\end{tabular}




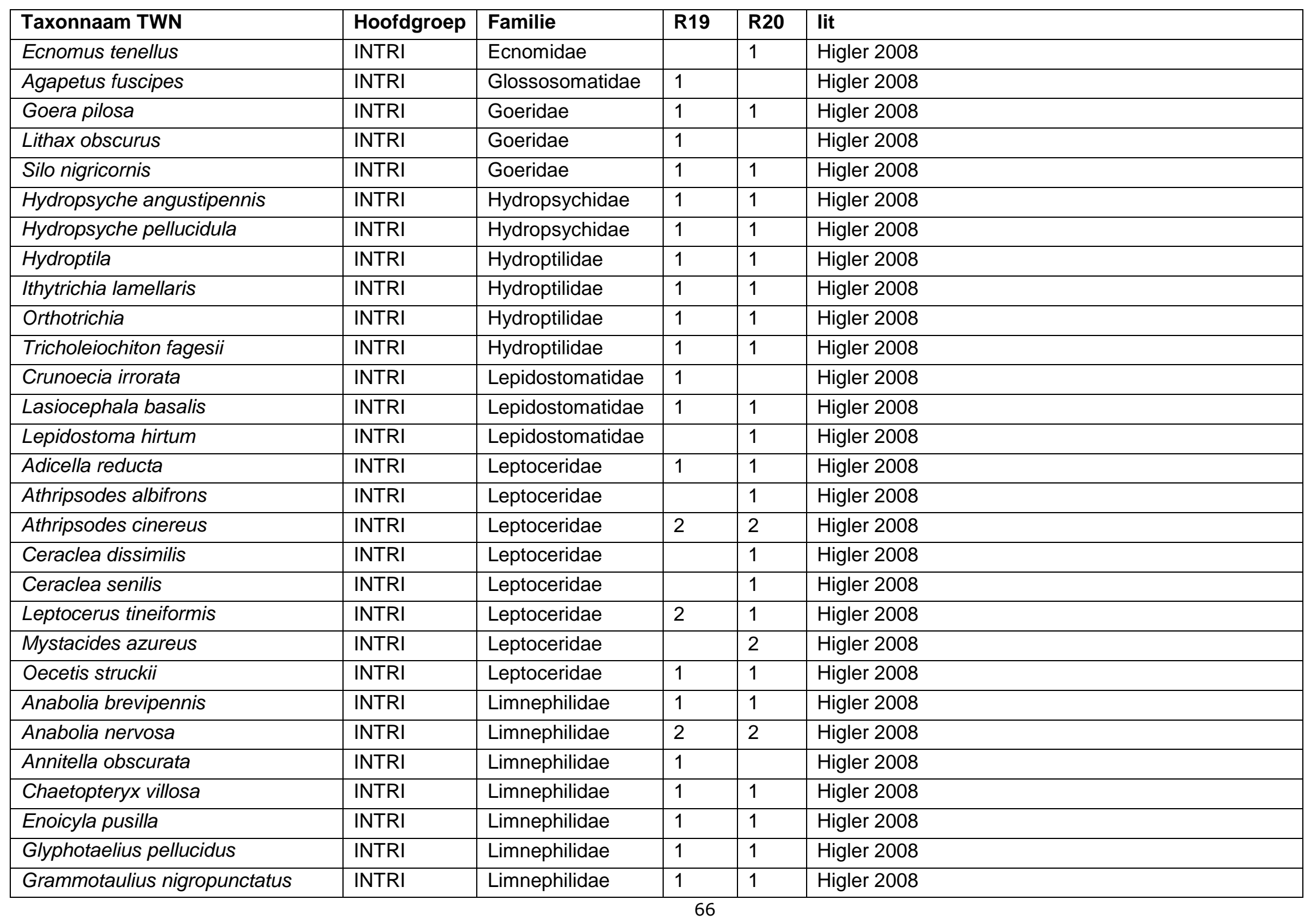




\begin{tabular}{|c|c|c|c|c|c|}
\hline Taxonnaam TWN & Hoofdgroep & Familie & R19 & $\mathbf{R 2 0}$ & lit \\
\hline Grammotaulius nitidus & INTRI & Limnephilidae & 1 & 1 & Higler 2008 \\
\hline Grammotaulius submaculatus & INTRI & Limnephilidae & 1 & 1 & Higler 2008 \\
\hline Halesus & INTRI & Limnephilidae & 1 & 1 & Higler 2008 \\
\hline Hydatophylax infumatus & INTRI & Limnephilidae & 1 & & Higler 2008 \\
\hline Ironoquia dubia & INTRI & Limnephilidae & 1 & 1 & Higler 2008 \\
\hline Limnephilus binotatus & INTRI & Limnephilidae & 1 & 1 & Higler 2008 \\
\hline Limnephilus centralis & INTRI & Limnephilidae & 1 & 1 & Higler 2008 \\
\hline Limnephilus decipiens & INTRI & Limnephilidae & 1 & 1 & Higler 2008 \\
\hline Limnephilus elegans & INTRI & Limnephilidae & 1 & 1 & Higler 2008 \\
\hline Limnephilus extricatus & INTRI & Limnephilidae & 1 & 1 & Higler 2008 \\
\hline Limnephilus flavicornis & INTRI & Limnephilidae & 2 & 2 & Higler 2008 \\
\hline Limnephilus fuscicornis & INTRI & Limnephilidae & 1 & 1 & Higler 2008 \\
\hline Limnephilus griseus & INTRI & Limnephilidae & 1 & 1 & Higler 2008 \\
\hline Limnephilus ignavus & INTRI & Limnephilidae & 1 & & Higler 2008 \\
\hline Limnephilus incisus & INTRI & Limnephilidae & 1 & 1 & Higler 2008 \\
\hline Limnephilus Iunatus & INTRI & Limnephilidae & 2 & 2 & Higler 2008 \\
\hline Limnephilus luridus & INTRI & Limnephilidae & 1 & & Higler 2008 \\
\hline Limnephilus marmoratus & INTRI & Limnephilidae & 2 & 2 & Higler 2008 \\
\hline Limnephilus nigriceps & INTRI & Limnephilidae & 1 & 1 & Higler 2008 \\
\hline Limnephilus politus & INTRI & Limnephilidae & 1 & 1 & Higler 2008 \\
\hline Limnephilus rhombicus & INTRI & Limnephilidae & 2 & 2 & Higler 2008 \\
\hline Limnephilus sparsus & INTRI & Limnephilidae & 1 & 1 & Higler 2008 \\
\hline Limnephilus stigma & INTRI & Limnephilidae & 1 & 1 & Higler 2008 \\
\hline Limnephilus subcentralis & INTRI & Limnephilidae & 1 & 1 & Higler 2008 \\
\hline Limnephilus vittatus & INTRI & Limnephilidae & 1 & 1 & Higler 2008 \\
\hline Micropterna lateralis & INTRI & Limnephilidae & 1 & & Higler 2008 \\
\hline
\end{tabular}




\begin{tabular}{|c|c|c|c|c|c|}
\hline Taxonnaam TWN & Hoofdgroep & Familie & R19 & R20 & lit \\
\hline Potamophylax cingulatus & INTRI & Limnephilidae & 1 & 1 & Higler 2008 \\
\hline Potamophylax latipennis & INTRI & Limnephilidae & 1 & 1 & Higler 2008 \\
\hline Potamophylax nigricornis & INTRI & Limnephilidae & 1 & & Higler 2008 \\
\hline Potamophylax rotundipennis & INTRI & Limnephilidae & 1 & 1 & Higler 2008 \\
\hline Rhadicoleptus alpestris & INTRI & Limnephilidae & 1 & & Higler 2008 \\
\hline Stenophylax permistus & INTRI & Limnephilidae & 1 & 1 & Higler 2008 \\
\hline Molanna angustata & INTRI & Molannidae & 1 & 1 & Higler 2008 \\
\hline Molannodes tinctus & INTRI & Molannidae & 1 & & Higler 2008 \\
\hline Agrypnia obsoleta & INTRI & Phryganeidae & 1 & & Higler 2008 \\
\hline Agrypnia varia & INTRI & Phryganeidae & 1 & 1 & Higler 2008 \\
\hline Hagenella clathrata & INTRI & Phryganeidae & 1 & & Higler 2008 \\
\hline Oligostomis reticulata & INTRI & Phryganeidae & 1 & 1 & Higler 2008 \\
\hline Oligotricha striata & INTRI & Phryganeidae & 1 & & Higler 2008 \\
\hline Trichostegia minor & INTRI & Phryganeidae & 1 & 1 & Higler 2008 \\
\hline Cyrnus trimaculatus & INTRI & Polycentropodidae & & 1 & Higler 2008 \\
\hline Holocentropus stagnalis & INTRI & Polycentropodidae & 1 & 1 & Higler 2008 \\
\hline Neureclipsis bimaculata & INTRI & Polycentropodidae & & 1 & Higler 2008 \\
\hline Plectrocnemia conspersa & INTRI & Polycentropodidae & 1 & 1 & Higler 2008 \\
\hline Polycentropus flavomaculatus & INTRI & Polycentropodidae & & 1 & Higler 2008 \\
\hline Polycentropus irroratus & INTRI & Polycentropodidae & 1 & 1 & Higler 2008 \\
\hline Lype & INTRI & Psychomyiidae & 1 & 1 & Higler 2008 \\
\hline Psychomyia pusilla & INTRI & Psychomyiidae & & 1 & Higler 2008 \\
\hline Tinodes assimilis & INTRI & Psychomyiidae & 1 & & Higler 2008 \\
\hline Tinodes pallidulus & INTRI & Psychomyiidae & 1 & & Higler 2008 \\
\hline Tinodes waeneri & INTRI & Psychomyiidae & & 1 & Higler 2008 \\
\hline Notidobia ciliaris & INTRI & Sericostomatidae & 1 & 1 & Higler 2008 \\
\hline Sericostoma personatum & INTRI & Sericostomatidae & 1 & 1 & Higler 2008 \\
\hline Musculium lacustre & MOBIV & Sphaeriidae & 2 & 2 & Gittenberger \& Janssen 1998; Killeen et al. 2004 \\
\hline Pisidium amnicum & MOBIV & Sphaeriidae & & 2 & Gittenberger \& Janssen 1998; Killeen et al. 2004 \\
\hline
\end{tabular}




\begin{tabular}{|c|c|c|c|c|c|}
\hline Taxonnaam TWN & Hoofdgroep & Familie & $\mathbf{R 1 9}$ & $\mathbf{R} 20$ & lit \\
\hline Pisidium henslowanum & MOBIV & Sphaeriidae & & 2 & Gittenberger \& Janssen 1998; Killeen et al. 2004 \\
\hline Pisidium moitessierianum & MOBIV & Sphaeriidae & & 1 & Gittenberger \& Janssen 1998; Killeen et al. 2004 \\
\hline Pisidium obtusale & MOBIV & Sphaeriidae & 2 & 2 & Gittenberger \& Janssen 1998; Killeen et al. 2004 \\
\hline Pisidium personatum & MOBIV & Sphaeriidae & 1 & & Gittenberger \& Janssen 1998; Killeen et al. 2004 \\
\hline Pisidium pseudosphaerium & MOBIV & Sphaeriidae & 1 & 1 & Gittenberger \& Janssen 1998; Killeen et al. 2004 \\
\hline Pisidium pulchellum & MOBIV & Sphaeriidae & 2 & 2 & Gittenberger \& Janssen 1998; Killeen et al. 2004 \\
\hline Pisidium supinum & MOBIV & Sphaeriidae & & 2 & Gittenberger \& Janssen 1998; Killeen et al. 2004 \\
\hline Sphaerium nucleus & MOBIV & Sphaeriidae & 1 & 1 & Gittenberger \& Janssen 1998; Killeen et al. 2004 \\
\hline Sphaerium ovale & MOBIV & Sphaeriidae & 2 & 2 & Soes 2008 \\
\hline Acroloxus lacustris & MOGAS & Acroloxidae & & 2 & Gittenberger \& Janssen (1998) \\
\hline Ancylus fluviatilis & MOGAS & Ancylidae & 1 & 1 & Gittenberger \& Janssen (1998) \\
\hline Ferrissia fragilis & MOGAS & Ancylidae & & 2 & Gittenberger \& Janssen (1998) \\
\hline Bithynia leachi & MOGAS & Bithyniidae & 3 & 3 & Gittenberger \& Janssen (1998) \\
\hline Marstoniopsis scholtzi & MOGAS & Hydrobiidae & & 1 & Gittenberger \& Janssen (1998) \\
\hline Omphiscola glabra & MOGAS & Lymnaeidae & 1 & 1 & Gittenberger \& Janssen (1998) \\
\hline Radix auricularia & MOGAS & Lymnaeidae & & 2 & Gittenberger \& Janssen (1998) \\
\hline Radix balthica gr. & MOGAS & Lymnaeidae & 3 & 3 & Gittenberger \& Janssen (1998) \\
\hline Aplexa hypnorum & MOGAS & Physidae & 1 & 1 & Gittenberger \& Janssen (1998) \\
\hline Physella acuta & MOGAS & Physidae & 3 & 3 & Gittenberger \& Janssen (1998) \\
\hline Anisus leucostoma & MOGAS & Planorbidae & 2 & 2 & Gittenberger \& Janssen (1998) \\
\hline Anisus vortex & MOGAS & Planorbidae & 3 & 3 & Gittenberger \& Janssen (1998) \\
\hline Bathyomphalus contortus & MOGAS & Planorbidae & 3 & 3 & Gittenberger \& Janssen (1998) \\
\hline Gyraulus albus & MOGAS & Planorbidae & 3 & 3 & Gittenberger \& Janssen (1998) \\
\hline Planorbarius corneus & MOGAS & Planorbidae & 3 & 3 & Gittenberger \& Janssen (1998) \\
\hline Planorbis planorbis & MOGAS & Planorbidae & 3 & 3 & Gittenberger \& Janssen (1998) \\
\hline Segmentina nitida & MOGAS & Planorbidae & 2 & 2 & Gittenberger \& Janssen (1998) \\
\hline
\end{tabular}




\begin{tabular}{|l|l|l|l|l|l|}
\hline Taxonnaam TWN & Hoofdgroep & Familie & R19 & R20 & lit \\
\hline Valvata piscinalis & MOGAS & Valvatidae & 3 & 3 & Gittenberger \& Janssen (1998) \\
\hline
\end{tabular}

Bijbehorende referenties indicatiewaarden:

Aukema, B., Cuppen, J.G.M., Nieser, N. \& D. Tempelman (2002) Verspreidingsatlas Nederlandse wantsen (Hemiptera: Heteroptera) Deel I: Dipsocoromorpha, Nepomorpha, Gerromorpha \& Leptopodomorpha. European Invertebrate Survey - Nederland, Leiden.

Bartsch, I., Deichsel, R. (2007) Chelicerata: Araneae/Acari. Spektrum Akademischer verlag, Heidelberg.

Cuppen, H., Tempelman, D, van Haaren T. (2015) Key for identification of 4th instar larvae of Tanytarsus Van der Wulp, 1874 of north-western

Europe (Diptera: Chironomidae: Tanytarsini) Lauterbornia 79: 1-21.

Den Hartog C (1962) De Nederlandse platwormen -Tricladida. Wetenschappelijke mededelingen KNNV 42. KNNV Hoogwoud

Di Sabatino, A., Gerecke, R., Geldhill, T., Smit, H. (2010) Acari: Hydrachnidia II. Spektrum Akademischer verlag, Heidelberg

Disney, R.H.L. (1999) British Dixidae (Meniscus midges) and Thaumaleidae (trickle midges): keys with ecological notes. Freshwater Biological

Association, Ambleside.

Drost, B. (2008) De genera Odeles en Elodes (Coleoptera: Scirtidae) in Nederland. Entomologische Berichten 68 (1): $1212-16$.

Drost, M.B.P., Cuppen, H.P.J.J., van Nieukerken, E.J. \& M. Schreijer (1992). De waterkevers van Nederland. KNNV Uitgeverij, Utrecht.

Drukker, D. De haften van Nederland en België, in prep.

Ekrem T. (2007) A taxonomic revision of the genus Stempellinella (Diptera: Chironomidae), Journal of Natural History 41:21-24.

Elliot, J.M. (2009) Freshwater megaloptera and neuroptera of Brittain en Ireland: keys to aduls and larvae, and a review of their ecology.

Freshwater Biological Association Scientific publication no. 65. Ambleside.

Faasch, H. (2015). Identification guide to aquatic and semi-aquatic Diptera larvae. DGL-Arbeitshilfe 1-2015

Gerecke, R., Geldhill, T., Pesic, V., Smit, H. (2016) Chelicerata: Acari III. Springer-Verlag, Berlin Heidelberg.

Gittenberger, E. \& A.W. Janssen (1998) De Nederlandse zoetwatermollusken. Recente en fossiele weekdieren uit zoet en brak water.

Nederlandse fauna 2. Nationaal Natuurhistorisch museum Leiden, KNNV uitgeverii, EIS-Nederland.

Higler L.W.G. (2008) Verspreidingsatlas Nederlandse kokerjuffers (Trichoptera) EIS-Nederland, Leiden.

Killeen, I., Aldridge, D.C., Oliver, G. (2004) Freshwater Bivalves of Britain and Ireland. FSC Publications, Shrewsbury.

Klink, A., Moller Pilot, H. (1996) Lijst van de Nederlandse Chironomidae bijgewerkt tot I januari 1996. Themanummer WEW-08. Werkgroep

Ecologisch Waterbeheer.

Koese, B. (2008) De Nederlandse steenvliegen (Plecoptera) Entomologische tabellen I, EIS-Nederland

Lock, K. van Maanen, b. (2014) De kriebelmuggen van nederland en vlaanderen (Diptera: Simuliidae) Nederlandse Faunistische Mededelingen 43.

Merritt, R.W., Wotton R.S. (1988) The Life History and Behavior of Limnophora riparia (Diptera:Muscidae), a Predator of Larval Black Flies.

Journal of the North American Benthological Society 7: 1-12

Moller-Pilot, H.K.M. (2009) Chironomidae larvae. Biology and ecology of the Chironomini. KNNV Publishing, Zeist. 
Moller-Pilot, H.K.M. (2013) Chironomidae larvae. Biology and ecology of the aquatic Orthocladiinae. KNNV Publishing, Zeist.

Reynoldson T.B., Young J.O. (2000) A Key to the Freshwater Triclads of Brtain and Ireland, With Notes on Their Ecology. Freshwater biological association scientific publication no. 58. Freshwater Biological Association, Ambleside.

Scheers, K., Mertens, J., Thys, N. (2014) On the occurrence of Suphrodytes dorsalis (Fabricius, 1787) and Suphrodytes figuratus (Gyllenhal, 1826) (Coleoptera: Dytiscidae) in Belgium with notes on the habitat. Bulletin van de Koninklijke Belgische Vereniging voor Entomologie 150: 187-189

Smit, H \& H. van der Hammen (2000) Atlas van de Nederlandse watermijten (Acari: Hydracarina). Nederlandse faunistische mededelingen 13: $1-273$.

Soes, D.M., 2009. De ovale hoornschaal (Sphaerium ovale) ook in Nederland. Spirula 366: 9-10.

Tempelman, D \& T. van Haaren (2009) Water- en oppervlaktewantsen van Nederland. Jeugdbondsuitgeverij, Utrecht.

Vallenduuk, H. Moller-Pilot, H.K.M. (2007) Chironomidae larvae. General ecology and Tanypodinae. KNNV Publishing, Zeist.

van Haaren, T., Hop, H., Soes, M., Tempelman, D. (2004) The freshwater leeches (Hirudinea) of the Netherlands. Lauterbornia 52: $113-131$. van Haaren, T., Soors J. (2013) Aquatic Oligochaetes of the Netherlands and Belgium. KNNV Publishing, Zeist.

Zeegers, T., van Haaren, T. (2000) Dazen en dazenlarven : inleiding tot en tabellen voor de Tabanidae (Diptera) van Nederland en België. KNNV Uitgeverij Utrecht. 


\section{Bijlage 2: Indicatorlijst macrofyten}

Ten behoeve van de kwaliteitsbeoordeling zijn de macrofyten ingedeeld in vier categorieën:

1. Primair kenmerkende soorten die een zeer hoge kwaliteit indiceren. Vooral soorten in die in doorstroomoerassen/moerasbeken kenmerkend zijn voor voedselarme grondwatergevoede doorstroomcondities, al dan niet met regenwaterlenzen.

2. Primair kenmerkende soorten die een goede kwaliteit indiceren. Vooral soorten die in doorstroommoerassen/moerasbeken kenmerkend zijn voor matig voedselrijke en vaak ook grondwatergevoede overstromingscondities.

3. Overige kenmerkende soorten, vooral soorten die kenmerkend zijn voor zeer voedselrijke natte situaties.

4. Negatief dominante soorten, in hoge abundanties kenmerkend voor sterk belaste (polysaprobe) of anderszins verstoorde situaties.

Soorten uit categorie 1 wijzen op (overgangen naar) doorstroommoerassen, en daarmee naar een zeer hoge kwaliteitsklasse en een voor Nederlandse begrippen zeer weinig verstoorde/zeer natuurlijke situatie. Soorten uit categorie 2 zijn kenmerkend voor weinig verstoorde overstromingszones en beekmoerassen en wijzen daarmee op een goede ecologische toestand. Soorten uit categorie 3 zijn kenmerkend voor verstoorde (te voedselrijke) situaties en daarmee voor een lagere kwaliteitsklasse (matig of ontoereikend). Categorie 4 bevat de negatief dominante soorten. Deze categorie is opgesplitst in de verschillende geaggregeerde abundantieklassen (laag: a, matig: b, hoog: $c$ ), omdat deze soorten vooral bij hoge bedekkingen kenmerkend zijn voor sterk verstoorde situaties. In categorie 4 vallen bijvoorbeeld soorten als klein kroos en liesgras. Ook pitrus en braam worden in hoge abundanties als negatief beschouwd omdat ze wijzen op verstoring en in het geval van braam ook op verdroging.

Op basis van de som van de scores van alle aangetroffen kenmerkende soorten wordt de Ecologische KwaliteitsRatio (EKR) en de resulterende kwaliteitsklasse (zeer goed, goed, matig, ontoereikend, slecht) bepaald. Hiervoor worden per categorie weegwaarden toegekend en kan daaruit een score worden berekend:

$$
\text { Score }=\sum_{i=1}^{c a t} W e e g(i) * N \operatorname{soort}(i)
$$

met $W e e g(i)=$ Weegwaarde categorie $i$ en $N$ soort $(i)=$ Aantal soorten in categorie $i$

\begin{tabular}{|l|l|}
\hline Categorie & Weegwaarde \\
\hline 1 & 10 \\
\hline 2 & 5 \\
\hline 3 & 1 \\
\hline $4 \mathrm{a}$ & 1 \\
\hline $4 \mathrm{~b}$ & -2 \\
\hline $4 \mathrm{c}$ & -5 \\
\hline
\end{tabular}

De weegwaarden voor de primair kenmerkende soorten (categorieën 1 en 2) zijn relatief hoog genomen om te voorkomen dat de score te sterk wordt bepaald door het aantal soorten. Een te groot gewicht toekennen aan het aantal soorten (door te kiezen voor lage(re) weegwaarden) maakt de maatlat minder robuust, omdat het aantal soorten dat gevonden 
wordt sterk waarnemersafhankelijk is (afbakening proefvlak, kennis van soorten e.d.) (Pot, 2012). Door juist veel gewicht toe te kennen aan soorten die indicerend zijn voor natuurlijke, weinig verstoorde situaties is de maatlat naar verwachting minder gevoelig voor waarnemerseffecten.

Als referentiegetal is een score van 132 genomen op basis van opnamen van het doorstroommoeras de Holmers. De EKR wordt ten opzichte van dit getal bepaald, oftewel een score $\geq 132$ leidt tot een EKR van 1.0.

Omdat soorten van doorstroommoerassen en moerasbeken door elkaar voor kunnen komen, wordt er voor de deelmaatlat soortensamenstelling geen onderscheid gemaakt tussen beide typen. 


\begin{tabular}{|c|c|c|c|c|c|c|c|c|}
\hline \multirow[b]{2}{*}{ PlantNaam } & \multirow[b]{2}{*}{ 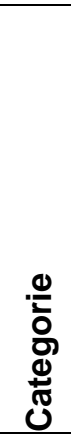 } & \multicolumn{7}{|c|}{$\begin{array}{l}\text { Onderbouwing toedeling op basis } \\
\text { habitateisen }\end{array}$} \\
\hline & & 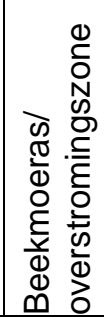 & 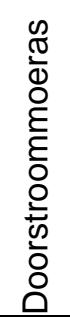 & 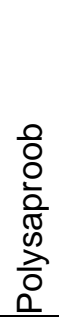 & 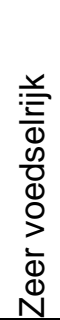 & 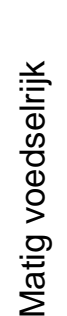 & 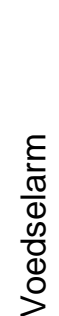 & 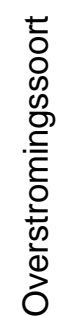 \\
\hline Acorus calamus & 3 & $x$ & & & $x$ & & & \\
\hline Adoxa moschatellina & 2 & $x$ & & & & $x$ & & \\
\hline Agrostis canina & 2 & & $x$ & & & $x$ & $x$ & \\
\hline Agrostis stolonifera & 3 & $x$ & & & $x$ & & & \\
\hline Alisma gramineum & 3 & $\mathrm{X}$ & & & $x$ & $\mathrm{X}$ & & \\
\hline Alisma lanceolatum & 3 & $x$ & & & $\mathrm{X}$ & & & \\
\hline Alisma plantago-aquatica & 3 & $x$ & & & $x$ & $x$ & & \\
\hline Alnus glutinosa & 2 & $x$ & & & & $x$ & & \\
\hline Alopecurus geniculatus & 3 & $x$ & & & $x$ & & & \\
\hline Angelica sylvestris & 2 & $\mathrm{X}$ & $\mathrm{X}$ & & & $\mathrm{X}$ & & \\
\hline Apium inundatum & 1 & & & & & & $x$ & \\
\hline Apium nodiflorum & 2 & & & & $x$ & $x$ & & \\
\hline Apium repens & 1 & $x$ & & & $x$ & $x$ & & $x$ \\
\hline Athyrium filix-femina & 2 & $\mathrm{X}$ & & & & $x$ & & \\
\hline Baldellia ranunculoides & 1 & & $x$ & & & & $x$ & \\
\hline Berula erecta & 3 & $X$ & & & $\mathrm{X}$ & $\mathrm{X}$ & & \\
\hline Betula pubescens & 2 & & $x$ & & & $x$ & $x$ & \\
\hline Bidens cernua & 4 & $x$ & & $x$ & & & & \\
\hline Bidens frondosa & 4 & $x$ & & $x$ & & & & \\
\hline Bidens tripartita & 4 & $x$ & & $x$ & & & & \\
\hline Blysmus compressus & 1 & $x$ & & & & $x$ & $x$ & \\
\hline Bolboschoenus maritimus & 3 & $x$ & & & $x$ & & & \\
\hline Butomus umbellatus & 3 & $x$ & & & $x$ & $\mathrm{X}$ & & \\
\hline Calamagrostis canescens & 3 & $x$ & & & & $x$ & & \\
\hline Calamagrostis stricta & 1 & $x$ & & & & $x$ & $x$ & \\
\hline Calla palustris & 1 & & $x$ & & & $x$ & & \\
\hline Callitriche & 3 & & & & $\mathrm{X}$ & $x$ & & \\
\hline Callitriche brutia & 3 & & & & $\mathrm{x}$ & $x$ & & \\
\hline Callitriche hermaphroditica & 3 & $\mathrm{X}$ & & & $\mathrm{X}$ & & & \\
\hline Callitriche obtusangula & 3 & $\mathrm{X}$ & & & $x$ & $\mathrm{X}$ & & \\
\hline Callitriche palustris & 1 & $\mathrm{X}$ & & & & $x$ & & $x$ \\
\hline Callitriche platycarpa & 3 & $x$ & & & $x$ & $x$ & & \\
\hline Caltha palustris & 2 & $x$ & & & $x$ & $x$ & & \\
\hline Calystegia sepium & 4 & $x$ & & & $x$ & & & \\
\hline Cardamine amara & 2 & $x$ & $x$ & & $x$ & $x$ & & \\
\hline Cardamine pratensis & 3 & $x$ & & & $x$ & & & \\
\hline
\end{tabular}




\begin{tabular}{|c|c|c|c|c|c|c|c|c|}
\hline \multirow[b]{2}{*}{ PlantNaam } & \multirow[b]{2}{*}{ 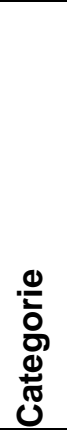 } & \multicolumn{7}{|c|}{$\begin{array}{l}\text { Onderbouwing toedeling op basis } \\
\text { habitateisen }\end{array}$} \\
\hline & & 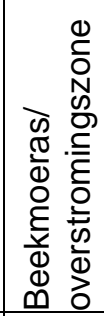 & 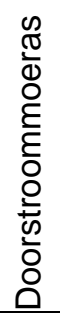 & 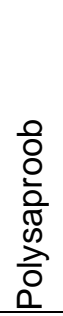 & 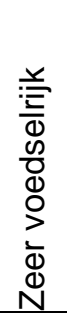 & 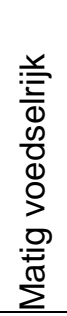 & $\begin{array}{l}\varepsilon \\
\frac{E}{D} \\
\frac{\pi}{D} \\
\frac{D}{0} \\
\mathbb{D} \\
>\end{array}$ & 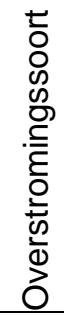 \\
\hline Carex acuta & 2 & $x$ & & & $x$ & $x$ & & \\
\hline Carex acutiformis & 2 & $x$ & & & & $x$ & & \\
\hline Carex appropinquata & 1 & $x$ & $x$ & & & $x$ & & \\
\hline Carex aquatilis & 2 & $x$ & & & & $x$ & & \\
\hline Carex curta & 1 & & $x$ & & & & $x$ & \\
\hline Carex diandra & 1 & & $x$ & & & & $x$ & \\
\hline Carex disticha & 3 & $x$ & & & $x$ & & & \\
\hline Carex echinata & 1 & & $x$ & & & & $x$ & \\
\hline Carex elata & 2 & $x$ & & & & $x$ & & \\
\hline Carex elongata & 2 & $x$ & & & & $x$ & & \\
\hline Carex lasiocarpa & 1 & & $x$ & & & & $x$ & \\
\hline Carex nigra & 1 & & $x$ & & & & $x$ & \\
\hline Carex panicea & 1 & & $x$ & & & & $x$ & \\
\hline Carex paniculata & 2 & $x$ & & & & $x$ & & \\
\hline Carex pseudocyperus & 2 & $x$ & & & & $x$ & & \\
\hline Carex remota & 2 & $x$ & & & & $x$ & & \\
\hline Carex riparia & 3 & $x$ & & & $x$ & $x$ & & \\
\hline Carex rostrata & 1 & & $x$ & & & & $x$ & \\
\hline Carex vesicaria & 2 & $x$ & $x$ & & & $x$ & & \\
\hline Catabrosa aquatica & 3 & $x$ & & $x$ & $x$ & & & \\
\hline Ceratophyllum demersum & 4 & $x$ & & $x$ & & & & \\
\hline Ceratophyllum submersum & 3 & $x$ & & $x$ & $x$ & & & \\
\hline Chara & 2 & & & & & $x$ & $x$ & \\
\hline Chara aspera & 2 & & & & & $x$ & $x$ & \\
\hline Chara globularis & 2 & & & & $x$ & $x$ & $x$ & \\
\hline Chara hispida & 2 & & & & $x$ & $x$ & $x$ & \\
\hline Chara vulgaris & 3 & $x$ & & & $x$ & $x$ & $x$ & \\
\hline Chrysosplenium alternifolium & 1 & $x$ & $x$ & & & & $x$ & \\
\hline Chrysosplenium oppositifolium & 1 & $\mathrm{X}$ & $x$ & & & & $x$ & \\
\hline Cicuta virosa & 2 & $x$ & & & & $x$ & & \\
\hline Cirsium palustre & 3 & $x$ & & & $x$ & $x$ & & \\
\hline Cladium mariscus & 2 & $x$ & & & & $\mathrm{X}$ & & \\
\hline Deschampsia cespitosa & 3 & $x$ & & & $x$ & $x$ & & \\
\hline Drepanocladus fluitans & 1 & & & & & & $x$ & \\
\hline Dryopteris carthusiana & 1 & & & & & $x$ & $x$ & \\
\hline Dryopteris dilatata & 2 & $X$ & & & & $x$ & $x$ & \\
\hline
\end{tabular}




\begin{tabular}{|c|c|c|c|c|c|c|c|c|}
\hline \multirow[b]{2}{*}{ PlantNaam } & \multirow[b]{2}{*}{$\begin{array}{l}\frac{0}{2} \\
\frac{0}{0} \\
\frac{\mathbb{d}}{\pi} \\
0\end{array}$} & \multicolumn{7}{|c|}{$\begin{array}{l}\text { Onderbouwing toedeling op basis } \\
\text { habitateisen }\end{array}$} \\
\hline & & 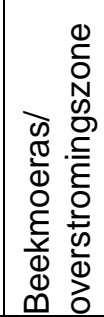 & 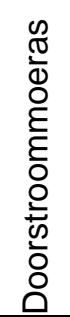 & 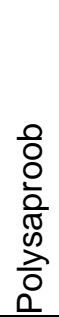 & 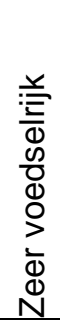 & 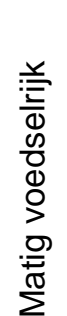 & 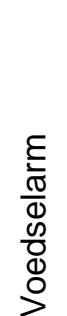 & 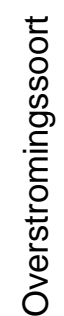 \\
\hline Elatine hexandra & 1 & $X$ & & & & $x$ & & $x$ \\
\hline Elatine hydropiper & 2 & $x$ & & & $x$ & & & $x$ \\
\hline Eleocharis acicularis & 2 & $x$ & & & & $x$ & $x$ & \\
\hline Eleocharis multicaulis & 1 & & $\mathrm{x}$ & & & & $x$ & \\
\hline Eleocharis palustris & 3 & $X$ & $x$ & & $x$ & $\mathrm{X}$ & $x$ & \\
\hline Eleogiton fluitans & 1 & & $\mathrm{X}$ & & & & $x$ & \\
\hline Elodea canadensis & 2 & & & & & $\mathrm{X}$ & & \\
\hline Elodea nuttallii & 3 & $x$ & & & $x$ & $x$ & & \\
\hline Epilobium hirsutum & 3 & $x$ & & & $x$ & & & \\
\hline Epilobium palustre & 2 & & $\mathrm{X}$ & & & $\mathrm{X}$ & & \\
\hline Epilobium parviflorum & 3 & $x$ & & $X$ & $x$ & & & \\
\hline Equisetum fluviatile & 2 & $x$ & $x$ & & & $x$ & & \\
\hline Equisetum sylvaticum & 1 & & $\mathrm{X}$ & & & & $x$ & \\
\hline Eriophorum angustifolium & 1 & & $\mathrm{x}$ & & & & $x$ & \\
\hline Eupatorium cannabinum & 2 & $x$ & & & & $x$ & & \\
\hline Filipendula ulmaria & 2 & $x$ & & & & $x$ & & \\
\hline Fontinalis antipyretica & 2 & & & & & $x$ & & \\
\hline Fraxinus excelsior & 3 & $x$ & & & $x$ & & & \\
\hline Galium palustre & 2 & $x$ & $x$ & & & $x$ & & \\
\hline Galium uliginosum & 1 & & $\mathrm{x}$ & & & $x$ & $x$ & \\
\hline Glyceria fluitans & 4 & $x$ & & $x$ & $x$ & & & \\
\hline Glyceria maxima & 4 & $x$ & & $x$ & & & & \\
\hline Groenlandia densa & 2 & & & & & $\mathrm{X}$ & & \\
\hline Hippuris vulgaris & 2 & & & & $x$ & $x$ & & \\
\hline Hottonia palustris & 2 & $\mathrm{X}$ & & & & $x$ & & \\
\hline Humulus lupulus & 2 & & & & & $x$ & & \\
\hline Hydrocharis morsus-ranae & 3 & $x$ & & & $\mathrm{X}$ & $x$ & & \\
\hline Hydrocotyle vulgaris & 1 & $x$ & $x$ & & & $x$ & $x$ & \\
\hline Hypericum elodes & 1 & $\mathrm{X}$ & $x$ & & & $x$ & & \\
\hline Iris pseudacorus & 3 & $x$ & & & $\mathrm{X}$ & $x$ & & \\
\hline Juncus acutiflorus & 1 & $\mathrm{x}$ & $x$ & & & $x$ & $x$ & \\
\hline Juncus articulatus & 3 & $x$ & & & $x$ & $x$ & $x$ & \\
\hline Juncus bulbosus & 1 & & & & & & $x$ & \\
\hline Juncus capitatus & 1 & & & & & & $x$ & \\
\hline Juncus conglomeratus & 3 & & & & & $\mathrm{X}$ & $x$ & \\
\hline Juncus effusus & 4 & $x$ & & & & $\mathrm{x}$ & & \\
\hline
\end{tabular}




\begin{tabular}{|c|c|c|c|c|c|c|c|c|}
\hline \multirow[b]{2}{*}{ PlantNaam } & \multirow[b]{2}{*}{ 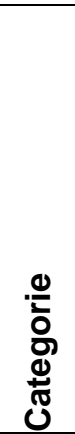 } & \multicolumn{7}{|c|}{$\begin{array}{l}\text { Onderbouwing toedeling op basis } \\
\text { habitateisen }\end{array}$} \\
\hline & & 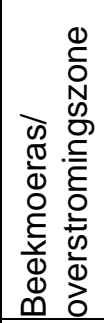 & 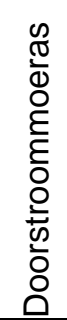 & 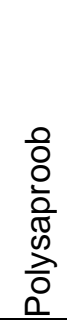 & 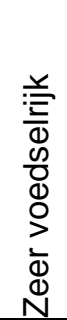 & 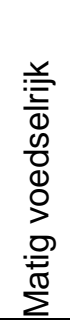 & 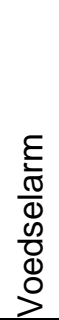 & 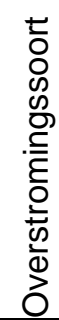 \\
\hline Juncus filiformis & 1 & $x$ & & & & $\mathrm{X}$ & $x$ & $x$ \\
\hline Juncus inflexus & 3 & $x$ & & & $x$ & $x$ & & \\
\hline Juncus subnodulosus & 2 & & $x$ & & & $x$ & & \\
\hline Lemna gibba & 4 & $x$ & & $x$ & & & & \\
\hline Lemna minor & 4 & $x$ & & $x$ & & & & \\
\hline Lemna minuta & 4 & $x$ & & $x$ & & & & \\
\hline Lemna trisulca & 3 & $x$ & & & $x$ & $x$ & & \\
\hline Limosella aquatica & 2 & $x$ & & & $x$ & & & $x$ \\
\hline Littorella uniflora & 1 & & & & & & $x$ & \\
\hline Lobelia dortmanna & 1 & & & & & & $x$ & \\
\hline Lonicera periclymenum & 3 & & & & & $x$ & & \\
\hline Lotus pedunculatus & 2 & $x$ & $x$ & & & $x$ & $x$ & \\
\hline Ludwigia palustris & 1 & $x$ & & & & $x$ & $x$ & $x$ \\
\hline Luronium natans & 1 & $x$ & & & & $x$ & $x$ & \\
\hline Lychnis flos-cuculi & 2 & $x$ & & & & $x$ & & \\
\hline Lycopus europaeus & 3 & $x$ & & & $x$ & $x$ & & \\
\hline Lysimachia nummularia & 3 & & & & $x$ & $x$ & & \\
\hline Lysimachia thyrsiflora & 2 & $x$ & $x$ & & & $x$ & & \\
\hline Lysimachia vulgaris & 2 & $x$ & & & & $x$ & & \\
\hline Lythrum portula & 1 & $x$ & & & & $x$ & $x$ & \\
\hline Lythrum salicaria & 2 & $x$ & & & $x$ & $x$ & & \\
\hline Mentha aquatica & 3 & $x$ & & & $x$ & $x$ & & \\
\hline Mentha pulegium & 2 & $x$ & & & $x$ & $x$ & & $x$ \\
\hline Menyanthes trifoliata & 2 & & $x$ & & & $x$ & $x$ & \\
\hline Myosotis scorpioides & 3 & $x$ & $x$ & & $x$ & $x$ & & \\
\hline Myosotis laxa & 3 & $x$ & $x$ & & $x$ & $x$ & & \\
\hline Myrica gale & 2 & & & & & & $x$ & \\
\hline Myriophyllum alterniflorum & 2 & & & & & $x$ & $x$ & \\
\hline Myriophyllum spicatum & 3 & $x$ & & & $x$ & & & \\
\hline Myriophyllum verticillatum & 2 & $x$ & & & $x$ & $x$ & & \\
\hline Najas marina & 2 & & & & & $x$ & & \\
\hline Nasturtium microphyllum & 3 & $x$ & & & $x$ & $x$ & & \\
\hline Nasturtium officinale & 3 & $x$ & & & $x$ & $x$ & & \\
\hline Nitella & 2 & & & & & $x$ & $x$ & \\
\hline Nitella flexilis & 2 & & & & & $x$ & $x$ & \\
\hline Nitella hyalina & 2 & & & & & $X$ & $X$ & \\
\hline
\end{tabular}




\begin{tabular}{|c|c|c|c|c|c|c|c|c|}
\hline \multirow[b]{2}{*}{ PlantNaam } & \multirow[b]{2}{*}{ 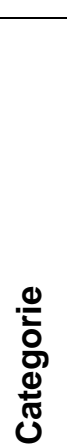 } & \multicolumn{7}{|c|}{$\begin{array}{l}\text { Onderbouwing toedeling op basis } \\
\text { habitateisen }\end{array}$} \\
\hline & & 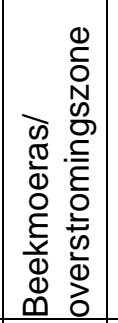 & 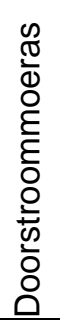 & 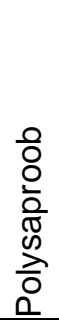 & 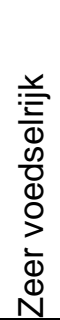 & 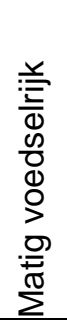 & 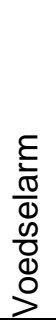 & 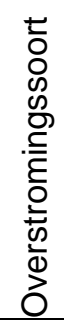 \\
\hline Nitella mucronata & 2 & & & & & $x$ & $x$ & \\
\hline Nitella opaca & 2 & & & & & $x$ & $\mathrm{X}$ & \\
\hline Nitella translucens & 2 & & & & & $\mathrm{X}$ & $x$ & \\
\hline Nitellopsis obtusa & 2 & & & & & $x$ & & \\
\hline Nuphar lutea & 3 & $x$ & & & $x$ & $x$ & & \\
\hline Nymphaea alba & 3 & $x$ & $x$ & & $x$ & $x$ & & \\
\hline Nymphoides peltata & 3 & $\mathrm{x}$ & & & $x$ & $x$ & & \\
\hline Oenanthe aquatica & 3 & $x$ & & & $x$ & $x$ & & \\
\hline Oenanthe fistulosa & 3 & $x$ & & & $x$ & $x$ & & \\
\hline Pedicularis palustris & 2 & $x$ & & & & $x$ & $x$ & \\
\hline Persicaria amphibia & 3 & $x$ & & & $x$ & $x$ & & \\
\hline Persicaria hydropiper & 3 & $x$ & & $x$ & $x$ & & & \\
\hline Persicaria mitis & 3 & $x$ & & & $x$ & $x$ & & \\
\hline Peucedanum palustre & 2 & $x$ & & & & $x$ & $x$ & \\
\hline Phalaris arundinacea & 4 & $x$ & & $x$ & $x$ & & & \\
\hline Phragmites australis & 3 & $\mathrm{x}$ & & & $x$ & $\mathrm{X}$ & & \\
\hline Pilularia globulifera & 2 & & & & & & $x$ & \\
\hline Poa palustris & 2 & $x$ & & & $x$ & $x$ & & $\mathrm{X}$ \\
\hline Potamogeton acutifolius & 2 & $\mathrm{X}$ & & & & $x$ & & \\
\hline Potamogeton alpinus & 2 & $\mathrm{X}$ & & & & $x$ & & \\
\hline Potamogeton berchtoldii & 2 & $x$ & & & & $x$ & & \\
\hline Potamogeton compressus & 2 & $x$ & & & & $x$ & & \\
\hline Potamogeton crispus & 3 & $x$ & & $\mathrm{X}$ & $\mathrm{X}$ & & & \\
\hline Potamogeton gramineus & 2 & & & & & $x$ & $x$ & \\
\hline Potamogeton lucens & 3 & $x$ & & & $\mathrm{X}$ & $x$ & & \\
\hline Potamogeton mucronatus & 3 & & & & $x$ & $x$ & & \\
\hline Potamogeton natans & 2 & $x$ & & & & $x$ & & \\
\hline Potamogeton obtusifolius & 2 & $\mathrm{x}$ & $\mathrm{X}$ & & & $x$ & & \\
\hline Potamogeton pectinatus & 3 & $\mathrm{x}$ & & $\mathrm{X}$ & $x$ & & & \\
\hline Potamogeton perfoliatus & 3 & & & & $x$ & $\mathrm{X}$ & & \\
\hline Potamogeton polygonifolius & 1 & & $x$ & & & $x$ & $x$ & \\
\hline Potamogeton praelongus & 2 & & & & & $x$ & & \\
\hline Potamogeton pusillus & 3 & $x$ & & & $x$ & & & \\
\hline Potamogeton trichoides & 2 & $\mathrm{X}$ & & & & $x$ & & \\
\hline Comarum palustre & 2 & & $x$ & & & $x$ & $x$ & \\
\hline Prunus padus & 2 & & & & & $x$ & $x$ & \\
\hline
\end{tabular}




\begin{tabular}{|c|c|c|c|c|c|c|c|c|}
\hline \multirow[b]{2}{*}{ PlantNaam } & \multirow[b]{2}{*}{ 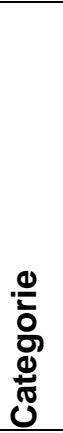 } & \multicolumn{7}{|c|}{$\begin{array}{l}\text { Onderbouwing toedeling op basis } \\
\text { habitateisen }\end{array}$} \\
\hline & & 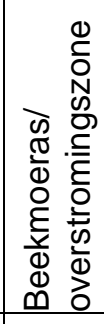 & 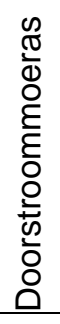 & 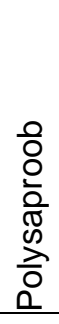 & 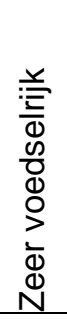 & 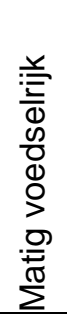 & 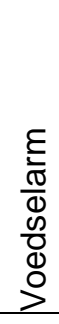 & 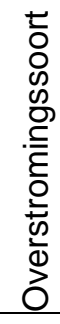 \\
\hline Primula elatior & 2 & $x$ & $x$ & & & $\mathrm{X}$ & & \\
\hline Pulicaria vulgaris & 2 & $x$ & & & $x$ & & & $x$ \\
\hline Ranunculus aquatilis & 3 & $x$ & & & $x$ & $x$ & & \\
\hline Ranunculus baudotii & 3 & & & & $x$ & $x$ & & \\
\hline Ranunculus circinatus & 3 & $x$ & & & $x$ & $x$ & & \\
\hline Ranunculus flammula & 2 & $x$ & $x$ & & & $x$ & $x$ & \\
\hline Ranunculus hederaceus & 2 & $x$ & & & $x$ & $x$ & & \\
\hline Ranunculus lingua & 1 & $x$ & & & & $x$ & & \\
\hline Ranunculus ololeucos & 1 & & & & & & $x$ & \\
\hline Ranunculus peltatus & 2 & & & & & $x$ & & \\
\hline Ranunculus repens & 3 & $x$ & & & $x$ & & & \\
\hline Ranunculus sceleratus & 3 & $x$ & & $x$ & $x$ & & & \\
\hline Rhamnus frangula & 3 & & & & & $x$ & & \\
\hline Ribes nigrum & 2 & $x$ & & & & $x$ & & \\
\hline Riccia fluitans & 2 & & & & & $x$ & & \\
\hline Ricciocarpos natans & 2 & $x$ & & & & $x$ & & \\
\hline Rorippa amphibia & 4 & $x$ & & $x$ & & & & \\
\hline Rubus fruticosus & 4 & $x$ & & & & $x$ & & \\
\hline Rubus idaeus & 2 & & & & & $x$ & $x$ & \\
\hline Rumex hydrolapathum & 3 & $x$ & & & $x$ & $x$ & & \\
\hline Sagittaria sagittifolia & 3 & $x$ & & & $x$ & $x$ & & \\
\hline Salix aurita & 2 & & $x$ & & & $x$ & $x$ & \\
\hline Salix cinerea & 3 & $x$ & $x$ & & & $x$ & $x$ & \\
\hline Salix pentandra & 2 & & $x$ & & & $x$ & $x$ & \\
\hline Schoenoplectus lacustris & 3 & $x$ & & & $x$ & & & \\
\hline $\begin{array}{l}\text { Schoenoplectus } \\
\text { tabernaemontani }\end{array}$ & 3 & $x$ & & & $x$ & & & \\
\hline Scirpus sylvaticus & 2 & $x$ & & & & $x$ & & \\
\hline Scorpidium scorpioides & 1 & & $x$ & & & $x$ & $x$ & \\
\hline Scrophularia auriculata & 3 & $x$ & & & $x$ & & & \\
\hline Scutellaria galericulata & 2 & $x$ & & & & $x$ & & \\
\hline Senecio aquaticus & 2 & $x$ & & & & $x$ & & $x$ \\
\hline Senecio paludosus & 2 & $x$ & & & $x$ & $x$ & & $x$ \\
\hline Sium latifolium & 3 & $x$ & & & $x$ & & & \\
\hline Solanum dulcamara & 2 & $x$ & & & $x$ & $x$ & & \\
\hline Sonchus palustris & 3 & $x$ & & & $x$ & & & \\
\hline Sorbus aucuparia & 3 & & & & & $x$ & & \\
\hline
\end{tabular}




\begin{tabular}{|c|c|c|c|c|c|c|c|c|}
\hline \multirow[b]{2}{*}{ PlantNaam } & \multirow[b]{2}{*}{ 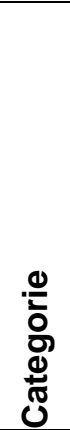 } & \multicolumn{7}{|c|}{$\begin{array}{l}\text { Onderbouwing toedeling op basis } \\
\text { habitateisen }\end{array}$} \\
\hline & & 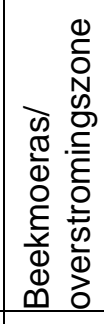 & 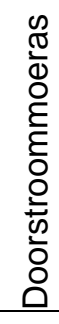 & 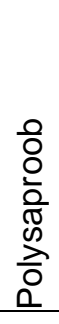 & 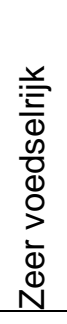 & 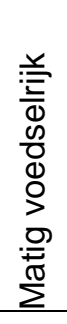 & 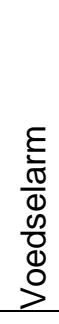 & 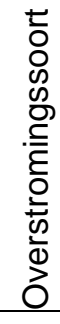 \\
\hline Sparganium angustifolium & 2 & & & & & & $X$ & \\
\hline Sparganium emersum & 3 & $x$ & & & $\mathrm{X}$ & $x$ & & \\
\hline Sparganium erectum & 3 & $x$ & & & $x$ & & & \\
\hline Sparganium natans & 1 & & $\mathrm{x}$ & & & $x$ & $x$ & \\
\hline Sphagnum & 2 & & & & & & $x$ & \\
\hline Sphagnum cuspidatum & 1 & & & & & & $x$ & \\
\hline Sphagnum denticulatum & 1 & & & & & & $x$ & \\
\hline Sphagnum fimbriatum & 2 & & & & & & $x$ & \\
\hline Sphagnum flexuosum & 1 & & & & & & $x$ & \\
\hline Sphagnum palustre & 1 & & $\mathrm{x}$ & & & & $x$ & \\
\hline Sphagnum r. var. recurvum & 1 & & & & & & $x$ & \\
\hline Sphagnum squarrosum & 2 & $x$ & & & & & $x$ & \\
\hline Sphagnum subsecundum & 1 & & & & & & $x$ & \\
\hline Spirodela polyrhiza & 4 & $x$ & & $x$ & & & & \\
\hline Stachys palustris & 3 & $x$ & & & $x$ & & & \\
\hline Stellaria palustris & 1 & $x$ & $x$ & & & $x$ & & \\
\hline Stratiotes aloides & 2 & $x$ & & & & $x$ & & \\
\hline Tephroseris palustris & 3 & $x$ & & & $x$ & & & \\
\hline Thalictrum flavum & 3 & $x$ & & & $x$ & & & \\
\hline Thelypteris palustris & 2 & & & & & $x$ & & \\
\hline Tolypella & 2 & & & & & $x$ & & \\
\hline Triglochin palustris & 2 & & & & $x$ & $x$ & & \\
\hline Typha angustifolia & 4 & $\mathrm{x}$ & & & $x$ & & & \\
\hline Typha latifolia & 4 & $x$ & & $x$ & & & & \\
\hline Ulmus laevis & 3 & $x$ & & & & & & $x$ \\
\hline Urtica dioica & 4 & $x$ & & $x$ & & & & \\
\hline Utricularia intermedia & 1 & & $x$ & & & & $x$ & \\
\hline Utricularia minor & 1 & & & & & & $x$ & \\
\hline Utricularia vulgaris & 2 & $x$ & & & & $x$ & & \\
\hline Valeriana dioica & 1 & & $x$ & & & $x$ & $x$ & \\
\hline Valeriana officinalis & 3 & $x$ & & & $x$ & & & \\
\hline Veronica anagallis-aquatica & 3 & $x$ & & & $\mathrm{X}$ & & & \\
\hline Veronica beccabunga & 3 & $x$ & & & $x$ & & & \\
\hline Veronica catenata & 3 & $x$ & & & $x$ & & & \\
\hline Veronica longifolia & 1 & $x$ & & & & $x$ & & $x$ \\
\hline Veronica scutellata & 2 & $x$ & $x$ & & & $x$ & $x$ & \\
\hline
\end{tabular}




\begin{tabular}{|c|c|c|c|c|c|c|c|c|}
\hline \multirow[b]{2}{*}{ PlantNaam } & \multirow[b]{2}{*}{ 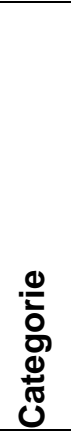 } & \multicolumn{7}{|c|}{$\begin{array}{l}\text { Onderbouwing toedeling op basis } \\
\text { habitateisen }\end{array}$} \\
\hline & & 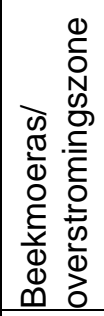 & 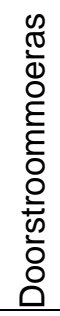 & $\begin{array}{l}\text { 으 } \\
\frac{0}{0} \\
\frac{0}{0} \\
\frac{0}{0} \\
0\end{array}$ & 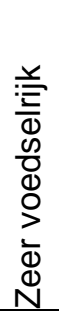 & 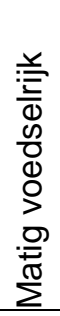 & 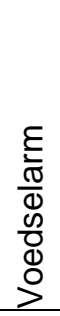 & 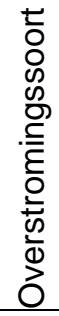 \\
\hline Viburnum opulus & 3 & & & & $x$ & $x$ & & \\
\hline Viola palustris & 1 & & $x$ & & & & $x$ & \\
\hline Viola persicifolia & 1 & & $x$ & & & $x$ & $x$ & \\
\hline Wolffia arrhiza & 3 & $\mathrm{X}$ & & $x$ & & & & \\
\hline Zannichellia palustris & 3 & $x$ & & $x$ & $x$ & & & \\
\hline
\end{tabular}

